Florida International University FIU Digital Commons

FIU Electronic Theses and Dissertations

University Graduate School

3-26-2013

\title{
Environmental Dynamics of Dissolved Black Carbon in Aquatic Ecosystems
}

Yan Ding

Florida International University, yding001@fiu.edu

DOI: $10.25148 /$ etd.FI13042308

Follow this and additional works at: https://digitalcommons.fiu.edu/etd

\section{Recommended Citation}

Ding, Yan, "Environmental Dynamics of Dissolved Black Carbon in Aquatic Ecosystems" (2013). FIU Electronic Theses and Dissertations. 846.

https://digitalcommons.fiu.edu/etd/846

This work is brought to you for free and open access by the University Graduate School at FIU Digital Commons. It has been accepted for inclusion in FIU Electronic Theses and Dissertations by an authorized administrator of FIU Digital Commons. For more information, please contact dcc@fiu.edu. 


\title{
FLORIDA INTERNATIONAL UNIVERSITY
}

Miami, Florida

\section{ENVIRONMENTAL DYNAMICS OF DISSOLVED BLACK CARBON IN AQUATIC ECOSYSTEMS}

\author{
A dissertation submitted in partial fulfillment of \\ the requirements for the degree of \\ DOCTOR OF PHILOSOPHY \\ in \\ CHEMISTRY
}

by

Yan Ding

2013 
To: Dean Kenneth G. Furton

College of Arts and Sciences

This dissertation, written by Yan Ding, and entitled Environmental Dynamics of Dissolved Black Carbon in Aquatic Ecosystems, having been approved in respect to style and intellectual content, is referred to you for judgment.

We have read this dissertation and recommend that it be approved.

$\begin{array}{r}\hline \text { Yong Cai } \\ \hline \text { Piero R. Gardinali } \\ \hline \text { J. Martin E. Quirke } \\ \hline \text { Leonard J. Scinto } \\ \hline \text { Rudolf Jaffé, Major Professor }\end{array}$

Date of Defense: March 26, 2013

The dissertation of Yan Ding is approved.

\begin{tabular}{r} 
Dean Kenneth G. Furton \\
College of Arts and Sciences \\
\hline Dean Lakshmi N. Reddi \\
University Graduate School
\end{tabular}

Florida International University, 2013 
C Copyright 2013 by Yan Ding

All rights reserved. 


\section{DEDICATION}

I dedicate this dissertation to my beloved parents, Ms. Suling Jiang and Mr. Sulin Ding. Without your love and support, the completion of this work would not have been possible. 


\section{ACKNOWLEDGMENTS}

I wish to express my special thanks to my advisor, Dr. Rudolf Jaffé, for providing the chance to work with him on such an interesting project. It has been a pleasant learning experience and wonderful journey, especially for an international student studying abroad like me. Without his valuable mentoring, research enthusiasm, and wonderful ideas, the completion of this work would not have been possible. I wish to thank my committee members, Dr. Yong Cai, Dr. Piero Gardinali, Dr. Martin Quirke and Dr. Leonard Scinto for their support and inspiring advices during each step of my research progress.

Sincerely thanks are extended to the research collaborators. I wish to thank Dr. Thorsten Dittmar for helping me set up the method at the beginning of this project, for his patient guidance on statistics for the global model and constructive input on publications. I would like to thank Dr. Kaelin Cawley and Dr. Youhei Yamashita for fielding sampling, sharing their knowledge of dissolved organic matter and for their warm encouragement. I also greatly appreciate Dr. Anssi Vähätalo, Dr. Aron Stubbins, and Dr. Robert Spencer for providing water samples from large world rivers and Arctic Rivers, as well as Dr. Thorson Dittmar and Dr. Jutta Niggemann for providing DBC data from intermediate rivers, for a global study in Chapter V. I want to thank Dr. John Campbell, Dr. Walter Dodds, Dr. Jeremy Jones, Dr. Diane McKnight, Dr. Akira Watanabem Dr. Catia Nunes da Cunha, and numerous other collaborators who assisted in the field sampling and data interpretation. Thanks also go to the Wetland Ecosystem Laboratory, especially Rafael Travieso, Adam Hines and Olga Sanchez, for field support and the SERC Water Quality Laboratory for DOC analyses. 
I would like to thank National Science Foundation (NSF) through the FCE-LTER program and the Department of Chemistry \& Biochemistry at Florida International University (FIU) for financial support through research and teaching assistantship, respectively. The University Graduate School of FIU is greatly acknowledged for offering me a Doctoral Evidence Acquisition (DEA) fellowship, making a field trip to Australia possible.

I wish to thank my extraordinary colleagues and friends from the Organic Geochemistry Group, including Dr. Meilian Chen, Dr. Cristina Romera-Castillo, Chao Ya, He Ding and Sasha Wagner, and from Dr. Gardinali's group, for their encouragement and making my life more colorful. Special thanks go to my good friends Dr. Oliva Pisani, Dr. Laura Belicka and Dr. Kaein Cawley for their friendship, support and all the cheerful moments we shared together. I also thank the FCE-LTER program to offer me opportunities to learn and sharing my knowledge of the Everglades through the annual science meetings and other interesting activities.

Finally, I am very grateful to my family in China for their endless love, caring and support. Lastly I would like to thank the journals Chemosphere and Science, for allowing me to include published work in my dissertation. 


\title{
ABSTRACT OF THE DISSERTATION \\ ENVIRONMENTAL DYNAMICS OF DISSOLVED BLACK CARBON \\ IN AQUATIC ECOSYSTEMS
}

\author{
by \\ Yan Ding
}

Florida International University, 2013

Miami, Florida

Professor Rudolf Jaffé, Major Professor

Black carbon (BC), the incomplete combustion product from biomass and fossil fuel burning, is ubiquitously found in soils, sediments, ice, water and atmosphere. Because of its polyaromatic molecular characteristic, $\mathrm{BC}$ is believed to contribute significantly to the global carbon budget as a slow-cycling, refractory carbon pool. However, the mass balance between global $\mathrm{BC}$ generation and accumulation does not match, suggesting a removal mechanism of $\mathrm{BC}$ to the active carbon pool, most probable in a dissolved form. The presence of BC in waters as part of the dissolved organic matter (DOM) pool was recently confirmed via ultrahigh resolution mass spectrometry, and dissolved black carbon (DBC), a degradation product of charcoal, was found in marine and coastal environments. However, information on the loadings of DBC in freshwater environments and its global riverine flux from terrestrial systems to the oceans remained unclear.

The main objectives of this study were to quantify $\mathrm{DBC}$ in diverse aquatic ecosystems and to determine its environmental dynamics. Surface water samples were collected from aquatic environments with a spatially significant global distribution, and 
DBC concentrations were determined by a chemical oxidation method coupled with HPLC detection. While it was clear that biomass burning was the main sources of BC, the translocation mechanism of BC to the dissolved phase was not well understood. Data from the regional studies and the developed global model revealed a strong positive correlation between DBC and dissolved organic carbon (DOC) dynamics, indicating a cogeneration and co-translocation between soil OC and BC. In addition, a DOC-assistant DBC translocation mechanism was identified. Taking advantage of the DOC-DBC

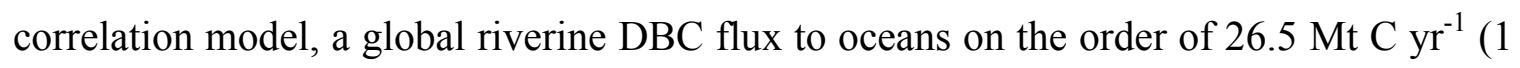
$\mathrm{Mt}=10^{12} \mathrm{~g}$ ) was determined, accounting for $10.6 \%$ of the global DOC flux. The results not only indicated that $\mathrm{DOC}$ was an important environmental intermediate for $\mathrm{BC}$ transfer and storage, but also provided an estimate of a major missing link in the global BC budget. The ever increasing DBC export caused by global warming will change the marine DOM quality and may have important consequences for carbon cycling in marine ecosystem. 


\section{TABLE OF CONTENTS}

CHAPTER

PAGE

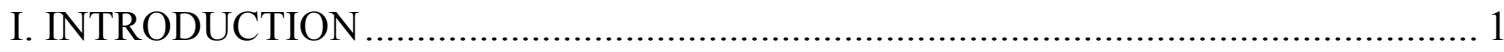

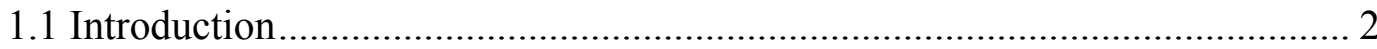

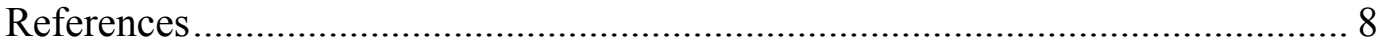

II. DISSOLVED BLACK CARBON IN GRASSLAND STREAMS: IS THERE AN

EFFECT OF RECENT FIRE HISTORY? ....................................................... 12

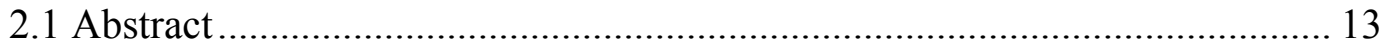

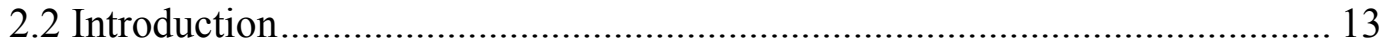

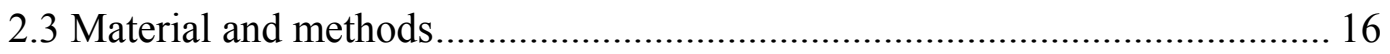

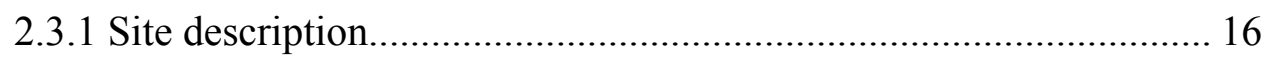

2.3.2 Sample collection and preparation................................................. 17

2.3.3 BC analysis - benzenepolycarboxylic acids (BPCAs) method ........ 19

2.3.4 High-performance liquid chromatography ……………………...... 22

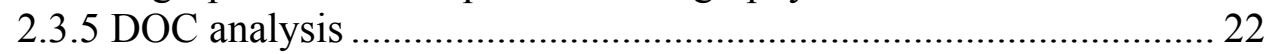

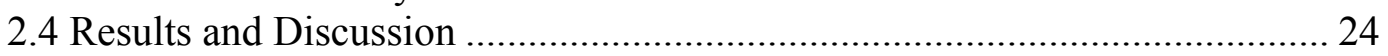

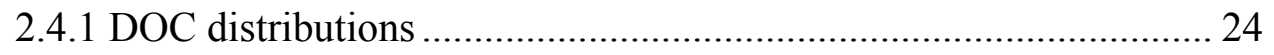

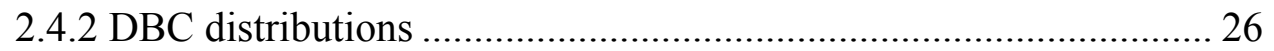

2.4.3 Fire frequency and DBC concentrations........................................ 28

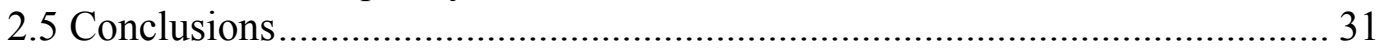

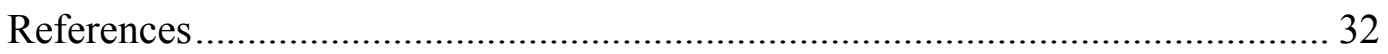

III. ENVIRONMENTAL DYNAMICS OF DISSOLVED BLACK CARBON IN

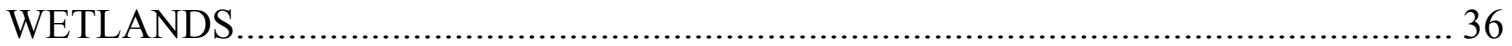

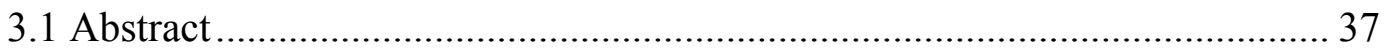

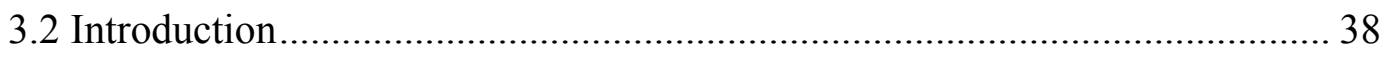

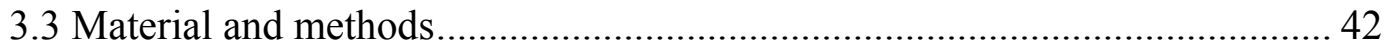

3.3.1 Site description.......................................................................... 42

3.3.2 Sample collection and preparation................................................... 45

3.3.3 BC analysis - Benzenepolycarboxylic acids (BPCAs) method....... 46

3.3.4 DOC analysis .............................................................................. 47

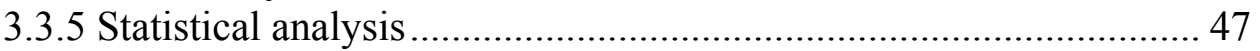

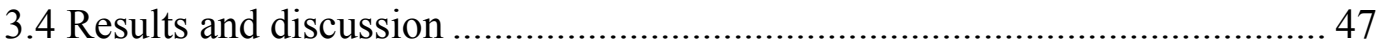

3.4.1 Spatial and seasonal dynamics of DOC, Everglades ....................... 47

3.4.2 Spatial and seasonal dynamics of DBC, Everglades ........................ 50

3.4.3 Annual export of DBC from SRS and TS, Everglades ..................... 53

3.4.4 Principal component analysis of BPCAs, Everglades ....................... 54

3.4.5 Comparison of three wetland systems - Everglades, Okavango

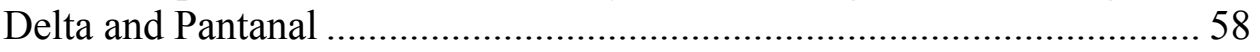

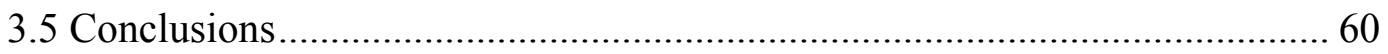

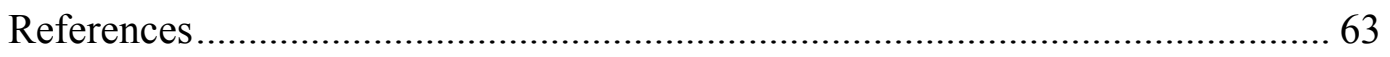




\section{SOURCES AND DYNAMICS OF DISSOLVED BLACK CARBON IN BOREAL}

FOREST RIVERS AND GLACIAL STREAMS OF CENTRAL ALASKA ................... 70

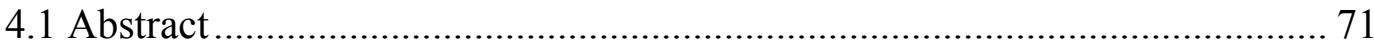

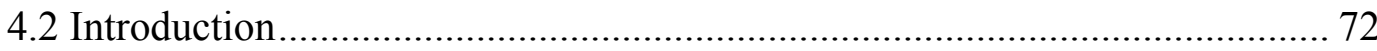

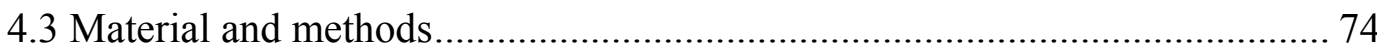

4.3.1 Site description and sample collection............................................ 74

4.3.2 Analytical methodology .............................................................. 77

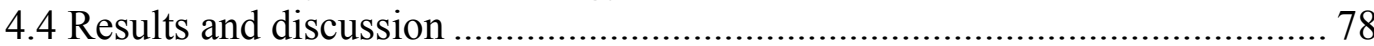

4.4.1 Linear correlation between DOC and DBC .................................. 78

4.4.2 Fire impacts on DBC concentrations .............................................. 81

4.4.3 Assessment of DBC sources derived from benzenepolycarboxylic acid (BPCA) composition .................................................................. 82

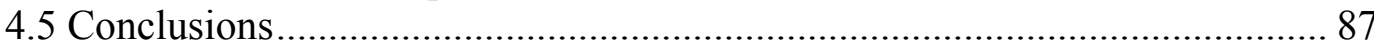

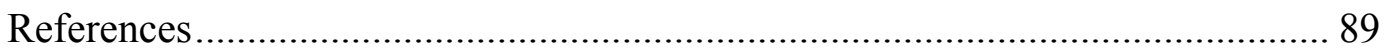

V. GLOBAL CHARCOAL MOBILIZATION FROM SOILS VIA DISSOLUTION AND SUBSEQUENT RIVERINE TRANSPORT TO THE OCEANS........................... 93

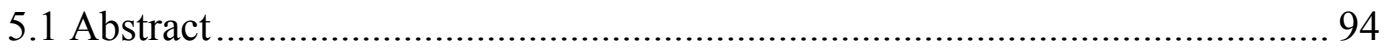

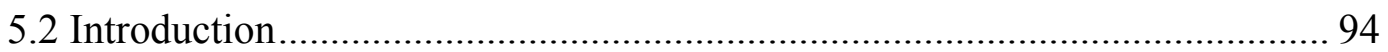

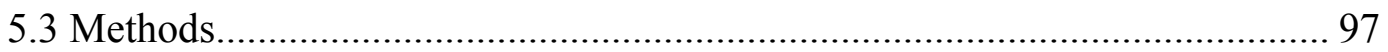

5.3.1 Water sample collection and analysis ............................................. 97

5.3.2 Classification of water samples and statistical analysis................... 99

5.3.3 Soil incubation experiment ......................................................... 102

5.3.4 Char incubation experiment......................................................... 103

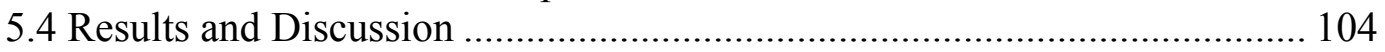

5.4.1 Estimation of global riverine DBC flux to the oceans................... 104

5.4.2 Soil and char incubations: possible soil BC translocation

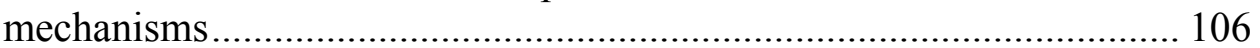

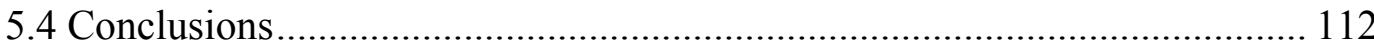

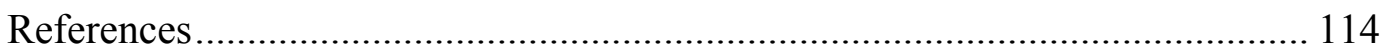

VI. DISSOLVED BLACK NITROGEN (DBN) IN FRESHWATER

ENVIRONMENTS: SOURCE AND LAND TO OCEAN FLUX ASSESSMENT ....... 118

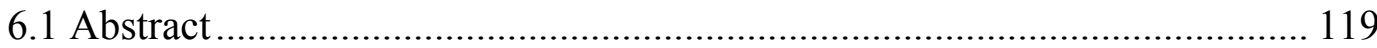

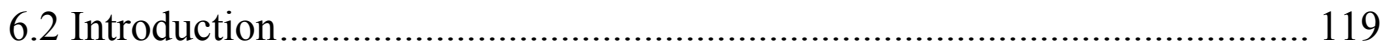

6.3 Materials and methods ....................................................................... 122

6.3.1 Sampling locations.................................................................. 122

6.3.2 Sample preparation ................................................................. 123

6.3.3 DBN analysis: X-ray photoelectron spectroscopy ......................... 124

6.3.4 DBC analysis: BPCA method .................................................... 125

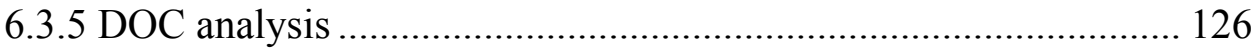

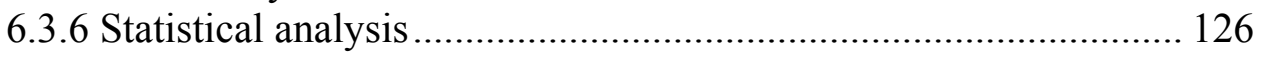

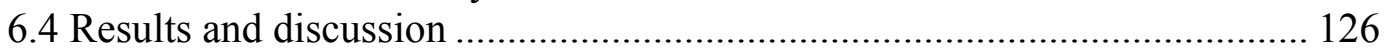

6.4.1 Potential source for DBN........................................................... 126

6.4.2 Controlling factors for DBN environmental dynamics.................. 129 
6.4.3 Estimate of global riverine DBN flux to the oceans .................. 130

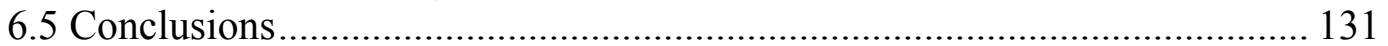

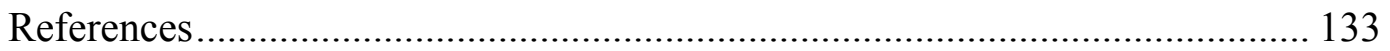

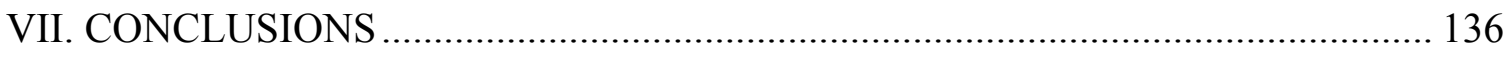

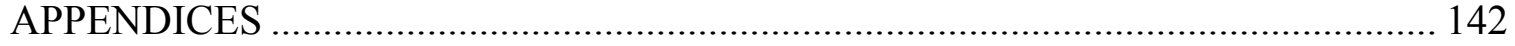

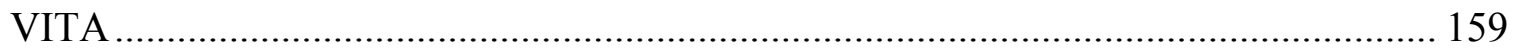




\section{LIST OF TABLES}

TABLE

PAGE

2.1 Oxidation efficiencies of fullerene $\left(\mathrm{C}_{60}\right)$ using three different oxidation conditions

2.2 Mobile phase mixing gradients

22

3.1 Statistical comparison of linear regressions between DOC and DBC concentrations in three wetlands.

4.1 DOC and DBC concentrations and \%DBC for Alaska rivers from different environmental settings.

5.1 Regression analysis of DOC and DBC from different environments. 


\section{LIST OF FIGURES}

FIGURE

PAGE

1.1 The black carbon combustion continuum .......................................................... 3

1.2 Chemical structures of some benzenepolycarboxylic acids (BPCAs) ...................... 4

1.3 Formation of polar functional groups on soot polyaromatic macro-molecules by oxidation of external rings with ozone, and subsequent hydrolysis of oxygen containing rings.

1.4 Two examples of probable structures for thermogenic DOM in the deep ocean based on the exact molecular mass obtained from FT/ICR-MS.

2.1 Sampling sites in Konza Prairie Biological Station (KPBS; Kansas, USA), showing different management practices

2.2 BPCA carbon recoveries of SRHA digested at $150{ }^{\circ} \mathrm{C}, 160^{\circ} \mathrm{C}$ and $170^{\circ} \mathrm{C}$ for up to 8 or 9 hours..

2.3 An example of HPLC chromatogram of benzenepolycarboxylic acids, the DBC

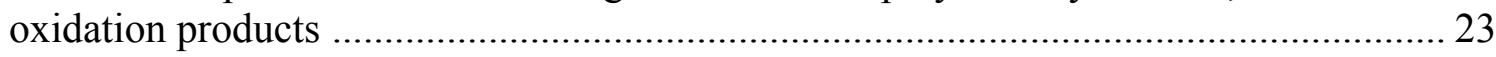

2.4 DOC and DBC concentrations from different streams at KPBS .......................... 25

2.5 DOC and DBC cross correlation from different streams at KPBS ........................ 27

2.6 Correlation between DBC concentrations and the years since last fire (a), and correlation between DBC concentrations and the burn return year (b)

2.7 $\mathrm{BC}$ formation from vegetation fires is dependent on burning efficiency, as exemplified for grasses (line) and two samples from deciduous wood.

3.1 Map of the Everglades sampling location.

3.2 Spatial distribution of DOC (a) and DBC (b) concentrations in the Everglades.

3.3 Seasonal distribution of DOC ( $\&$ \& $)$ and DBC (c \& d) concentrations in SRS and TS, Everglades 50

3.4 Seasonal distribution of \%DBC in DOC in SRS and TS, Everglades ..................... 52

3.5 Correlation between DOC and DBC concentrations in the Everglades. 53 
3.6 Principal component analysis for BPCA proportions of the Everglades water samples: (a) Score plot; (b) Loading plot. ...................................................................... 55

3.7 Comparison of DOC and DBC concentrations in three wetlands..............................59

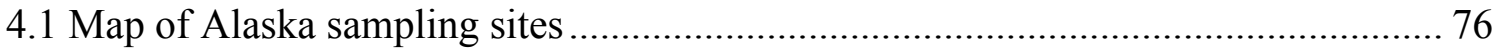

4.2 Linear regressions between DOC and DBC concentrations in sub-groups with

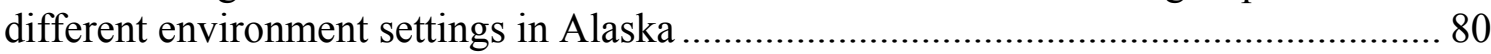

4.3 Scores (a) and loadings (b) of principal component analysis of BPCA proportions

4.4 Average principal component 1 (PC1) values of samples from different

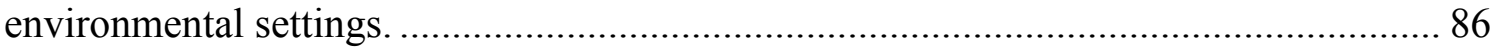

5.1 Map for global freshwater DBC sampling sites................................................... 98

5.2 Inter-laboratory comparison of DBC quantification ................................................ 99

5.3 DOC versus DBC concentrations of global rivers ................................................. 106

5.4 72-hour changes of DOC (a) and DBC (b) amounts released from unit gram of

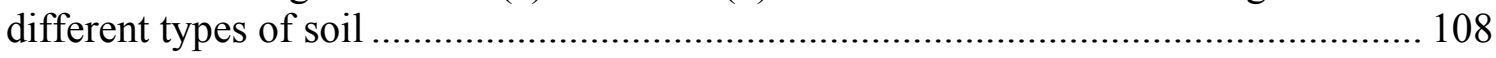

5.5 Correlation between DOC and DBC released from unit gram of different types of soil.

5.6 C-normalized DOC (a) and DBC (b) amounts leached from unit gram of fresh and aged chars incubated with $\mathrm{DI} \mathrm{H}_{2} \mathrm{O}$ and DOM solution.

6.1 A map shows the UDOM samples collected from six different LTER sites across climatic regions of North America

6.2 An example of a XPS-N1s spectrum: (a) primary amine N group, (b) peptide/amide $\mathrm{N}$ group, and (c) aromatic $\mathrm{N}$ group

6.3 Linear correlations between \%DBC (\%UDBC) and \%DBN (\%UDBN) in both UDOM samples and DOM samples

6.4 Linear correlations between UDBC and UDBN concentrations (a) and linear correlations between bulk DOC and UDBN concentrations (black circles), including one bulk DOM sample (open circle, SRS4) from the Everglades (b) 
Chapter I

INTRODUCTION 


\subsection{Introduction}

Black Carbon (BC) is the incomplete combustion product of biomass and fossil fuels (Goldberg, 1985). Because of its aromatic characteristic, BC is believed to be refractory, and thus to contribute significantly to the global carbon budget as a slowcycling carbon pool (Kuhlbusch, 1998; Masiello, 2004; Middelburg et al., 1999). The non-active carbon sink can reduce the net $\mathrm{CO}_{2}$ released from deforestation by $2-18 \%$ (Crutzen \& Andreae, 1990; Kuhlbusch, 1998).

A large number of $\mathrm{BC}$ related studies have been conducted in the past few decades because of its relevance to global carbon cycle and potential climate change, focusing on the BC storage in the atmosphere, ocean sediments, soils and rivers as soot, char, or particulate organic matter (Czimczik et al., 2003; Masiello \& Druffel, 1998; Mitra et al., 2002). However, a large diversity exists among BC measurements because of its broad definition and challenges in analytical methodologies. To better define and describe the physical and chemical diversity of BC, Hedges et al. (2000) proposed a combustion continuum model to define $\mathrm{BC}$, which refers to a wide range of combustion products from large pieces of slightly charred biomass to highly condensed, sub-micron soot particles (Fig. 1.1) (Hammes et al., 2007; Masiello, 2004). Besides the size, different $\mathrm{BC}$ materials in this continuum concept also vary in chemical structures, optical and physical properties, reactivity/lability, and interactivity with non-BC organic/inorganic matters (Knicker 2007; Liang et al. 2010; Masiello 2004; Nocentini et al. 2010; Schneider et al. 2010). So far, several analytical techniques have been developed for BC measurements, such as thermal oxidation (Gustafsson et al., 1997), BPCA molecular markers (Fig. 1.2; Glaser et al., 1998), optical transmittance and reflectance (Chow et al. 
2004), UV photooxidation coupled with ${ }^{13} \mathrm{C}-\mathrm{NMR}$ (Skjemstad et al. 1999) and ultrahigh resolution mass spectrometry (Kim et al., 2003; Dittmar and Koch, 2006). Because each technique measures only a limited region of $\mathrm{BC}$ continuum, the estimation of global black carbon budgets is very challenging (Hammes et al. 2007; Masiello 2004).

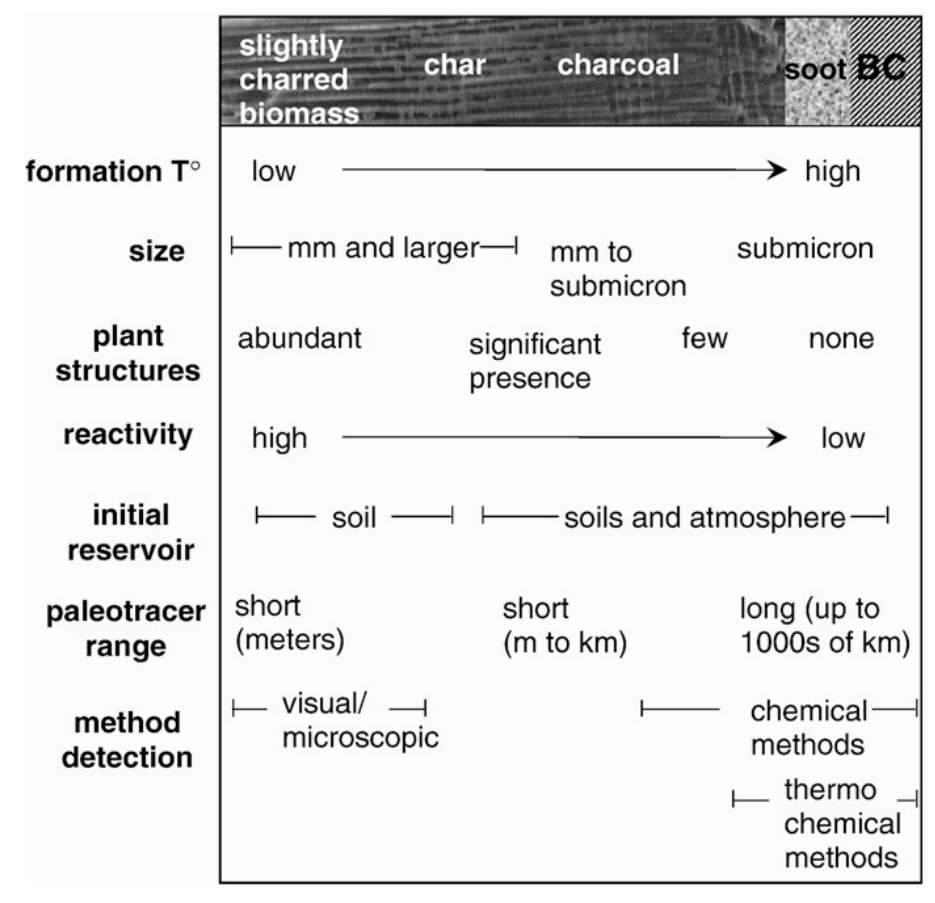

Figure 1.1 The black carbon combustion continuum (from Masiello, 2004)

The annual formation of $\mathrm{BC}$ was estimated to range from 50 to $200 \mathrm{Tg}(1 \mathrm{Tg}=$ $10^{12} \mathrm{~g}$ ), with more than $80 \%$ remaining on site as charred residues (Kuhlbusch \& Crutzen, 1996; Suman et al., 1997). With such a large input, the notion that BC is one of the major components of the soil/sediment organic matter (SOM) has been widely accepted and confirmed. Up to $35 \%$ of SOM was identified as BC all around the world (Czimczik et al., 2003; Glaser et al., 1998; Schmidt et al., 2002). The percentage of BC in the tropical Atlantic sediment can even reach up to $>50 \%$ (Verardo \& Ruddiman, 1996). Many mechanisms may introduce $\mathrm{BC}$ to ocean sediment, including atmospheric deposition of 
land-derived $\mathrm{BC}$ aerosol and river-estuary transport of terrestrial soil $\mathrm{BC}$ (Mannino \& Harvey, 2004; Suman et al., 1997). What remains unclear is whether the massive BC input will be buried in oceanic sediment and accumulate over a geological scale time, or be mobilized back into the active $\mathrm{C}$-cycle in the form of dissolved organic matter (DOM) on centennial or decade-time scales. Recent studies suggest that on the basis of massbalance approaches, $\mathrm{BC}$ is indeed less refractory than previously assumed (Masiello, 2004), and incubation studies conducted in the laboratory have confirmed this suggestion (Zimmerman, 2010). An increasing number of recent studies suggest that BC also exists in the water phase as dissolved $\mathrm{BC}(\mathrm{DBC})$ and that consequently, the DOM pool is an important intermediate in the BC cycle (Dittmar et al., 2012; Masiello \& Druffel, 1998).
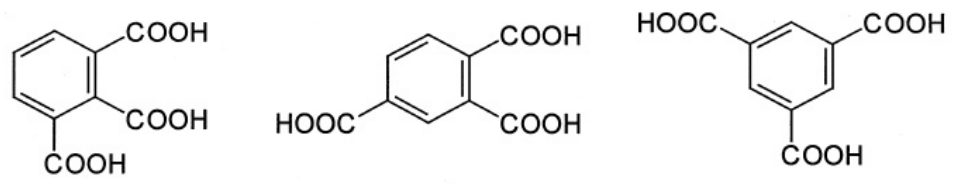

hemimellitic acid

trimellitic acid trimesic acid<smiles>O=C(O)c1ccc(C(=O)O)c(C(=O)O)c1C(=O)O</smiles><smiles>O=C(O)c1cc(C(=O)O)c(C(=O)O)c(C(=O)O)c1</smiles><smiles>O=C(O)c1cc(C(=O)O)c(C(=O)O)cc1C(=O)O</smiles>

prehnitic acid

mellophanic acid

pyromellitic acid<smiles>O=C(O)c1cc(C(=O)O)c(C(=O)O)c(C(=O)O)c1C(=O)O</smiles><smiles>O=C(O)c1c(C(=O)O)c(C(=O)O)c(C(=O)O)c(C(=O)O)c1C(=O)O</smiles>

benzenepentacarboxylic acid

Figure 1.2 Chemical structures of some benzenepolycarboxylic acids (BPCAs; from Glaser et al., 1998) 
The mechanisms of the dissolution processes or translocation of soil BC to DBC however, remain unclear. Lary et al. (1999) proposed that soot, one segment in the BC continuum mentioned above, could be oxidized by ozone to form polar surface groups such as carboxylates and thus have $\mathrm{BC}$ become more hydrophilic (Fig. 1.3), a process that was confirmed by Decesari et al. (2002). Kim et al. (2004) suggested that watersoluble $\mathrm{BC}$ contributed to the DOM pool through either microbial or photochemical oxidation. The existence of DBC as part of DOM has also been confirmed by advanced analytical techniques, such as ultrahigh resolution mass spectrometry and compound specific radiocarbon analysis (Dittmar, 2008; Dittmar et al., 2008; Dittmar \& Koch, 2006; Hockaday et al., 2007; Kim et al., 2004; Mannino \& Harvey, 2004; Ziolkowski \& Druffel, 2010). Figure 1.4 presents two possible structures of thermogenic DOM in the deep ocean detected by ultrahigh resolution mass spectrometry (Dittmar and Paeng, 2009). They are polycyclic aromatic hydrocarbons consisting of seven condensed rings and varying numbers of carboxyl, hydroxyl and aliphatic functional groups (Dittmar and Koch, 2006). However, still very little is known about the biogeochemistry and environmental dynamics of dissolved organic matter associated black carbon, (DOM-BC) or $\mathrm{DBC}$, and the majority of publications on this subject are focused on marine and coastal areas. The lack of information on freshwater environments is critical, since the DBC pool in marine environments is presumably derived from riverine transport and freshwater runoff. As such, global rivers DBC export could be an important player in the carbon cycle and critical to global carbon budgets. 


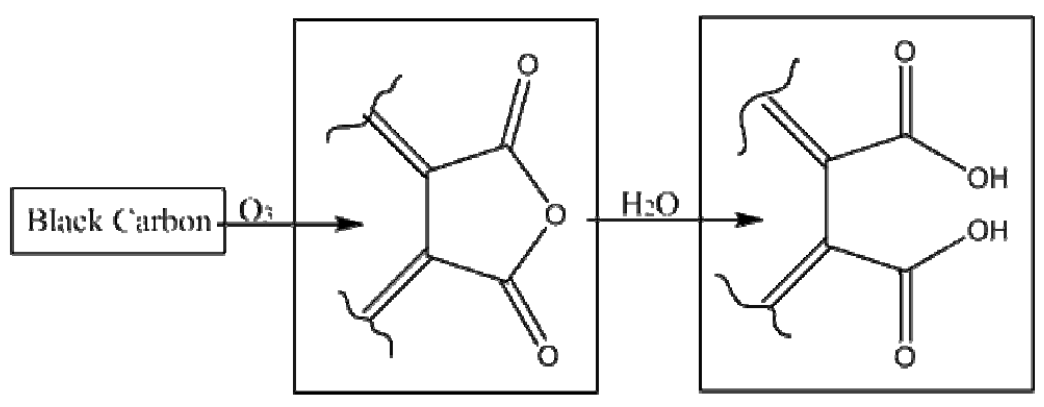

Figure 1.3 Formation of polar functional groups on soot polyaromatic macro-molecules, by oxidation of external rings with ozone, and subsequent hydrolysis of oxygen containing rings (from Chughtai et al., 1991; Decesari et al., 2002).

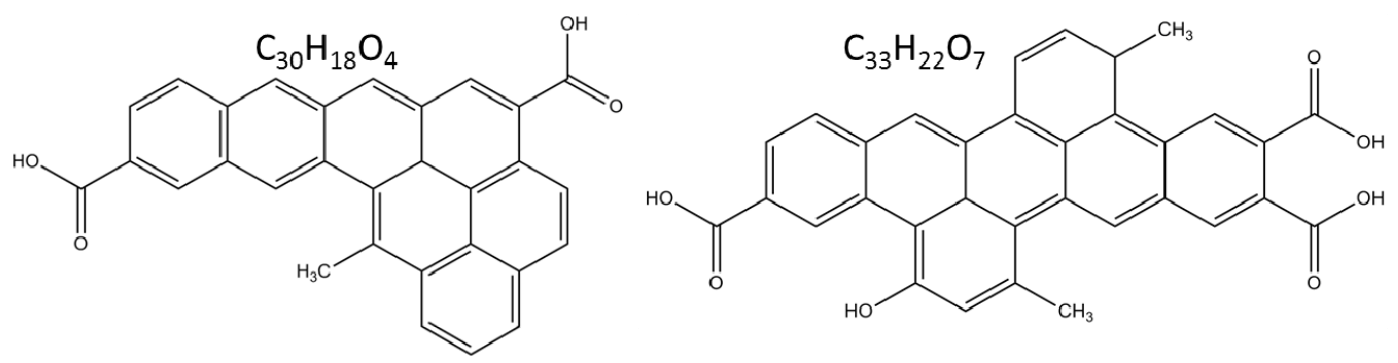

Figure 1.4 Two examples of probable structures for thermogenic DOM in the deep ocean based on the exact molecular mass obtained from FT/ICR-MS (from Dittmar and Paeng, 2009).

The main objective of my doctoral research project is to study the biogeochemistry of DBC in freshwater environments, on the basis of the general hypothesis that $\mathrm{BC}$ is less refractory than previously believed and consequently terrestrial environments export significant quantities of $\mathrm{BC}$ in the dissolved form (DBC) to the oceans. Specific objectives include: (1) to determine the background levels of DBC in diverse freshwater environments on a global scale (Chapters II-V); (2) to assess the importance of recent fire history and fire frequency on DBC in streams (Chapters II and III); (3) to assess DBC dynamics on spatial and temporal scales (Chapter III); (4) to study possible reasons for a molecular level discrimination of $\mathrm{DBC}$ collected from diverse 
geographic areas (Chapter IV); (5) to better understand the BC dissolution mechanisms in order to determine the controlling factor for DBC translocation (Chapter V); (6) to investigate the sources and biogeochemical characteristics of dissolved black nitrogen (DBN) as it related to DBC (Chapter VI); and (7) ultimately, to estimate the global flux of riverine $\mathrm{DBC}$ (and $\mathrm{DBN}$ ) to the oceans, in order to assess its importance in the global carbon cycle and to better constrain the global black carbon budget (Chapter V). 


\section{REFERENCES}

Brodowski S, Rodionov A, Haumaier L, Glaser B, Amelung W (2005) Revised black carbon assessment using benzene polycarboxylic acids. Organic Geochemistry 36(9): $1299-1310$

Chow JC, Watson JG, Chen LWA, Arnott WP, Moosmuller H (2004) Equivalence of elemental carbon by thermal/optical reflectance and transmittance with different temperature protocols. Environmental Science \& Technology 38(16): 4414-4422

Chughtai AR, Jassim JA, Peterson JH, Stedman DH, Smith DM (1991) Spectroscopic and solubility characteristics of oxidized soots. Aerosol Science and Technology 15(2): $112-126$

Crutzen PJ, Andreae MO (1990) Biomass burning in the tropics - impact on atmospheric chemistry and biogeochemical cycles. Science 250(4988): 1669-1678

Czimczik CI, Preston CM, Schmidt MWI, Schulze ED (2003) How surface fire in Siberian Scots pine forests affects soil organic carbon in the forest floor: Stocks, molecular structure, and conversion to black carbon (charcoal). Global Biogeochemical Cycles 17(1): GB1956

Decesari S, Facchini MC, Matta E, Mircea M, Fuzzi S, Chughtai AR, Smith DM (2002) Water soluble organic compounds formed by oxidation of soot. Atmospheric Environment 36(11): 1827-1832

Dittmar T (2008) The molecular level determination of black carbon in marine dissolved organic matter. Organic Geochemistry 39(4): 396-407

Dittmar T, Rezende CE, Manecki M, Niggemann J, Ovalle ARC, Stubbins A, Bernardes MC (2012) Continuous flux of dissolved black carbon from a vanished tropical forest biome. Nature Geoscience 5(9): 618-622

Dittmar T, Koch B, Hertkorn N, Kattner G (2008) A simple and efficient method for the solid-phase extraction of dissolved organic matter (SPE-DOM) from seawater. Limnology and Oceanography-Methods 6: 230-235

Dittmar T, Koch BP (2006) Thermogenic organic matter dissolved in the abyssal ocean. Marine Chemistry 102(3-4): 208-217

Dittmar T, Paeng J (2009) A heat-induced molecular signature in marine dissolved organic matter. Nature Geoscience 2(3): 175-179

Glaser B, Haumaier L, Guggenberger G, Zech W (1998) Black carbon in soils: the use of benzenecarboxylic acids as specific markers. Organic Geochemistry 29(4): 811-819 
Goldberg ED (1985) Black carbon in the environment: Properties and distribution. John Wiley \& Sons, New York

Gustafsson O, Haghseta F, Chan C, MacFarlane J, Gschwend PM (1997) Quantification of the dilute sedimentary soot phase: Implications for PAH speciation and bioavailability. Environmental Science \& Technology 31(1): 203-209

Hammes K, Schmidt MWI, Smernik RJ, Currie LA, Ball WP, Nguyen TH, Louchouarn P, Houel S, Gustafsson O, Elmquist M, Cornelissen G, Skjemstad JO, Masiello CA, Song J, Peng P, Mitra S, Dunn JC, Hatcher PG, Hockaday WC, Smith DM, Hartkopf-Froeder C, Boehmer A, Luer B, Huebert BJ, Amelung W, Brodowski S, Huang L, Zhang W, Gschwend PM, Flores-Cervantes DX, Largeau C, Rouzaud JN, Rumpel C, Guggenberger G, Kaiser K, Rodionov A, Gonzalez-Vila FJ, Gonzalez-Perez JA, de la Rosa JM, Manning DAC, Lopez-Capel E, Ding L (2007) Comparison of quantification methods to measure fire-derived (black/elemental) carbon in soils and sediments using reference materials from soil, water, sediment and the atmosphere. Global Biogeochemical Cycles 21(3): 18

Hedges JI, Eglinton G, Hatcher PG, Kirchman DL, Arnosti C, Derenne S, Evershed RP, Kogel-Knabner I, de Leeuw JW, Littke R, Michaelis W, Rullkotter J (2000) The molecularly-uncharacterized component of nonliving organic matter in natural environments. Organic Geochemistry 31(10): 945-958

Hockaday WC, Grannas AM, Kim S, Hatcher PG (2007) The transformation and mobility of charcoal in a fire-impacted watershed. Geochimica et Cosmochimica Acta 71(14): 3432-3445

Jaffé R, Yamashita Y, Maie N, Cooper WT, Dittmar T, Dodds WK, Jones JB, Myoshi T, Ortiz-Zayas JR, Podgorski DC, Watanabe A (2012) Dissolved organic matter in headwater streams: compositional variability across climatic regions of North America. Geochimica et Cosmochinica Acta 94: 95-108

Kim SW, Kaplan LA, Benner R, Hatcher PG (2004) Hydrogen-deficient molecules in natural riverine water samples - evidence for the existence of black carbon in DOM. Marine Chemistry 92(1-4): 225-234

Kim SW, Simpson AJ, Kujawinski EB, Freitas MA, Hatcher PG (2003) High resolution electrospray ionization mass spectrometry and 2D solution NMR for the analysis of DOM extracted by C18 soil phase disk. Organic Geochemistry 34(1-4): 1325-1335

Knicker H (2007) How does fire affect the nature and stability of soil organic nitrogen and carbon? A review. Biogeochemistry 85(1): 91-118

Kuhlbusch TAJ (1998) Black carbon and the carbon cycle. Science 280(5371): 19031904 
Kuhlbusch TAJ, Crutzen PJ (1996) Black Carbon, the Global Carbon Cycle, and Atmospheric Carbon Dioxide. In: Levine JS (ed.) Biomass burning and Global Change. MIT Press, Campbridge, MA. p 160-169

Lary DJ, Shallcross DE, Toumi R (1999) Carbonaceous aerosols and their potential role in atmospheric chemistry. Journal of Geophysical Research-Atmospheres 104(D13): $15929-15940$

Liang BQ, Lehmann J, Sohi SP, Thies JE, O'Neill B, Trujillo L, Gaunt J, Solomon D, Grossman J, Neves EG, Luizao FJ (2010) Black carbon affects the cycling of non-black carbon in soil. Organic Geochemistry 41(2): 206-213

Maie N, Parish KJ, Watanabe A, Knicker H, Benner R, Abe T, Kaiser K, Jaffé R (2006) Chemical characteristics of dissolved organic nitrogen in an oligotrophic subtropical coastal ecosystem. Geochimica Et Cosmochimica Acta 70(17): 4491-4506.

Mannino A, Harvey HR (2004) Black carbon in estuarine and coastal ocean dissolved organic matter. Limnology and Oceanography 49(3): 735-740

Masiello CA (2004) New directions in black carbon organic geochemistry. Marine Chemistry 92(1-4): 201-213

Masiello CA, Druffel ERM (1998) Black carbon in deep-sea sediments. Science 280(5371): 1911-1913

Middelburg JJ, Nieuwenhuize J, van Breugel P (1999) Black carbon in marine sediments. Marine Chemistry 65(3-4): 245-252

Mitra S, Bianchi TS, McKee BA, Sutula M (2002) Black carbon from the Mississippi River: Quantities, sources, and potential implications for the global carbon cycle. Environmental Science \& Technology 36(11): 2296-2302

Nocentini C, Certini G, Knicker H, Francioso O, Rumpel C (2010) Nature and reactivity of charcoal produced and added to soil during wildfire are particle-size dependent. Organic Geochemistry 41(7): 682-689

Schmidt MWI, Skjemstad JO, Jager C (2002) Carbon isotope geochemistry and nanomorphology of soil black carbon: Black chernozemic soils in central Europe originate from ancient biomass burning. Global Biogeochemical Cycles 16(4): 8

Schneider MPW, Hilf M, Vogt UF, Schmidt MWI (2010) The benzene polycarboxylic acid (BPCA) pattern of wood pyrolyzed between 200 degrees C and 1000 degrees C. Organic Geochemistry 41(10): 1082-1088 
Skjemstad JO, Taylor JA, Smernki JM (1999) Estimateion of charcoal (char) in soils. Communication in Soil Science and Plant Analysis 39(15-16): 343-359

Suman DO, Kuhlbusch TAJ, Lim B (1997) Marine sediments: a reservoir for black carbon and their use as spatial and temporal records of combustion. In: Clark JS, Cachier H, Goldammer JG \& Stock BJ (eds.) Sediment Records of Biomass Burning and Global Change. Springer Verlag, Berlin.

Verardo DJ, Ruddiman WF (1996) Late pleistocene charcoal in tropical Atlantic deep-sea sediments: Climatic and geochemical significance. Geology 24(9): 855-857

Zimmerman AR (2010) Abiotic and Microbial Oxidation of Laboratory-Produced Black Carbon (Biochar). Environmental Science \& Technology. 44(4): 1295-1301

Ziolkowski LA, Druffel ERM (2010) Aged black carbon identified in marine dissolved organic carbon. Geophysical Research Letters 37: L16601 
Chapter II

DISSOLVED BLACK CARBON IN GRASSLAND STREAMS: IS THERE AN EFFECT OF RECENT FIRE HISTORY?

(This chapter is modified from Ding et al., 2013, Chemosphere) 


\subsection{Abstract}

While the existence of black carbon as part of dissolved organic matter (DOM) has been confirmed, quantitative determinations of dissolved black carbon (DBC) in freshwater ecosystem and information on factors controlling its concentration are scarce. In this study, stream surface water samples from a series of watersheds subject to different burn frequencies in Konza Prairie (Kansas, USA) were collected in order to determine if recent fire history has a noticeable effect on DBC concentration. The DBC levels detected ranged from 0.04 to $0.11 \mathrm{mg} \mathrm{L}^{-1}$, accounting for ca. $3.32 \pm 0.51 \%$ of dissolved organic carbon (DOC). No correlation was found between DBC concentration and neither fire frequency nor time since last burn. I suggest that limited DBC flux is related to high burning efficiency, possibly greater export during periods of high discharge and/or the continuous export of DBC over long time scales. A linear correlation between DOC and DBC concentrations was observed, suggesting the export mechanisms determining DOC and DBC concentrations are likely coupled. The potential influence of fire history was less than the influence of other factors controlling the DOC and DBC dynamics in this ecosystem. Assuming similar conditions and processes apply in grasslands elsewhere, extrapolation to a global scale would suggest a global grasslands

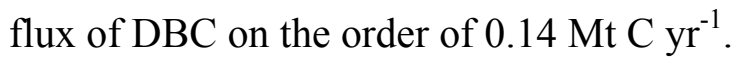

\subsection{Introduction}

Black Carbon (BC) has been characterized as a combustion-derived, highly aromatic and recalcitrant material which is ubiquitous in the environment (Masiello, 2004). Until recently, BC was believed to have a geological-scale turnover time and thus 
contributing significantly to global carbon budgets as a slow-cycling carbon sink (Goldberg, 1985; Kuhlbusch, 1998; Masiello, 2004). With more than $80 \%$ of the vegetation-generated $\mathrm{BC}$ remaining on site, up to $35 \%$ of soil organic matter (SOM) has been identified as BC worldwide (e.g., Glaser et al., 2000; Schmidt et al., 2002). Approximately $5-20 \%$ of the annual burial of organic matter to oceanic sediments could be BC (Gustafsson and Gschwend, 1998; Masiello and Druffel, 1998), and the global reservoir for BC has been estimated at 300-500 Pg C (1 Pg $=10^{15} \mathrm{~g}$; Hockaday et al., 2007).

However, the lability of charred materials can vary dramatically, with half-life estimates of soil $\mathrm{BC}$ ranging from $<50$ to $10^{7}$ years (e.g., Bird et al., 1999; Zimmerman, 2010). Such results in conjunction with mass balance estimates (Masiello, 2004) imply that BC may be lost from soils at higher than expected rates. Such losses could be controlled by two main processes, respiration and dissolution (e.g., Hockaday et al., 2007; Zimmerman, 2010). Masiello and Druffel (1998) first suggested the dissolved organic carbon (DOC) pool as a possible intermediate reservoir for BC and estimated the $\mathrm{BC}$ content in oceanic DOC ranging from $4 \%$ to $22 \%$. Although the mechanism of $\mathrm{BC}$ dissolution remains unclear, the existence of dissolved $\mathrm{BC}$ (DBC) has been confirmed and quantified (e.g., Hockaday et al., 2007; Dittmar, 2008; Dittmar et al., 2012a, b). While most quantitative determinations of $\mathrm{DBC}$ have thus far been focused on marine and coastal systems, little is known about the processes that control DBC levels in freshwater ecosystems that drain the continents, where one potential and likely driver is fire frequency. 
Fires are very common across climatic regions, in natural and managed lands. The impacts of biomass burning on the quality and quantity of soil organic matter are varied (e.g., Hamer et al., 2004; Wardle et al., 2008). Thus, fire frequency could play an important role in SOM characteristics and BC accumulation. Czimczik et al. (2005) studied the effects of fire frequency on BC and SOM in Podzols of Siberian Scot pine forest, reporting that the stocks of $\mathrm{BC}$ and $\% \mathrm{BC}$ of $\mathrm{SOM}$ were not directly correlated with the time elapsed since the last fire. Instead, intensity of the last fire was more important in controlling the fate of BC. Similarly, Kane et al. (2010) reported no significant correlation between mineral soil BC stocks and fire frequencies, but suggested that $\mathrm{BC}$ in organic-rich soils was more vulnerable to re-oxidation by recurring fires compared to $\mathrm{BC}$ in mineral soils. Thus, topographic controls, including interactions between SOM depth, soil density and landscape position may drive the burial processes of $\mathrm{BC}$ and exert an important influence on BC preservation in soils (Kane et al., 2010).

Considerable uncertainties remain about the effects of fire on char residue accumulation and preservation in soils, and even less is known about the effect of fires on the fate of DBC in aquatic systems. To the best of my knowledge, very few studies have been conducted on fire impacts on DBC in aquatic environments. Vergnoux et al. (2011) reported that fires had only qualitative and short-term impacts on the water extractable SOM, and the number of fires was not a controlling factor on its quality and quantity. In a more recent study (Dittmar et al., 2012b) the long term effects of slash and burn activities on the export of DBC by streams has clearly been demonstrated. In the latter study, as well as in the work described here, DBC was molecularly defined as condensed polycyclic aromatic hydrocarbon with peripheral functional groups (Dittmar and Koch, 
2006), that are believed to be generated under high temperature conditions and are among the less reactive BC components (Masiello, 2004; Dittmar, 2008).

About $28 \%$ of global runoff originates from grasslands and wooded grasslands (Dodds, 1997). While many of these grasslands are maintained by regular fires (Bond et al., 2005), little is known about how much of the burned organic material reaches grassland streams, or has the export of such materials from grasslands worldwide been estimated. The main objective of this study was to determine if recent fire history has a noticeable effect on DBC concentrations. A long-term watershed-based fire frequency experiment has been performed at the relatively natural tallgrass prairie site, Konza Prairie Biological Station (KPBS), since the 1970s. Thus, surface water in a series of watersheds subjected to different fire regimes was sampled.

\subsection{Material and methods}

\subsubsection{Site description}

The KPBS is located in the Flint Hills region of North America $\left(39^{\circ} 05^{\prime} \mathrm{N}\right.$, $96^{\circ} 35^{\prime} \mathrm{W}$ ), and it is the focal site of Konza Prairie Long Term Ecological Research (KNZLTER) program. Konza Prairie is a relatively large contiguous unplowed tallgrass prairie and floristically diverse (Knapp and Seastedt, 1998). The regional climate is typical Midwestern North American continental with hot and wet summers, dry and cold winters, and low humidity. $75 \%$ of the annual precipitation (an average of $835 \mathrm{~mm}$ ) falls during the growing season (May-June) while December and January are generally the driest months (Collins, 1992; Gray, 1997). The vegetation at KPBS is dominated by a few native $\mathrm{C}_{4}$ grasses (Freeman, 1998). Small areas of deciduous riparian forests also occur 
along the main channels of Kings Creek and Shane Creek, draining KPBS. The ecology, biogeochemistry and geomorphology of the streams on KPBS have been described in more detail elsewhere (e.g., Gray et al., 1998; Dodds et al., 2004)

Wild fires caused by lightning are thought to commonly occur in spring when fuel loading from last year is sufficient and frequent thunderstorms occur (Hulbert, 1973). Frequent burning alters soil properties as it lowers soil $\mathrm{N}$ availability and alters the energy, water, and nutrient relationships of the prairie (Knapp and Seastedt, 1986). During the last four decades, replicated watersheds in Konza Prairie have been burned at target frequencies of 20, 4, 2 and 1-year in the spring (April $10 \pm 20 \mathrm{~d}$ ). Thus, this site is ideal to perform a DBC dynamics study with the objective to assess the effect of fire frequency on DBC levels in grassland streams.

The Kings Creek watershed (1059 ha) is one of the five major drainage basins on KPBS and the only one located entirely within the boundaries of the site. Eleven surface water samples were collected from its south and north branches in June 2009, 2 months after the peak flow occurred in the main stream of the creek. One of the watersheds (20B) drains to the south and not into Kings Creek. Soils are similar within the watershed with increasing influence of deeper fluvial deposits and decreasing average slope as basin area increases, but with similar soils and slopes in sub-basins of similar size.

\subsubsection{Sample collection and preparation}

Eight liters of surface water were collected into pre-acid and base rinsed plastic bottles in June, 2009 from 11 watersheds (Fig. 2.1). Samples were filtered immediately in the field through $\mathrm{GF} / \mathrm{F}$ filters (Whatman, $0.7 \mu \mathrm{m}$ ). Aliquots of each sample were 
transferred into $60 \mathrm{~mL}$ amber glass bottles and stored at $4{ }^{\circ} \mathrm{C}$ for $\mathrm{DOC}$ analysis. The remaining samples were acidified to $\mathrm{pH} 2$ using concentrated $\mathrm{HCl}$. Dissolved organic matter (DOM) from each sample was extracted by solid phase extraction (SPE) via Varian Bond Elut PPL cartridges and eluted with $10 \mathrm{~mL}$ MeOH (Dittmar, 2008). Milli-Q water was used as a procedural blank, and no contamination was observed.

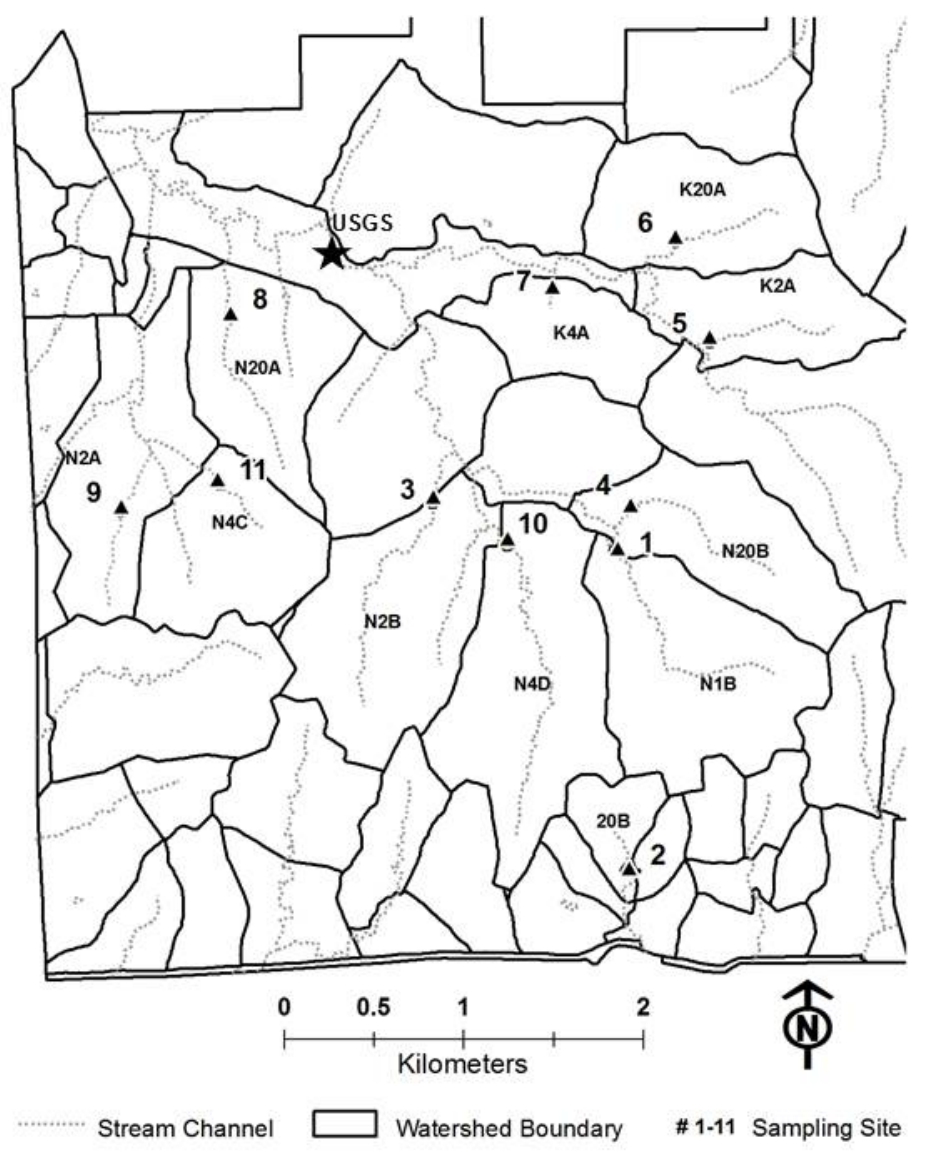

Figure 2.1. Sampling sites in Konza Prairie Biological Station (KPBS; Kansas, USA), showing different management practices. Watershed codes indicate burn frequencies (the number indicates target burn frequency; $\mathrm{K}=$ North Branch Kings Creek, ungrazed; $\mathrm{N}=$ native grazers, bison; the last letter in the code is the burn replicate). The star indicates the USGS site. 
Continuous water discharge data for the year of 2009 were recorded from a USGS site on Kings Creek (06879650; marked as star in Fig. 2.1) located in the main drainage of the creek where the south branch and north branch meet. Samples were collected immediately downstream from this site three times per week during times of flow and filtered. DOC for all samples (including those from 1995-1997) was determined by high temperature catalytic conversion on a TOC-5000A analyzer (Shimadzu, Japan; AlvarezSalgado and Miller, 1998).

\subsubsection{BC analysis - benzenepolycarboxylic acids (BPCAs) method}

The benzenepolycarboxylic acids (BPCAs, structures shown in Chapter I, Fig. 1.2) method was used for the DBC determinations (Dittmar, 2008). Briefly, an equivalent of 20-80 $\mu \mathrm{mol} \mathrm{C}$ of MeOH extracts of DOM were placed into $1 \mathrm{~mL}$ glass ampoules, dried under nitrogen and flame sealed after the addition of $0.5 \mathrm{~mL}$ concentrated nitric acid. The ampoules were slowly heated to $160{ }^{\circ} \mathrm{C}(30 \mathrm{~min})$ in a programmable GC oven (HP 5890 Series II GC) and kept at $160{ }^{\circ} \mathrm{C}$ for $6 \mathrm{~h}$. After digestion, nitric acid was evaporated under nitrogen at $50{ }^{\circ} \mathrm{C}$ and samples in the ampoules were re-dissolved in $300 \mu \mathrm{L}$ mobile phase A (see Section 2.3.4) for high-performance liquid chromatography (HPLC) analysis.

Different digestion temperatures and time have been reported for the BPCA methodology. To compare the oxidation efficiencies under different conditions, fullerene $\left(\mathrm{C}_{60}\right)$, Suwannee River Humic Acid Standard II (SRHA) and freshwater DOM samples from Shark River Slough (Everglades National Park, FL) were analyzed using two previously reported oxidation conditions, namely $170^{\circ} \mathrm{C}$ for 8 or $9 \mathrm{~h}$ (Glaser et al., 1998; Dittmar, 2008), $180{ }^{\circ} \mathrm{C}$ for $8 \mathrm{~h}$ (Ziolkowski and Druffel, 2009), and for comparative 
purposes, at a lower temperature $\left(160{ }^{\circ} \mathrm{C}\right.$ for up to $\left.8 \mathrm{~h}\right)$. The oxidation of $\mathrm{C}_{60}$ yielded exclusively benzenehexacarboxylic acid (B6CA) $(>99.7 \%$ in total BPCAs) at all three temperatures during 8-9 $\mathrm{h}$ oxidation. C recovery (percentage of mol-C of BPCAs produced to mol-C of sample subjected to oxidation) is the lowest for oxidations at the highest temperature $\left(180{ }^{\circ} \mathrm{C}\right)$, while there is no statistical difference in $\mathrm{C}$ recoveries between oxidations at $160{ }^{\circ} \mathrm{C}$ and $170{ }^{\circ} \mathrm{C}$ (Table $2.1 ; \alpha=0.05, \mathrm{n}=3$ for each oxidation temperature). The $\mathrm{C}$ recoveries results of activated charcoal (Appendix 2.1), another $\mathrm{BC}$ analog, were very similar to those of fullerene. Similarly, for SRHA and the freshwater DOM samples, digestion at lower temperatures yielded the highest BPCA-C yields cause of reduced decomposition of less substituted BPCAs (i.e., B3CA and B4CA). At the temperature of $160^{\circ} \mathrm{C}$, the total amount of BPCAs reached the maximum at around $4-5 \mathrm{~h}$, whereas digestions lasting longer than $8 \mathrm{~h}$ resulted in BPCA losses (Fig. 2.2). Losses of BPCAs under high temperatures were examined by digesting BPCA standard mix and the results indicated $36 \%$ to $<2 \%$ of $\mathrm{BPCAs}(\mathrm{B} 3 \mathrm{CA}>\mathrm{B} 4 \mathrm{CA}>\mathrm{B} 5 \mathrm{CA} \approx \mathrm{B} 6 \mathrm{CA})$ were lost at $160^{\circ} \mathrm{C}$ for $6 \mathrm{~h}$ (Appendix 2.2). Degradation was higher at higher temperatures. The BPCA standards loss during digestion at $150{ }^{\circ} \mathrm{C}$ is negligible; however, the $\mathrm{C}$ recovery at this temperature is too low (Fig. 2.2). Thus, digestion conditions of heating at $160{ }^{\circ} \mathrm{C}$ for $6 \mathrm{~h}$ were adopted to obtain comprehensive BPCA information for DOM samples (Appendix 2.3). This analytical procedure was also applied to a series of standards, such as lignin phenols (tannins and vanillin), carbohydrates (glucose), fatty acids (p-coumaric acid), and amino acids (bovine serum albumin) for potential false positive results, but no detectable amounts of BPCAs were found. 
Table 2.1 Oxidation efficiencies of fullerene $\left(\mathrm{C}_{60}\right)$ using three different oxidation conditions. $\mathrm{C}$ recovery $=$ mol-C of all BPCAs $/$ mol-C of fullerene subjected to oxidation

\begin{tabular}{lccc}
\hline & $160^{\circ} \mathrm{C}, 6 \mathrm{~h}$ & $170^{\circ} \mathrm{C}, 9 \mathrm{~h}$ & $180^{\circ} \mathrm{C}, 8 \mathrm{~h}$ \\
\hline$\% \mathrm{~B} 3 \mathrm{CA}$ & $0.04 \pm 0.01$ & $0.03 \pm 0.00$ & N.D.* \\
$\%$ B4CA & $0.04 \pm 0.03$ & $0.16 \pm 0.03$ & $0.21 \pm 0.02$ \\
$\%$ B5CA & N.D. & N.D. & N.D. \\
$\%$ B6CA & $99.81 \pm 0.04$ & $99.79 \pm 0.03$ & $99.76 \pm 0.03$ \\
C recovery & $(22.81 \pm 1.07) \%$ & $(23.14 \pm 0.12) \%$ & $(20.21 \pm 0.49) \%$ \\
\hline
\end{tabular}

$*$ N.D. $=$ not detected

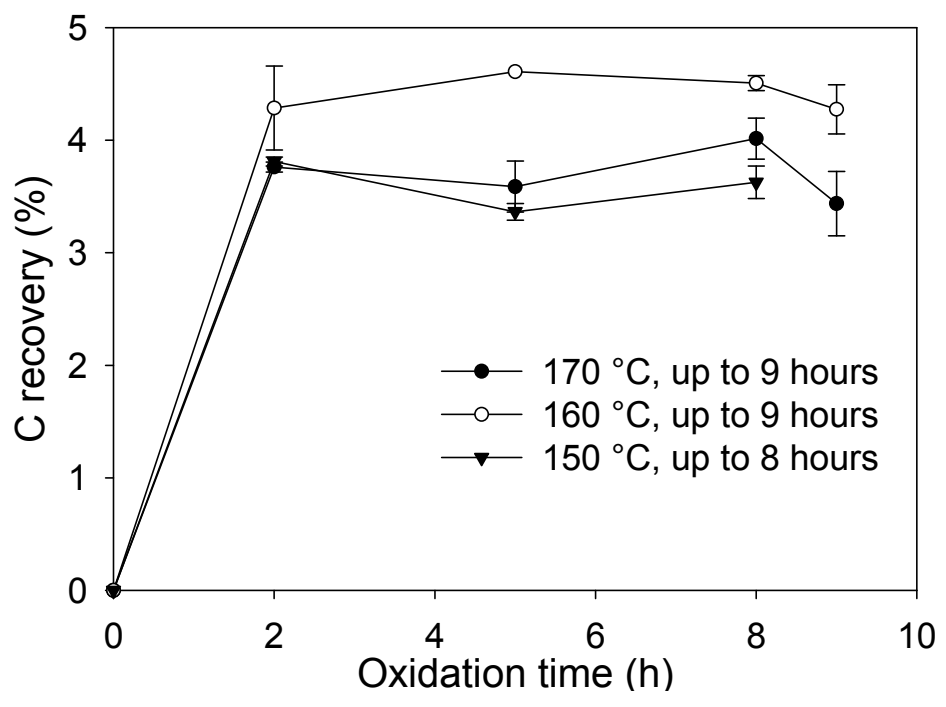

Figure 2.2 BPCA carbon recoveries of SRHA digested at $150{ }^{\circ} \mathrm{C}, 160{ }^{\circ} \mathrm{C}$ and $170{ }^{\circ} \mathrm{C}$ for up to 8 or 9 hours. The $\mathrm{C}$ recovery is defined as the sum of mol-C of all BPCAs divided by the mol-C of SRHA oxidized. 


\subsubsection{High-performance liquid chromatography}

The BC oxidation products, BPCAs, were separated and quantitatively detected on a high-performance liquid chromatography system coupled with a diode array detector (Surveyor, Thermo Scientific). A $\mathrm{C}_{18}$ column $(3.5 \mu \mathrm{m}, 2.1 \times 150 \mathrm{~mm}$, Waters Sunfire) and a binary gradient consisting of mobile phase A (4 mM Tetrabutylammonium bromide, 50 mM Sodium acetate and $10 \% \mathrm{MeOH})$ and mobile phase $\mathrm{B}(\mathrm{MeOH})$ were employed to achieve chromatographic separation. Detailed chromatographic settings and BPCA peak identifications can be obtained from Dittmar (2008). An example of a HPLC chromatogram is shown in Fig. 2.3 and HPLC solvent gradients are described in Table 2.2. The instrument detection limit for BPCA standards ranged from 0.03 to $0.15 \mu \mathrm{M}$. DBC concentrations were calculated from Equation (1), which is deduced by Dittmar (2008) on the basis of the molecular structures of marine thermogenic PAH proposed by Dittmar and Koch (2006). All samples were measured in triplicate with RSD $<5 \%$.

$$
[\mathrm{BC}]=33.4 \times([\mathrm{B} 6 \mathrm{CA}]+[\mathrm{B} 5 \mathrm{CA}]+0.5 \times[\mathrm{B} 4 \mathrm{CA}]+0.5 \times[\mathrm{B} 3 \mathrm{CA}])
$$

\subsubsection{DOC analysis}

DOC concentrations of all water samples were determined by high temperature catalytic conversion on a TOC-5000A analyzer (Shimadzu, Japan). Four mL (4 mL) of water samples were acidified to $\mathrm{pH}<2$ with $3 \mathrm{~N} \mathrm{HCl}$ to convert inorganic carbon into $\mathrm{CO}_{2}$. After being sparged with $\mathrm{CO}_{2}$-free compressed air (ultra-zero grade, Airgas), $100 \mu \mathrm{L}$ pretreated samples were injected and oxidized in the TOC-5000A furnace, filled with pre-

conditioned platinum-catalyst, at $680{ }^{\circ} \mathrm{C}$. The combustion derived $\mathrm{CO}_{2}$ was carried by 
ultra-zero grade compressed air and detected by a non-dispersive infrared $\mathrm{CO}_{2}$ detector (Alvarez-Salgado \& Miller 1998).

Table 2.2 Mobile phase mixing gradients (optimized from Dittmar, 2008)

\begin{tabular}{cccc}
\hline Time (min) & Mobile phase A (vol. \%) & Mobile phase B (vol. \%) & Flow rate (mL/min) \\
\hline 0 & 94 & 6 & 0.18 \\
8 & 94 & 6 & 0.18 \\
68 & 86 & 14 & 0.18 \\
70 & 20 & 80 & 0.18 \\
100 & 20 & 80 & 0.18 \\
102 & 94 & 6 & 0.18 \\
125 & 94 & 6 & 0.18 \\
\hline
\end{tabular}

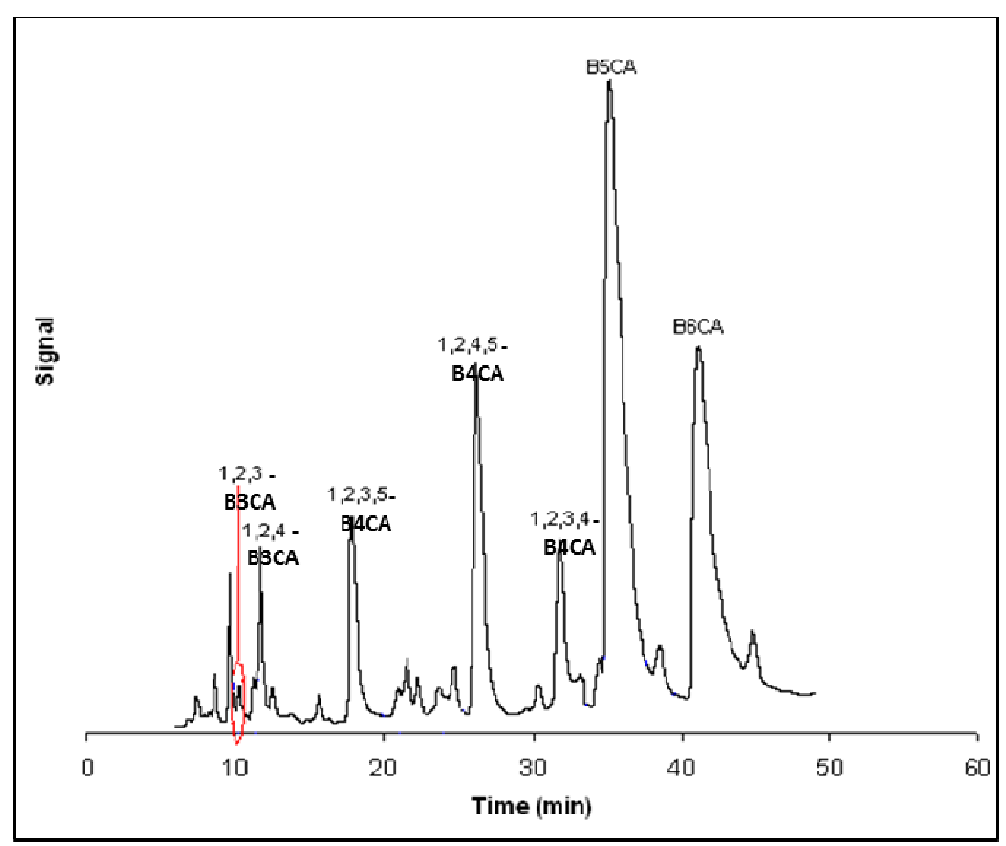

Figure 2.3 An example of HPLC chromatogram of benzenepolycarboxylic acids, the DBC oxidation products. 


\subsection{Results and Discussion}

\subsubsection{DOC distributions}

The DOC concentrations of individual samples collected for the 11 sites during June 2009 ranged from 1.4 to $2.5 \mathrm{mg} \mathrm{L}^{-1}$, while DBC concentrations for the same sites ranged from 0.04 to $0.11 \mathrm{mg} \mathrm{L}^{-1}$, accounting for $3.32 \pm 0.51 \%$ of DOC (Fig. 2.4, Appendix 2.4). Most grassland streams in the Great Plains are characterized as intermittent streams with high flood frequency and low predictability. The peak discharge in Kings Creek generally occurs between April and July, while some tributaries dry out during part of the year (Gray et al., 1998). This hydrology controls the microbial communities in the streams lowering organic matter decomposition rates (Dodds et al., 2004). Unlike perennial forest streams, prairie streams, especially in their upper reaches, have very little canopy cover. As a result, carbon flux into prairie streams is also influenced by primary production by microalgae (Dodds et al., 1996). In the lower reaches much of the organic matter is likely derived from riparian forests. The frequent flash floods and a lack of large retentive structures reduce the preservation of allochthonous OM inputs (Gurtz et al., 1988). During the dry season, evapotranspiration is greater than the precipitation and groundwater discharge becomes the main water source to maintain some persistent spring-fed pools while the remaining channels are dry (Gray et al., 1998). 


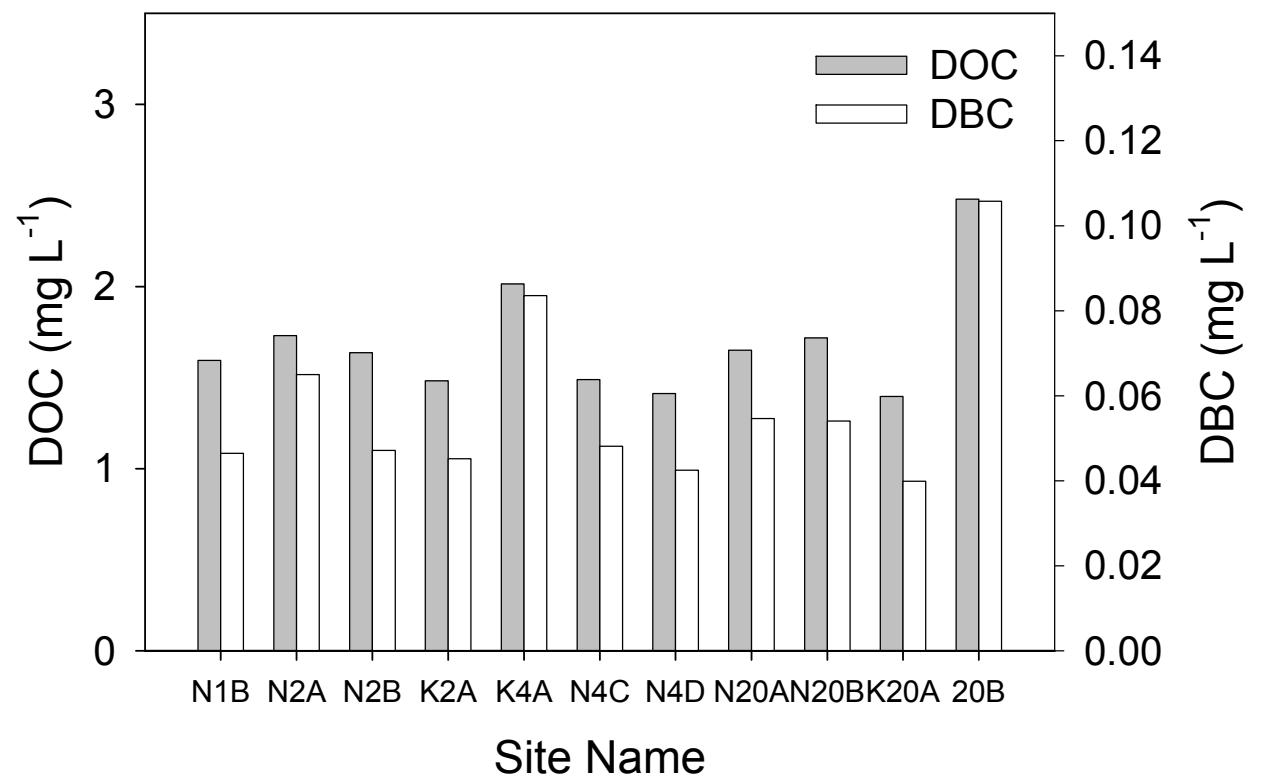

Figure 2.4 DOC and DBC concentrations from different streams at KPBS.

While most of the sites had about equal amounts of DOC concentrations, sites K4A and 20B had slightly greater DOC concentrations (Fig. 2.4). The drainage area above sampling sites for $\mathrm{K} 4 \mathrm{~A}$ and $20 \mathrm{~B}$ are smaller than most other sites, and $20 \mathrm{~B}$ also has very high biomass of woody vegetation because it is not burned. Discharge is more sporadic in smaller watersheds, and the high DOC concentrations could be related DOC flushing out of the watershed over short periods of time. However, it is difficult at this time for us to speculate on factors controlling DOC during this single sampling period because of the highly variable nature of prairie streams. To test potential DOC single time sampling variability, existing DOC data (1995-1997) from watersheds N1B, N2B, N4D, N20B, were averaged by seasons. About $70 \%$ of the over 800 DOC measurements available were from the wet season (April-August) as most of these streams are dry during part of the remaining year. No statistical seasonal difference (wet vs. dry) was 
observed for DOC concentrations neither within each catchment, nor between catchments with different fire frequencies. Thus, there was little correlation of DOC with burn frequency or watershed slope. The key determinant of DOC flux rates in these sites is water yield of the watersheds. Long-term records will be needed for more comprehensive understanding of the DOC and associated DBC dynamics in this ecosystem.

\subsubsection{DBC distributions}

The major source of DBC in Kings Creek is probably soil leachate of tallgrass combustion residues. The Konza Prairie area is relative pristine and well preserved, implying that DBC observed in this study is primarily derived from biomass burning in this landscape. In agreement, the average relative proportions of BPCAs were dominated by $\mathrm{B} 5 \mathrm{CA}(43.4 \%)$, B4CA (37.8\%), B6CA (11.1\%) and $\mathrm{B} 3 \mathrm{CA}(7.6 \%)$, typical of terrestrial-derived DBC signatures (Dittmar, 2008).

The spatial variations in DBC for the 11 sampling sites co-vary with the DOC concentrations (Fig. 2.5). In fact, a linear correlation between DOC and $\mathrm{DBC}\left(\mathrm{R}^{2}=0.96\right.$, $\mathrm{P}<0.001, \mathrm{n}=11$ ) was observed (Fig. 2.5), suggesting a coupling between the two parameters. Such coupling, also reported by Dittmar et al. (2012a), suggests the mechanisms controlling DOC mobilization and transport are likely related to those of DBC. According to the regression equation, $6.6 \pm 0.5 \%$ of the DOC from Kings Creek was determined as combustion-derived. This number was in the range of reported DBC\% from Little St. Marks River (3.2\%) and Apalachicola River (8.1\%; Dittmar et al., 2012a). The $x$-intercept of the linear equation is significantly different from zero $(0.758 \pm$ $0.134 \mathrm{mg} \mathrm{L}^{-1}$ ), indicating a DBC-free DOC pool, probably derived from vegetation 
leachates or from microbial primary productivity as previously reported (Jaffé et al., 2012). Thus, a DBC-free DOC flux can be estimated by multiplying the $\mathrm{x}$-intercept and the total water discharge recorded during 2009. Excluding this DBC-free DOC component from the total DOC flux, a conservative estimation of the DBC flux from the Kings Creek was $0.10 \pm 0.08$ tons carbon $\mathrm{yr}^{-1}$ on the basis of $6.6 \pm 0.5 \%$ of the remaining DOC component being combustion derived. Considering the $c a$. $12.5 \mathrm{Mt}^{\mathrm{arb}} \mathrm{yr}^{-1}$ of terrestrial DOC exported from grasslands (Hedges et al., 1997) and the estimated annual grassland runoff of $13709 \mathrm{~km}^{3}$ reported by Dodds (1997), a global flux of DBC on the order of $0.14 \mathrm{Mt}_{\text {carbon }} \mathrm{yr}^{-1}$ was estimated for DBC from grasslands. Further studies in a much wider array of grassland types around the world are needed to better constrain this estimate.

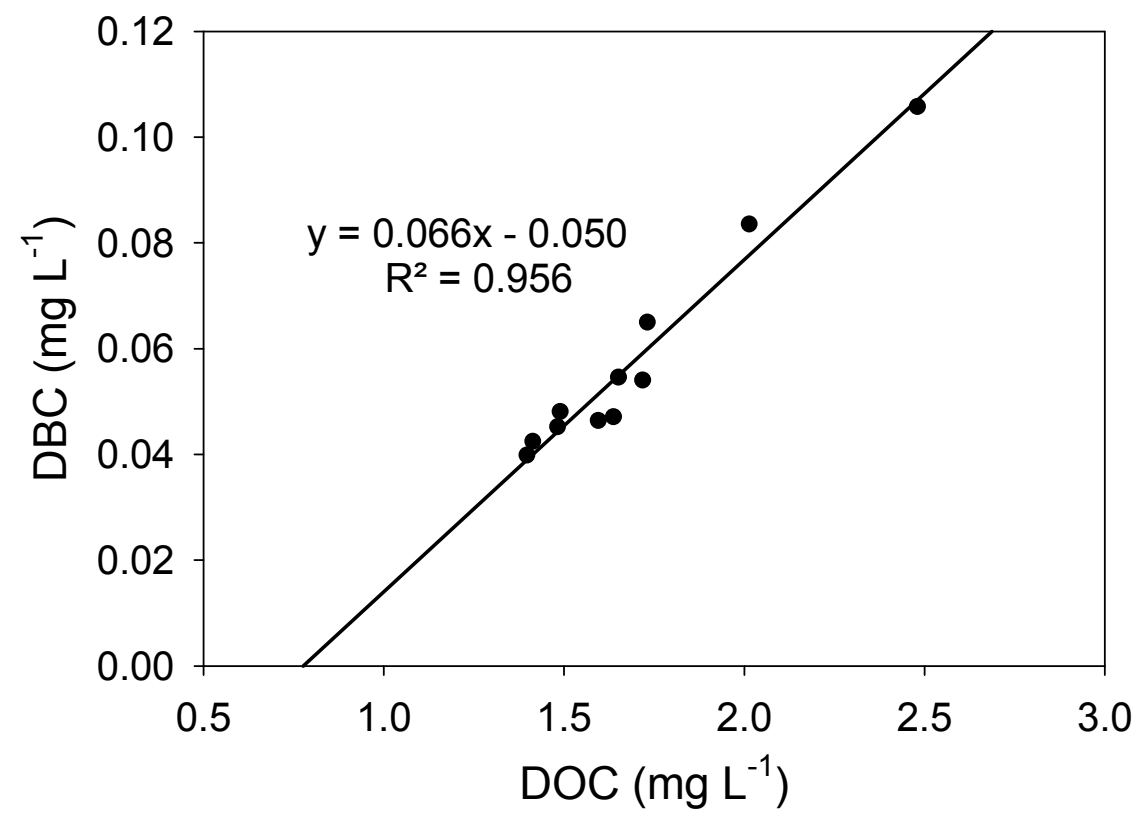

Figure 2.5 DOC and DBC cross correlation from different streams at KPBS. 


\subsubsection{Fire frequency and DBC concentrations}

I examined the potential correlation between DBC concentrations and burn return times for streams from different watersheds to assess if fire frequency can influence DBC quantity (Fig. 2.6a), as well as the correlation between DBC concentration and time since last burn (Fig. 2.6b). Detailed fire regimes in each sampling site are described in Appendix 2.4. However, and in agreement with a reported lack of correlation between soil BC and fire frequency (Kane et al., 2010), recent fire history and concentrations of DBC in streams seem uncoupled. I suggest three possible scenarios for these observations: (1) the local landscape conditions lead to low soil $\mathrm{BC}$ generation and accumulation; (2) the mobile pool of freshly produced soil BC is efficiently removed in a relatively short time period; and (3) historical soil BC could continuously export DBC over a long time scale.
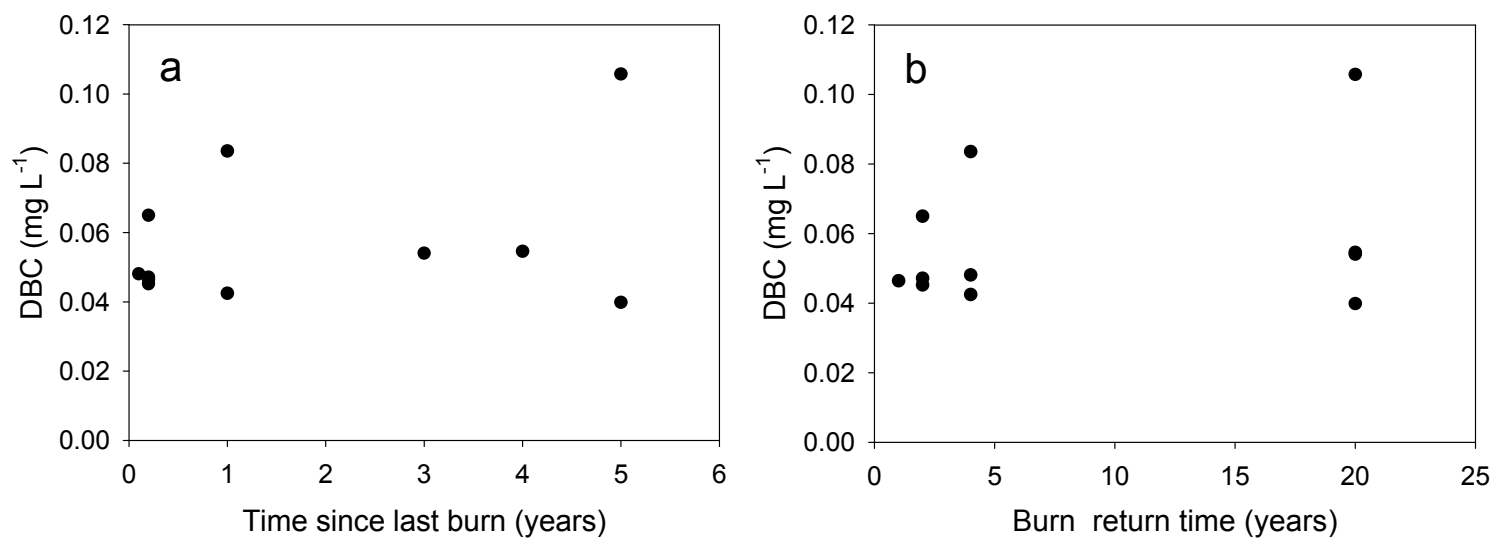

Figure 2.6 Correlation between DBC concentrations and the years since last fire (a), and correlation between DBC concentrations and the burn return year (b).

First, soil BC generation and accumulation in grasslands is low (Schmidt and Noack, 2000), and the conversion rate of $\mathrm{BC}$ as a percentage of carbon consumed by fire 
$(\mathrm{BC} / \mathrm{CC})$ for non-woody grassland biomass was reported to be lower $(<3 \%)$ than that of forest environments (4-5\%; Forbes et al., 2006). Higher burning efficiency will produce more ash, which is enriched in mineral carbon content rather than BC (Forbes et al., 2006). Schmidt and Noack (2000) used grassland as an example to elucidate the relationship between $\mathrm{BC}$ formation (\%) and burning efficiency(\%), showing that both low burning efficiency $(<85 \%)$ or high burning efficiency $(>95 \%)$ resulted in lower BC formation (Fig. 2.7). More than $90 \%$ of the vegetation in Konza Prairie is unplowed native grasses (Freeman, 1998), and during the spring months, sufficient dry fuel load at Konza Prairie could result in high burning efficiency reducing the quantity of $\mathrm{BC}$ produced and accumulated after each fire event. In addition, little rill or sheet erosion occurs following fires, suggesting transport of burned particulate materials into streams is modest and slow (Oviatt, 1998).

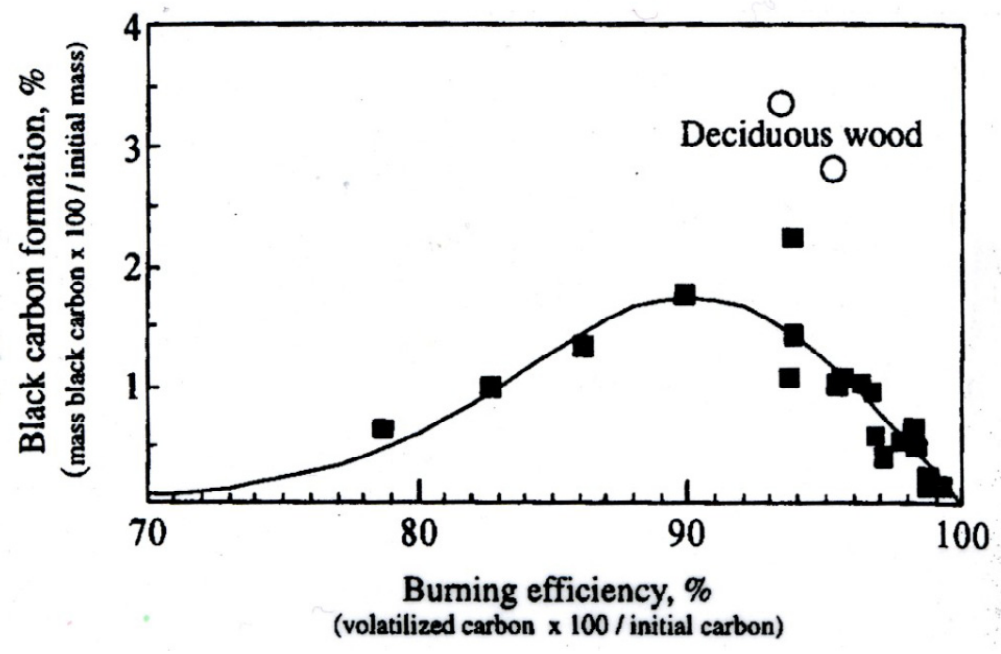

Figure 2.7 BC formation from vegetation fires is dependent on burning efficiency, as exemplified for grasses (line) and two samples from deciduous wood (from Schmidt \& Noack, 2000). 
Secondly, a large proportion of newly generated soil BC can be lost by surface runoff in a short time. While Rumpel et al. (2006) reported a preferential erosion of BC on steep slopes compared to other SOM because of its light nature and absence of interactions with minerals, Bisiaux et al. (2011) observed that after large fires, BC nanoparticles were present in the DOC pool as an initial BC pulse, but this signal was rapidly attenuated back to normal levels in less than 2 months. Therefore, I suggest a possible quick 'washout' of $\mathrm{BC}$ nanoparticles early in the wet season could result in further low soil $\mathrm{BC}$ accumulation and the observed lack in correlation between $\mathrm{DBC}$ and recent fire frequency. If such washout occurs, my global estimates are low.

Lastly, the export of DBC from burned watersheds can extend over much longer time scales than the time intervals between prescribed fires. As a result, the DBC measured today is derived from the sum of historical burning events, rather than the prescribed burnings during the latest 40 years. Ziolkowski and Druffel (2010) reported the ${ }^{14} \mathrm{C}_{\mathrm{BC}}$ age of freshwater (Suwannee River, GA) DBC to be in the order of 130-690 years, which is about one to two orders of magnitude higher than the recent prescribed fire frequency reported for the KNZ site. Dittmar et al. (2012b) also showed that significant amounts of DBC continued to be mobilized at present days from a watershed that was deforested through slash and burn activities during the 1850-1973 periods. Considering that Konza Prairie has probably been burned at return times from 1 to 10 years for centuries, as this frequency maintains the tallgrass prairie ecosystem (Abrams, 1992), it is likely that the DBC detected in this study was primarily produced from historical fires prior to the prescribed burning project. 


\subsection{Conclusions}

The concentrations of DBC from headwater streams in a grassland ecosystem were determined by the state-of-the-art methodology, and no correlation was found between $\mathrm{DBC}$ and recent fire history. I suggest that the lack of charcoal residue accumulation in soils after each fire event, a possible 'washout' of soil BC early in the wet season, and long export times for $\mathrm{DBC}$ from historical fires may explain the lack of correlation with recent fire history. The linear correlation between DOC and DBC concentrations suggests that the mobilization mechanisms of DOC and DBC are coupled, and that these mechanisms may play more important roles in controlling DBC fluxes than the recent fire history. On the basis of this correlation, $0.10 \pm 0.08$ tons $\mathrm{C} \mathrm{yr}^{-1}$ was the conservatively estimated DBC flux from Kings Creek. Globally, the annual DBC flux of grasslands to the ocean was estimated on the order of $0.14 \mathrm{Mt} \mathrm{C} \mathrm{yr}^{-1}$. 


\section{REFERENCES}

Abrams MD (1992) Fire and the development of oak forests. Bioscience 42(5):346-353

Alvarez-Salgado XA, Miller AEJ (1998) Simultaneous determination of dissolved organic carbon and total dissolved nitrogen in seawater by high temperature catalytic oxidation: conditions for precise shipboard measurements. Marine Chemistry 62(3-4): $325-333$

Bird MI, Moyo C, Veenendaal EM, Lloyd J, Frost P (1999) Stability of elemental carbon in a savanna soil. Global Biogeochemical Cycles 13(4): 923-932

Bisiaux MM, Edwards R, Heyvaert AC, Thomas JM, Fitzgerald B, Susfalk RB, Schladow SG, Thaw M (2011) Stormwater and Fire as Sources of Black Carbon Nanoparticles to Lake Tahoe. Environmental Science \& Technology 45(6): 2065-2071

Bond WJ, Woodward FI, Midgley GF (2005) The global distribution of ecosystems in a world without fire. New Phytologist 165(2): 525-537

Collins SL (1992) Fire frequency and community heterogeneity in tallgrass prairie vegetation. Ecology 73(6): 2001-2006

Czimczik CI, Schmidt MWI, Schulze ED (2005) Effects of increasing fire frequency on black carbon and organic matter in Podzols of Siberian Scots pine forests. European Journal of Soil Science 56(3): 417-428

Dittmar T (2008) The molecular level determination of black carbon in marine dissolved organic matter. Organic Geochemistry 39(4): 396-407.

Dittmar T, Koch BP (2006) Thermogenic organic matter dissolved in the abyssal ocean. Mar Chem 102(3-4): 208-217

Dittmar T, Paeng J, Gihring TM, Suryaputra IGNA, Huettel M (2012a) Discharge of dissolved black carbon from a fire-affected intertidal system. Limonology and Oceanography 57(4): 1171-1181

Dittmar T, Rezende CE, Manecki M, Niggemann J, Ovalle ARC, Stubbins A, Bernardes MC (2012b) Continuous flux of dissolved black carbon from a vanished tropical forest biome. Nature Geoscience 5(9): 618-622

Dodds WK (1997) Distribution of runoff and rivers related to vegetative characteristics, latitude, and slope: A global perspective. Journal of the North American Benthological Society 16(1): 162-168 
Dodds WK, Gido K, Whiles MR, Fritz KM, Matthews WJ (2004) Life on the edge: The ecology of great plains prairie streams. Bioscience 54(3): 205-216

Dodds WK, Hutson RE, Eichem AC, Evans MA, Gudder DA, Fritz KM, Gray L (1996) The relationship of floods, drying, how and light to primary production and producer biomass in a prairie stream. Hydrobiologia 333(3): 151-159

Forbes MS, Raison RJ, Skjemstad JO (2006) Formation, transformation and transport of black carbon (charcoal) in terrestrial and aquatic ecosystems. Science of the Total Environment 370(1): 190-206

Freeman CC (1998) The Flora of Konza Prairie: A Historical Review and Contemporary Patterns. In: Knapp AK, Briggs JM, Hartnett DC, Collins SL (eds.), Grassland Dynamics: Long-Term Ecological Research in Tallgrass Prairie. Oxford University Press, New York. p 69-80.

Glaser B, Balashov E, Haumaier L, Guggenberger G, Zech W (2000) Black carbon in density fractions of anthropogenic soils of the Brazilian Amazon region. Organic Geochemistry 31(7-8): 669-768

Glaser B, Haumaier L, Guggenberger G, Zech W (1998) Black carbon in soils: the use of benzenecarboxylic acids as specific markers. Organic Geochemistry 29(4): 811-819

Goldberg ED (1985) Black carbon in the environment: Properties and distribution. John Wiley \& Sons, New York

Gray LJ (1997) Organic matter dynamics in Kings Creek, Konza Prairie, Kansas, USA. Journal of the North American Benthological Society 16(1): 50-54

Gray LJ, Macpherson GL, Koelliker JK, Dodds WK (1998) Hydrology and Aquatic Chemistry. In: Knapp AK, Briggs JM, Hartnett DC, Collins SL (eds.), Grassland Dynamics: Long-Term Ecological Research in Tallgrass Prairie. Oxford University Press, Oxford, New York. p 159-176

Gurtz ME, Marzolf GR, Killingbeck KT, Smith DL, McArthur JV (1988) Hydrologic and riparian influences on the import and storage of coarse particulate organic-matter in a prairie stream. Canadian Journal of Fisheries and Aquatic Sciences 45(4): 655-665

Gustafsson O, Gschwend PM (1998) The flux of black carbon to surface sediments on he New England continental shelf. Geochimoca et Cosmochimica Acta 62(3): 465-472

Hamer U, Marschner B, Brodowski S, Amelung W (2004) Interactive priming of black carbon and glucose mineralisation. Organic Geochemistry 35(7): 823-830 
Hedges JI, Kei RG, Benner R (1997) What happens to terrestrial organic matter in the ocean? Organic Geochemistry 27(5-6): 195-212

Hockaday WC, Grannas AM, Kim S, Hatcher PG (2007) The transformation and mobility of charcoal in a fire-impacted watershed. Geochimical et Cosmochimica Acta 71(14): 3432-3445

Hulbert LC (1973) Management of Konza Prairie to approximate pre-white-man fire influence. In: Hulbert LC (ed.), The Third Midwest Prairie Conference proceedings. Kansas State University, Manhattan. p 14-16

Jaffé R, Yamashita Y, Maie N, Cooper WT, Dittmar T, Dodds WK, Jones JB, Myoshi T, Ortiz-Zayas JR, Podgorski DC, Watanabe A (2012) Dissolved organic matter in headwater streams: compositional variability across climatic regions of North America. Geochimica et Cosmochinica Acta 94: 95-108

Kane ES, Hockaday WC, Turetsky MR, Masiello CA, Valentine DW, Finney BP, Baldock JA (2010) Topographic controls on black carbon accumulation in Alaskan black spruce forest soils: implications for organic matter dynamics. Biogeochemistry 100(1-3): $39-56$

Knapp AK, Seastedt TR (1986) Detritus accumulation limits productivity of tallgrass prairie. Bioscience 36(10): 662-668

Knapp AK, Seastedt TR (1998) Introduction: Grasslands, Konza Prarie, and Long-Term Ecological Research. In: Knapp AK, Briggs JM, Hartnett DC, Collins SL (eds.), Grassland Dynamics: Long-Term Ecological Research in Tallgrass Prairie. Oxford University Press, New York. p 3-15

Kuhlbusch TAJ (1998) Black carbon and the carbon cycle. Science 280(5371): 19031904

Masiello CA (2004) New directions in black carbon organic geochemistry. Marine Chemistry 92(1-4): 201-213

Masiello CA, Druffel ERM (1998) Black carbon in deep-sea sediments. Science 280(5371): 1911-1913

Oviatt CG (1998) Geomorphology of Konza Prairie. In: Knapp AK, Briggs JM, Hartnett DC, Collins SL (eds.), Grassland Dynamics: Long-Term Ecological Research in Tallgrass Prairie. Oxford University Press, Oxford, New York. p 35-47

Rumpel C, Chaplot V, Planchon O, Bernadou J, Valentin C, Mariotti A (2006) Preferential erosion of black carbon on steep slopes with slash and burn agriculture. Catena 65(1): 30-40 
Schmidt MWI, Noack AG (2000) Black carbon in soils and sediments: Analysis, distribution, implications, and current challenges. Global Biogeochemical Cycles 14(3): $777-793$

Schmidt MWI, Skjemstad JO, Jager C (2002) Carbon isotope geochemistry and nanomorphology of soil black carbon: Black chernozemic soils in central Europe originate from ancient biomass burning. Global Biogeochemical Cycles 16(4): 8

Vergnoux A, Di Rocco R, Domeizel M, Guiliano M, Doumenq P, Theraulaz F (2011) Effects of forest fires on water extractable organic matter and humic substances from Mediterranean soils: UV-vis and fluorescence spectroscopy approaches. Geoderma 160(3-4): 434-443

Wardle DA, Nilsson MC, Zackrisson O (2008) Fire-derived charcoal causes loss of forest humus. Science 320(5876): 629-629

Zimmerman AR (2010) Abiotic and Microbial Oxidation of Laboratory-Produced Black Carbon (Biochar). Environmental Science \& Technology 44(4): 1295-1301

Ziolkowski LA, Druffel ERM (2009) The feasibility of isolation and detection of fullerenes and carbon nanotubes using the benzene polycarboxylic acid method. Marine Pollution Bulletin 59(4-7): 213-218

Ziolkowski LA, Druffel ERM (2010) Aged black carbon identified in marine dissolved organic carbon. Geophysical Research Letters 37: L16601 
Chapter III

ENVIRONMENTAL DYNAMICS OF DISSOLVED BLACK CARBON IN

WETLANDS 


\subsection{Abstract}

Wetlands are ecosystems characterized by commonly elevated levels of dissolved organic carbon, and although they cover a surface area less than $2 \%$ worldwide, they are an important carbon source representing an estimated $15 \%$ of global annual DOC flux to the oceans. Because of their unique hydrological characteristics, fire can be an important ecological driver in pulsed wetland systems. Consequently, wetlands may be important sources not only of DOC but also of products derived from biomass burning, such as dissolved black carbon (DBC). However, the biogeochemistry of DBC in wetlands has not been studied in detail. The objective of this study is to determine the environmental dynamics of $\mathrm{DBC}$ in different wetlands, including a coastal wetland, the Everglades (Florida) and two inland wetlands, the Okavango Delta (Botswana) and the Pantanal (Brazil). Here I report on an intensive, two-year spatial and temporal dynamics study of DBC in the Everglades system, as well as on one-time sampling surveys for the other two wetlands. The data reveal that DBC dynamics are strongly coupled with the DOC dynamics regardless of location, season or fire frequency. The significant linear regression between $\mathrm{DOC}$ and $\mathrm{DBC}$ was applied to estimate $\mathrm{DBC}$ fluxes through the two main riverine DOC export routs in the Everglades system, and to assess the global

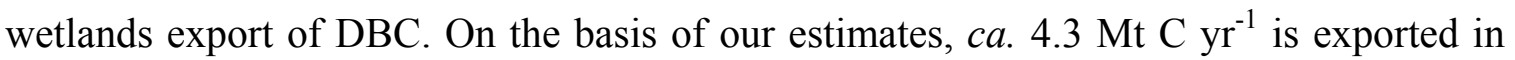
the form of $\mathrm{DBC}$ from wetlands, accounting for $c a .17 \%$ of the estimated global annual riverine $\mathrm{DBC}$ flux. The discrimination of $\mathrm{DBC}$ molecular structure (i.e., aromaticity) between coastal and terrestrial samples, and between samples collected in wet and dry season, suggests that spatially-significant variation in DBC source strength and/or degree of degradation may also influence DBC dynamics. 


\subsection{Introduction}

Organic matter residues generated by incomplete combustion processes are generally referred to as black carbon (BC), and have been found in the atmosphere, soil, sediment and water (Kim et al., 2004; Penner et al., 1993; Schmidt \& Noack, 2000). Black Carbon can be transported as atmospheric aerosols or as particulate organic matter (POM) and dissolved organic matter (DOM) in aquatic systems (Crutzen \& Andreae, 1990; Forbes et al., 2006; Hockaday et al., 2007; Mitra et al., 2002; Suman et al., 1997). As such, BC is recognized to be ubiquitous in the environment (Goldberg, 1985). The annual estimates of global $\mathrm{BC}$ production are 50 to $200 \mathrm{Tg}_{\mathrm{yr}^{-1}}\left(1 \mathrm{Tg}=10^{12} \mathrm{~g}\right)$ from biomass burning (Kuhlbusch \& Crutzen, 1996) and 12-24 $\mathrm{Tg}^{-1}$ from fossil fuel combustion (Penner et al., 1993). Coastal areas accumulate a significant amount of terrestrial-derived BC (2000-5000 Pg, $\left.1 \mathrm{Pg}=10^{15} \mathrm{~g}\right)$, and represent an important transfer point between terrestrial and marine BC pools (Schmidt \& Noack, 2000). As such, about $10 \mathrm{Tg} \mathrm{yr}^{-1} \mathrm{BC}$ is deposited in ocean sediments, largely in the coastal area (Suman et al., 1997).

Because of its aromatic character, $\mathrm{BC}$ is expected to be more resistant to biomineralization than other biomolecules, and the half-life for $\mathrm{BC}$ has been estimated to vary from decades to millennia (Bird et al., 1999; Dickens et al., 2004; Masiello, 2004). Both charring temperature and fuel type contribute to the reactive character of $\mathrm{BC}$ in soil and sediment, where $\mathrm{BC}$ generated during higher combustion temperatures and from more condensed fuels (i.e., woody plants) usually has more functional groups and is more aromatic than $\mathrm{BC}$ generated from low-temperature fires and non-woody, grassland vegetation (Forbes et al., 2006; Schneider et al., 2010). In addition, soil properties and 
topographic controls determine the transport and fate of $\mathrm{BC}$ in the soil (Czimczik \& Masiello, 2007; Forbes et al., 2006; Guggenberger et al., 2008; Kane et al., 2010). Recent findings of $\mathrm{BC}$ in the dissolved phase suggest that degradation of charred materials in soils results in the generation of carboxylic-acid derivatives, which may increase the solubility of BC and thus aid the translocation from soil BC to the dissolved phase (Ding et al., 2013; Dittmar et al., 2012a; Dittmar et al., 2012b; Jaffé et al., 2013).

As mentioned above, the transfer of terrestrial-derived $\mathrm{BC}$ to the marine environment through estuaries is likely controlled by riverine export (Dittmar et al., 2012b; Jaffé et al., 2013). In a recent study, Jaffé et al. (2013) demonstrated that the global export of $\mathrm{BC}$ as $\mathrm{DBC}$ accounts for a significant gap in the $\mathrm{BC}$ budget and represents $c a .25 \mathrm{Mt} \mathrm{C} \mathrm{yr}^{-1}\left(1 \mathrm{Mt}=10^{12} \mathrm{~g}\right)$. Mannino and Harvey (2004) first detected DBC in the ultrafiltered high-molecular weight DOM (UDOM) in the Delaware Estuary area, and reported that the BC content ranged from 5-72\% of UDOM. Subsequently, Dittmar (2008) determined $0.9-2.6 \%$ of dissolved organic carbon (DOC) was combustion-derived from near shore to offshore in Gulf of Mexico. Detailed tidal studies of DBC in a fire-affected marsh in the northern Gulf of Mexico revealed that tidal flushing was the primary carrier of continental runoff-derived DBC (Dittmar et al., 2012b) to the coastal ocean.

In addition to riverine export, coastal wetlands are an important source of DOC to coastal areas (Maie et al., 2006a; Maie et al., 2006b; Tzortziou et al., 2008), but data on the levels of DBC in wetlands are limited in the literature (Jaffé et al., 2013). Although coastal wetlands, which are characterized by diverse vegetation, soil types and hydrology, are usually saturated with water permanently or seasonally, seasonal fires are a common 
and ecologically important phenomenon (Flores et al., 2011; Ramberg et al., 2010; Xu et al., 2011). For instance, in the Florida Everglades, one of the largest subtropical wetlands in the world, periodic fire events are an important driver to rejuvenate extensive sawgrass (Cladium jamaicense Crantz) marshes and to control invasive species in the subtropical pine savannas area (Beckage \& Platt, 2003; Wade et al., 1980). Another large inland wetland ecosystem is the Okavango Delta in southern Africa. With distinctive wet and dry seasons, the floodplains of Okavango Delta are periodically burnt during the dry season and inundated during the wet season (Heinl et al., 2006). Compared to the upstream drylands, Okavango floodplains were identified as the center of fire activities with higher fire frequency (Heinl et al., 2007). Mladenov et al. (2005) reported a pulsed increase in DOC concentration and $\mathrm{SUVA}_{254}$ values (corresponding to higher aromaticity; Weishaar et al., 2003) that occurred immediately after a big fire but lasted for only 3 4 months before dropping back to normal levels. Although fires are common and important in wetlands, reports regarding the generation, long-term accumulation, and potential export of BC in and from wetlands is very limited (Deforce et al., 2013; Iriarte et al., 2012; Baker et al., 2011), compared to the information on forest, savanna and grassland ecosystems (e.g., Czimczik \& Masiello, 2007; Forbes et al., 2006; GonzalezPerez et al., 2004).

In the Everglades, fire is an important and primary ecological driver shaping vegetation patterns (Wu et al., 1996). Natural fires caused by lightning usually occur in the transition period from dry to wet season when the water levels are the lowest (April to May; Beckage \& Platt, 2003). They usually occur in the northern freshwater marsh prairies of the Everglades where the major vegetation (Cladium jamaicense Crantz) is 
susceptible to fires. In contrast, the southern fringe mangrove systems of the Everglades are associated with more extensive flooding and tidal exchange, and consequently are not subject to either wildfires or prescribed burning (Wade et al., 1980). The 700,000 acre Everglades Agricultural Area (EAA), located between Lake Okeechobee and the northern Everglades, is also subjected to frequent fires from the annual burning of sugarcane fields (Bottcher \& Lzuno, 1994). The frequent fires in the Everglades combined with inputs from agricultural fires in the EAA result in a significant accumulation of charcoal, an important component of the BC continuum, in soils (Winkler et al., 2001; Saunders et al., 2006). As such, this ecosystem can serve both as a carbon sink and a potential source of DBC to coastal areas. Evidence for the effect of fires on the DOM composition in the Everglades was evidenced through the presence of dissolved hetero-aromatic nitrogen (or black nitrogen; Knicker, 2004) as reported by Maie et al. (2006) and DBC (Jaffé et al., 2013) in this system. The highly refractory nature of hetero-aromatic nitrogen and DBC is possibly the reason for the surprisingly low bioavailability of DOM, specifically DON, in the Everglades (Jaffé et al., 2005). The presence of DBC was also reported in other wetlands such as the Okavango Delta and the Pantanal (Jaffé et al., 2013). However, no detailed information on spatial and temporal environmental dynamics of DBC in any wetland ecosystem has been reported.

Here I present the first detailed DBC data for wetland ecosystems. The objectives of this work include: (1) to assess temporal and spatial variations in DBC concentrations in the Everglades; (2) to assess possible correlations between DBC dynamics and local fire regimes; (3) to estimate annual fluxes of DBC from the Everglades to the coastal ocean; (4) to assess potential DBC source differences through variations in DBC 
molecular characteristics; (5) to compare DBC levels in different subtropical wetlands characterized by frequent fires.

\subsection{Material and methods}

\subsubsection{Site description}

The Everglades is a unique subtropical wetland located at the southern end of Florida, USA. The climate of the region is characterized by a wet and dry season with $80 \%$ of the total annual precipitation occurring from June through November. Summer in South Florida is hot and humid, with an average daily temperature of $27^{\circ} \mathrm{C}$. The average daily temperature is above $10^{\circ} \mathrm{C}$ throughout the winter (Duever et al., 1994).

Everglades surface water samples were collected monthly from July 2009 to June 2011 along the two main drainage systems, Shark River Slough (SRS) and Taylor Slough (TS). Three sites, designated as S2, S4 and S6, are located along SRS, two sites, T2 and T7 are located along TS, and an additional site (T10) is centrally located downstream of both sloughs in Florida Bay (FB) (Fig. 3.1). S2 and T2 are freshwater marsh sites dominated by emergent vegetation such as sawgrass (Cladium jamaicense Crantz) and Spikerush (Eleocharis cellulosa Torr.), and represent the areas most commonly impacted by either prescribed or wild fires. These sites also receive significant canal inputs, and S2 has been shown to receive measurable amounts of EAA-derived DOM (Yamashita et al., 2010). The S6 and T7 sites are located in the mangrove fringes and are subjected to tidal inputs from the Gulf of Mexico and seasonal, wind driven water inputs from Florida Bay (dry season). The tidal influence is significantly attenuated in the upper estuary at site S4. The vegetation at $\mathrm{S} 4, \mathrm{~S} 6$ and $\mathrm{T} 7$ is dominated by red mangroves (Rhizopohra mangle $\mathrm{L}$.) 
where fires are infrequent because much of the area is permanently flooded. The soil type along the SRS and TS transects are peat and marl, respectively. The T10 site is located in the shallow, seagrass-dominated Florida Bay. More detailed descriptions of sampling sites can be found elsewhere (Childers et al., 2006; Maie et al., 2006c; Maie et al., 2007).

The Okavango Delta, a seasonal, pulsed inland wetland, covers a maximum area of $12,000 \mathrm{~km}^{2}$ and is located in northern Botswana. The annual rainfall is about $490 \mathrm{~mm}$, typically falling from November to March. The annual flood pulse reaches the Delta during the dry season, between April and September, supplying the seasonal swamps with most of their annual water supply (McCarthy et al., 2000). However, annual evapotranspiration can remove about $1800 \mathrm{~mm}$ of water (97\%) from the system (Wolski \& Savenije, 2006). Because the water inflow into the system is highly variable, the water distribution in the three major hydro-ecological zones (permanent swamps, seasonal swamps and occasionally floodplains) of Okavango Delta has significant annual variations (Ellery et al., 2003). The main fire season is from the middle to the end of the dry season, approximately June to September. The highest burning probability was reported for floodplains because of higher biomass production and fuel loads. As a result, floodplains are the center and source of fires spreading to the adjacent drylands (Heinl et al., 2007; Heinl et al., 2006). Eight surface water samples in the Okavango Delta were collected during a trans-Okavango sampling trip (Cawley et al., 2012) in July 2010. Two samples were collected from the Okavango River (panhandle), two from a major tributary (Jao River) in the upstream permanent swamp, and the other four samples were collected from channels located in the seasonal and occasional floodplains of the Delta. Sample preparation was as described below. 
The Pantanal wetland system, located mostly in Brazil with smaller areas in Bolivia and Paraguay, is associated with the floodplains along the upper Paraguay River with an inundation area of $131,000 \mathrm{~km}^{2}$. The annual precipitation is $1000-1500 \mathrm{~mm}$ and almost $80 \%$ of the rainfall occurs in the summer (November to March; Hamilton et al., 1996). A variety of savanna and emergent marsh vegetation is supported by the Pantanal, where the typical vegetation is an open arboreal and grassland (cattle ranching) savanna, woodlands, dry forests and rooted floating plants or free floating plants in long hydroperiod areas (Por, 1995). The floods often occur during the wet season (November to March), while natural and anthropogenic fires are frequent during the dry season (July to October; Marques et al., 2008). $17 \%$ of the Pantanal has been deforested and $63 \%$ of the natural vegetation cover of the surrounding plateaus in the Planalto (savanna woodland and semi-deciduous forest) has been lost through the use of fires induced by ranchers to rid the natural vegetation for cattle farming. The fire frequency per unit area in Pantanal is the highest among different biomes in Brazil (Schroeder et al., 2005). A total of eight (1 L) surface water samples were collected in July 2010 during a transect study in the Pantanal representing diverse habitats. Six samples were collected along the Paraguay River and associated floodplains, one from the Cuiabá River and one from a lake in the Cuiaba River floodplain. Sample preparation was as described below. 


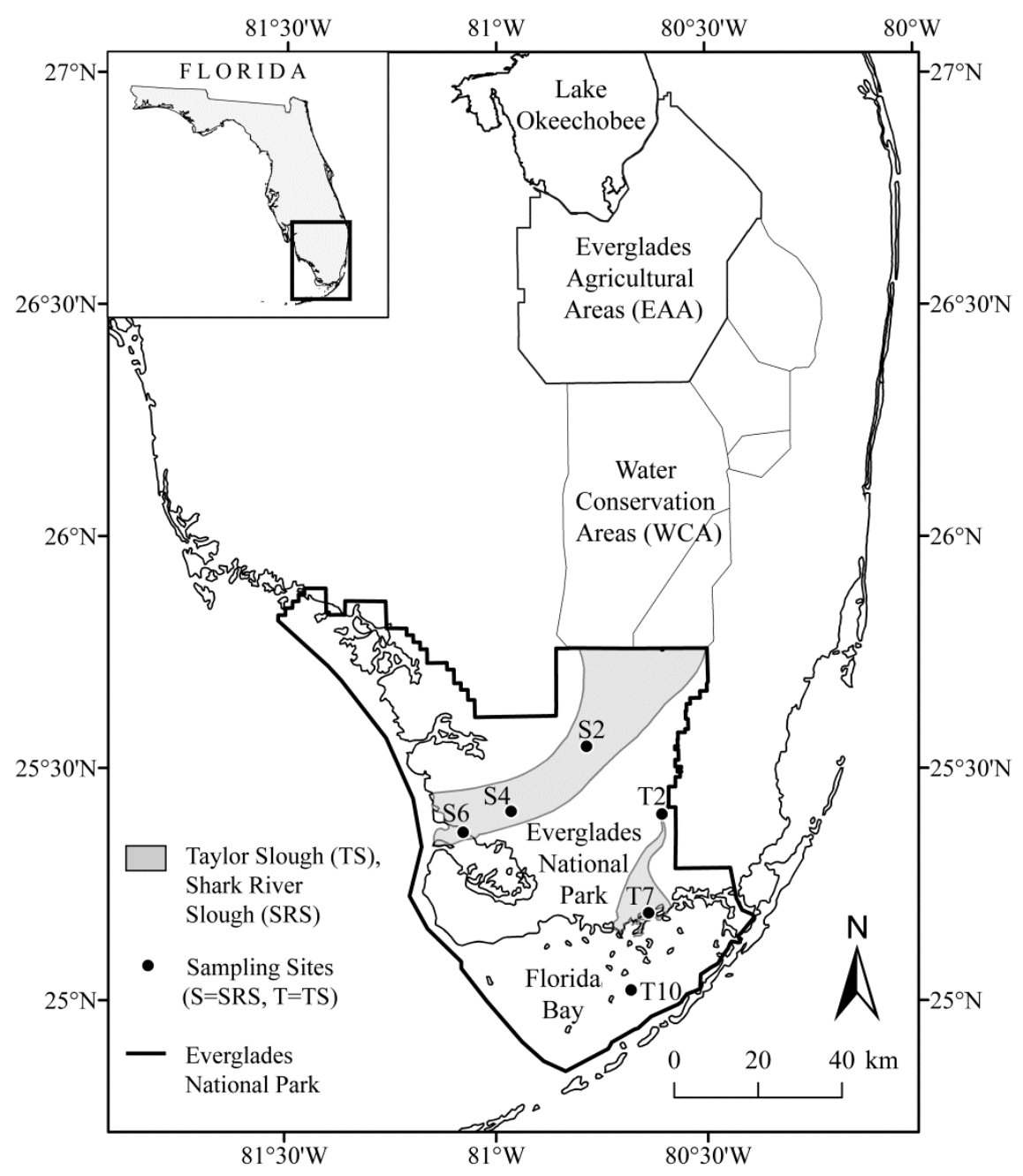

Figure 3.1 Map of the Everglades sampling location.

\subsubsection{Sample collection and preparation}

Surface water samples from the five station in the Everglades (S2, S6, T2, T7 and T10) were collected monthly in acid rinsed 2.5 L glass bottles starting in July 2009 for a two-year time period; additional samples from S4 was collected for 14 months starting in May 2010. Because of dry-out conditions, no samples were obtained between April and June 2011 and from March to June 2011 for S2 and T2, respectively. Samples from the 
Okavango Delta and the Pantanal were spatially distributed, but sampled only once. All water samples were stored on ice and refrigerated immediately upon arrival in the laboratory. Samples were filtered through pre-combusted $\left(450^{\circ} \mathrm{C}\right.$ for $\left.4 \mathrm{~h}\right) \mathrm{GF} / \mathrm{F}$ glass fiber filters $(0.7 \mu \mathrm{m}$, Whatman $)$ within 48 hours after collection. Sixty $\mathrm{mL}$ filtered water samples were stored in pre-combusted wide mouth amber glass bottles for DOC analysis. The remaining water was acidified to $\mathrm{pH} 2$ with concentrated $\mathrm{HCl}(32 \%$, ACS plus grade). DOM, including DBC, was isolated though solid phase extraction (SPE) on PPL cartridge (Ding et al., 2013; Dittmar, 2008). MeOH (HPLC grade) eluents from the PPL cartridges were stored at $-20{ }^{\circ} \mathrm{C}$ for further $\mathrm{DBC}$ analysis. Samples collected in the Okavango Delta and the Pantanal were extracted in the same manner, but the PPL cartridges were wrapped in aluminum foil and extracted with $\mathrm{MeOH}$ once returned to the main laboratory in Miami.

\subsubsection{BC analysis - Benzenepolycarboxylic acids (BPCAs) method}

A chemical oxidation technique (BPCAs method) was used to quantify DBC concentrations in the PPL isolates. Compared to conventional thermal oxidation methods (Gustafsson et al., 1997), the BPCA method produces negligible analytical artifacts for the BC determinations (Brodowski et al., 2005; Hammes et al., 2007) and the relative abundance of BPCAs can be used as a proxy for BC aromaticity (Glaser et al., 1998). The BPCA method was first adapted to the dissolved phase measurements by Dittmar (2008) for marine DBC. Ding et al. (2013) optimized the oxidation parameters for freshwater DBC applications. Detailed chemical oxidation procedures and modification can be retrieved from Dittmar (2008) and Ding et al. (2013). 


\subsubsection{DOC analysis}

Dissolved organic carbon (DOC) concentrations of all water samples were measured by a TOC-5000A analyzer, which uses a high temperature combustion platinum-catalyst method (Shimadzu, Japan). $4 \mathrm{~mL}$ water samples were acidified to $\mathrm{pH}<2$ with $3 \mathrm{~N} \mathrm{HCl}$ and sparged with $\mathrm{CO}_{2}$-free compressed air (ultra-zero grade, Airgas) before injection. Samples were oxidized in the TOC-5000A furnace at $680{ }^{\circ} \mathrm{C}$ with a preconditioned platinum-catalyst. The combustion derived $\mathrm{CO}_{2}$ was carried by ultra-zero grade compressed air and detected by a non-dispersive infrared $\mathrm{CO}_{2}$ detector (AlvarezSalgado \& Miller 1998).

\subsubsection{Statistical analysis}

All statistical data were subjected to Pearson test (parametric correlation), Spearman test (nonparametric correlation), principal component analysis (PCA), one-way ANOVA analysis and nonparametric significant test using SPSS statistics 17.0 software. A normality test was performed before any regression analysis and homogeneity test of variances was performed before the one-way ANOVA analysis. A 95\% confidence interval was used in all statistical analyses $(\alpha=0.05)$.

\subsection{Results and discussion}

\subsubsection{Spatial and seasonal dynamics of DOC, Everglades}

Dissolved Organic Carbon concentrations in the Everglades showed a wide range of variation in spatial and temporal scales (Fig. 3.2 and 3.3). The measurements of different parameters (i.e., DOC, DBC, \%DBC, salinity) for samples from each site, as 
well as relative abundance of $\mathrm{BC}$ oxidation products, were reported as mean $\pm \mathrm{SD}$ in Appendix 3.1. The average concentrations of DOC were highest in peat based freshwater marshes (S2) and DOC concentrations decreased towards the south for the SRS transect as the salinity increased (Fig. 3.2a). The pattern was somewhat different for the TS transect with the highest average DOM concentration at $\mathrm{T} 7$ site rather than the freshwater site, however the freshwater T2 DOC levels were still higher than in Florida Bay (Fig. 3.2a). Seasonally, only DOC concentrations from site S2 and T7 showed strong variability (Fig. 3.3a\&b). Recently, long-term (2004-2008) DOC concentrations and DOM characteristics for the sites studied here were reported (Chen et al., 2012) in an attempt to assess their spatial and temporal variations. The two-year DOC spatial and temporal data presented here (Fig. 3.2a and Fig. 3.3a\&b, respectively) follows the same general patterns described by Chen et al. (2013) and are likely driven by the same processes. Briefly, seasonal patterns at S2 are likely driven by evapo-concentration combined with enhanced inputs from canal waters through water management during the dry season, and dilution during the wet season (Chen et al., 2013). While the seasonal patterns at T2 are similar to those of S2 but much less significant, the non-conservative mixing along TS is probably caused by the fact that $\mathrm{T} 7$ not only receives DOC from freshwater discharge from its upper watershed (wet season), but also from seawater intrusions (dry season) and mangrove derived DOM exports (Chen et al., 2013; Maie et al., 2005). These processes explain the relatively large seasonal DOC concentration variations. 

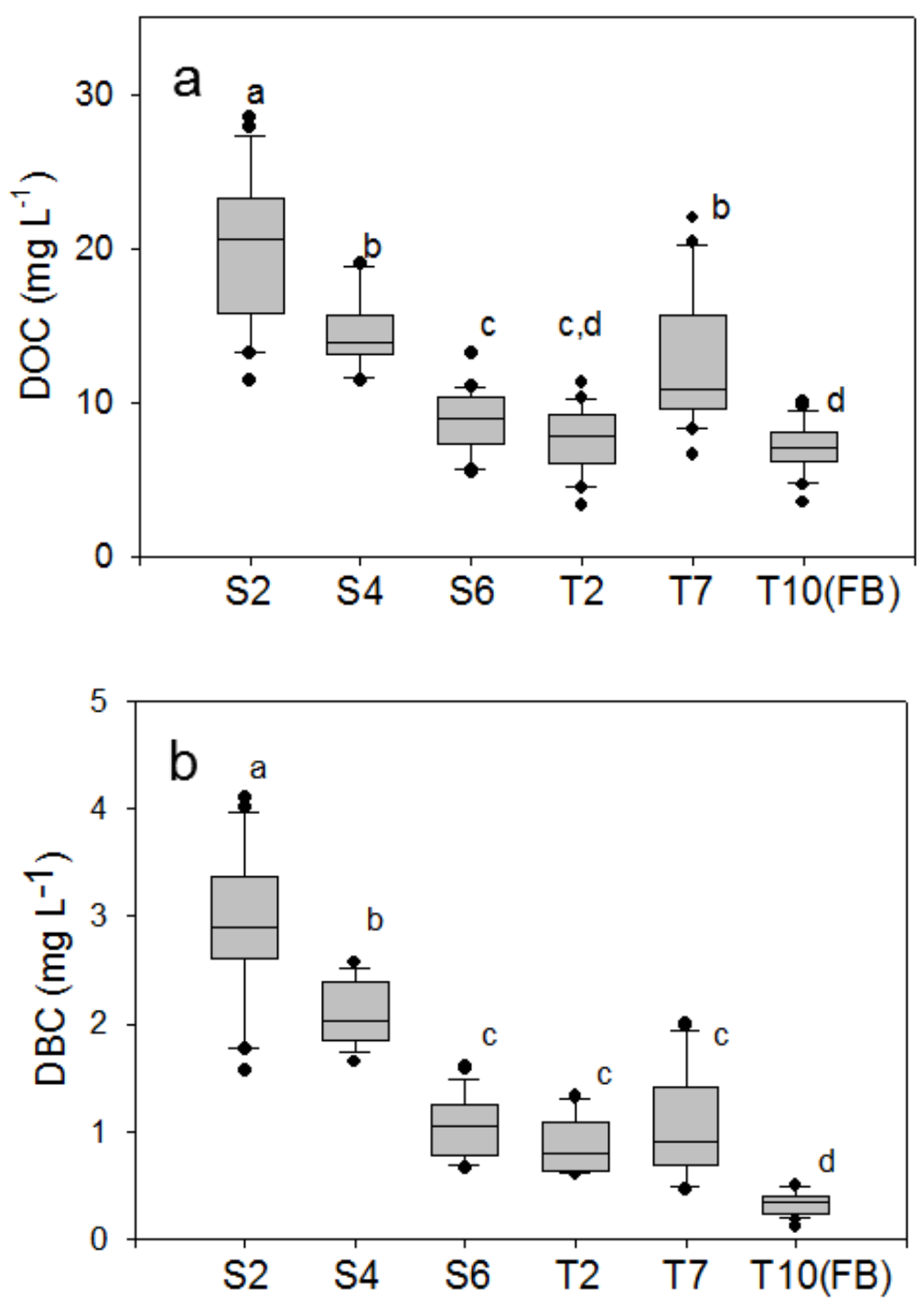

Figure 3.2 Spatial distribution of DOC (a) and DBC (b) concentrations in the Everglades. Box plots labeled with the same letter stand for no significant difference between mean values while different letters stand for significant differences of mean values among sites. All populations passed the normality test. Groups with equal variance were tested by oneway ANOVA analysis while otherwise tested by Welch's test ( $\alpha=0.05$ in both tests). 

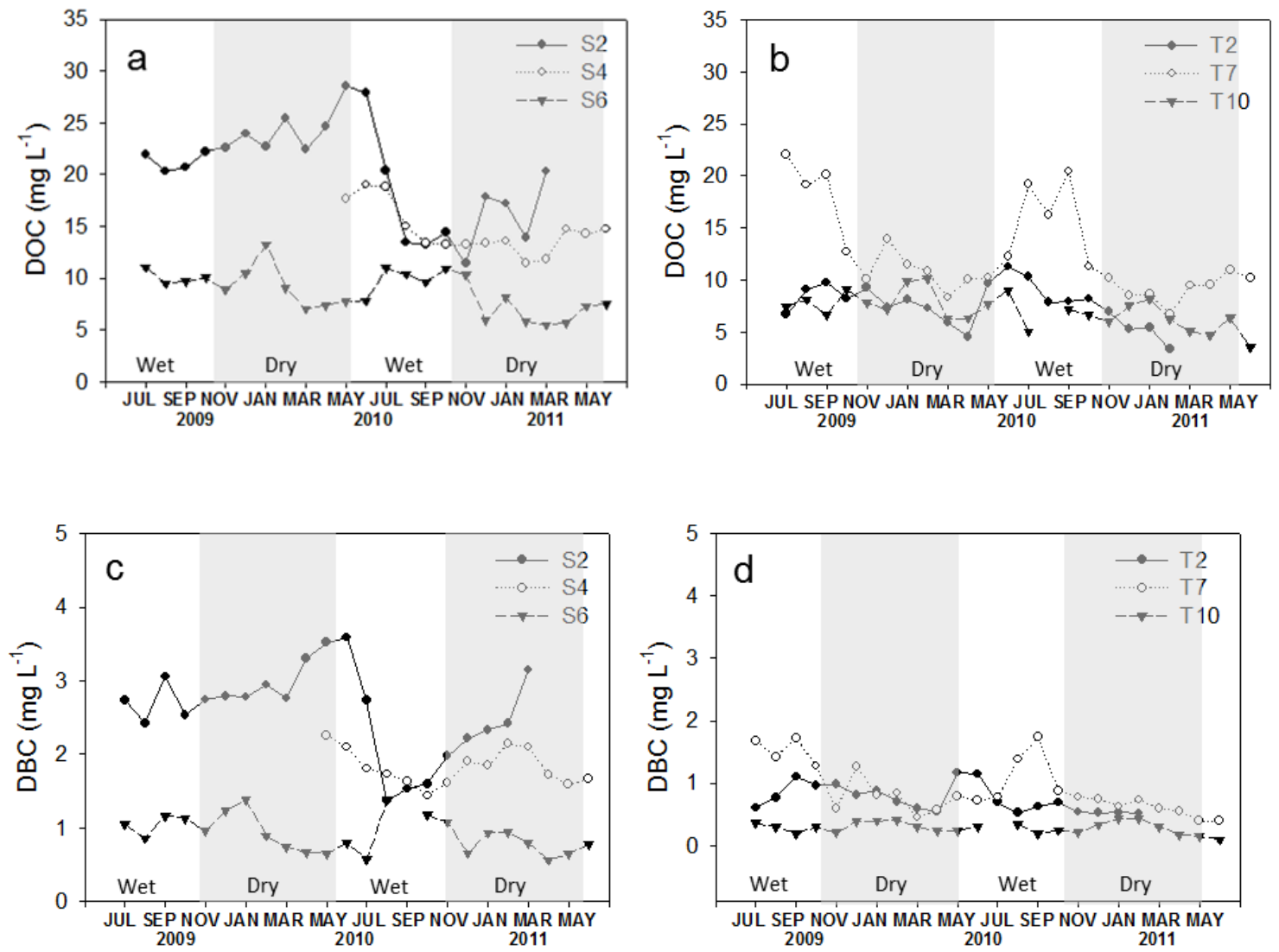

Figure 3.3 Seasonal distribution of DOC ( $\&$ \& b) and DBC (c \& d) concentrations in SRS and TS, Everglades

\subsubsection{Spatial and seasonal dynamics of DBC, Everglades}

Both spatial and seasonal dynamics of DBC concentrations showed a great similarity to those of DOC concentrations (Fig. 3.2b; Fig. 3.3c\&d). The DBC concentrations were the highest at the freshwater marsh site (S2), which is subject to frequent wild fires and prescribed burns, primarily during the dry season. This site has also been shown to receive DOM inputs, through canal water discharge, from DOC enriched effluents originated at the EAA (Yamashita et al., 2010), where sugarcane fields are routinely burned between late-October through mid-April (Bottcher \& Lzuno, 1994). 
Similar to DOC, a concentration gradient of DBC was also observed along the two transects and probably caused by dilution effects from saline water inputs from Florida Bay containing low DBC and DOC (Fig. 3.2b; Yamashita et al., 2010). The DBC concentration at site S2 showed a seasonal change, while S4 and T7 featured only slight but opposite variations in DBC concentration. The remaining sites showed no evident seasonal changes (Fig. 3.3c\&d). Both S2 and S4 reached the highest DBC concentrations during the wet-dry transition period, which co-occurs with frequent marsh fires and high DOC concentrations. The T7 samples contained higher DBC levels in the wet season when they received DBC enriched water from the upstream compared to the dry season when the freshwater head is low and low DOC Florida Bay waters intrude (Chen et al., 2013).

If the DBC levels are indeed driven by fire history, the relative contribution of $\mathrm{DBC}$ to the total $\mathrm{DOC}$ (\%DBC in $\mathrm{DOC}$ ) would be expected to increase during the late dry season and early wet season, especially for the two freshwater sites (S2 and T2). However, no obvious increase was observed (Fig. 3.4). DBC concentrations at sites S2, S4, and S6 (Fig. 3.4a) showed small increments in the middle dry season of year 2011, but the same pattern was not observed in the dry season of year 2010 and no major fires were reported during February and March, 2011. Thus, the slight increments might be caused by changes in the DOC dynamics. The lack of correlation between DBC and fire history has also be reported by Ding et al. (2013) for a study conducted in a freshwater grass prairie environment with detailed fire records for the past four decades. Similarly, Dittmar et al. (2012b) showed a linear correlation between DOC and DBC for an intertidal system, and a globally significant coupling between DOC and DBC was 
recently reported (Jaffé et al., 2013). Expectedly, a strong positive correlation $\left(\mathrm{R}^{2}=0.807\right.$, $\mathrm{P}<0.001$ ) between DOC and DBC was observed for the two year Everglades data set as shown in Fig. 3.5. The positive correlation indicates that DOC dynamics, rather than fire history, is the determinant factor controlling DBC dynamics in wetland ecosystems as well. The exact reasons for the tight coupling between DOC and DBC remain unknown, but similarity in the microbial oxidation between soil OM and charcoal, and a DOCmediated transport of DBC have been suggested to explain this phenomenon (Jaffé et al., 2013).
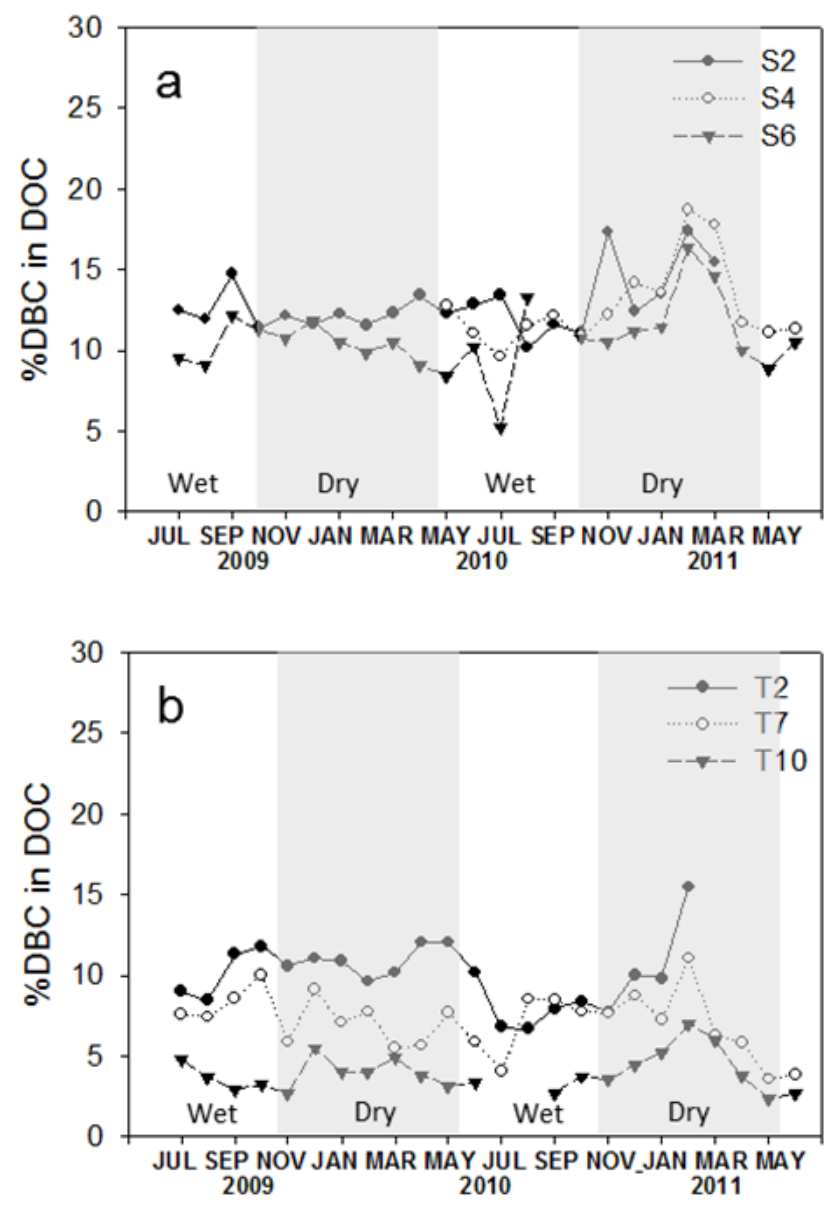

Figure 3.4 Seasonal distribution of \%DBC in DOC in SRS and TS, Everglades. 


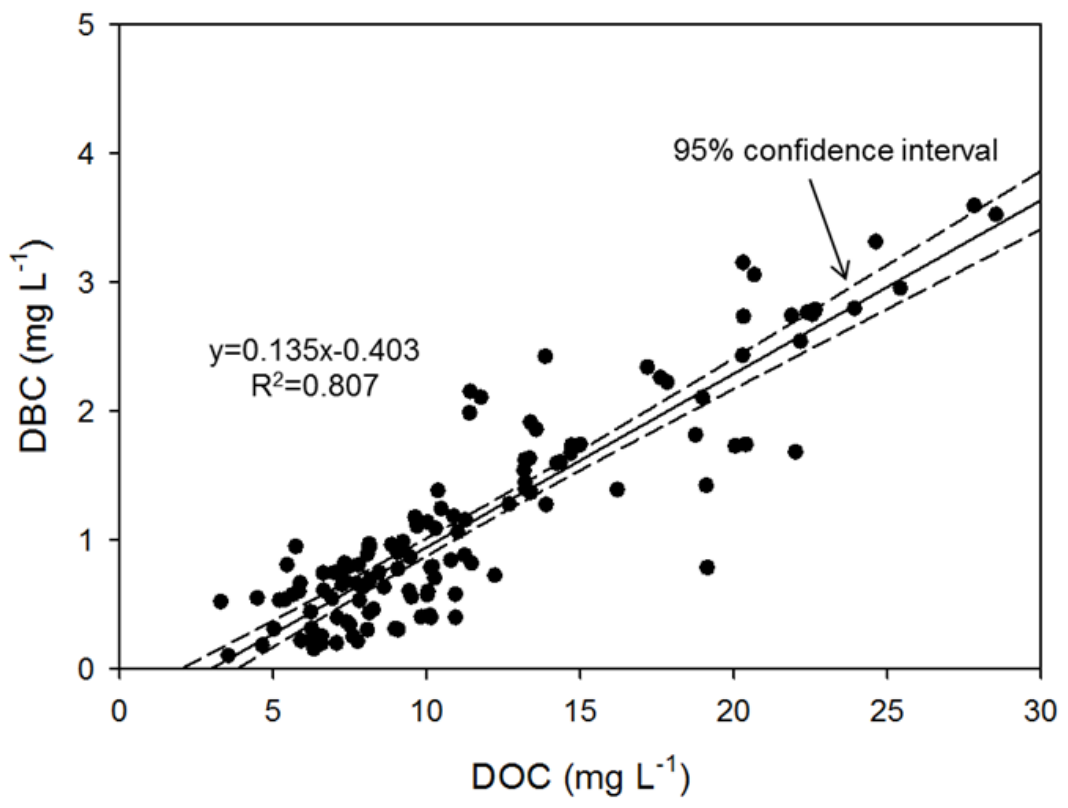

Figure 3.5 Correlation between DOC and DBC concentrations in the Everglades $(\mathrm{n}=$ $124, \mathrm{P}<0.0001)$.

\subsubsection{Annual export of DBC from SRS and TS, Everglades}

On the basis of the linear correlations between DOC and DBC, several recent reports have estimated DBC exports from DOC data (Ding et al., 2013; Dittmar et al., 2012b). From a global perspective, riverine DBC export to the oceans was estimated at $25 \mathrm{Mt} \mathrm{C} \mathrm{yr}^{-1}$ (Jaffé et al., 2013). Using a similar approach, I can estimate the DBC flux from the Shark River on the basis of DOC flux data reported by Bergamaschi et al. (2012). Daily fluxes of DOC from SRS during the wet and dry season were estimated as $9.1( \pm 0.6) \times 10^{9} \mathrm{mg} \mathrm{d}^{-1}$ and $1.5( \pm 0.02) \times 10^{9} \mathrm{mg} \mathrm{d}^{-1}$, respectively (Bergamaschi et al., 2012). This estimate includes mangrove-derived DOC in addition to that derived from the freshwater end-member. However, a recent report quantifying Everglades mangrovederived DOC export to the Florida Shelf reveals that only $7.5 \%$ and $6.3 \%$ of the DOC (wet and dry season, respectively) in the Shark River is derived from fringe mangrove 
systems (Cawley et al., under review), and the upstream freshwater marshes are the dominant source. Assuming that the great majority of DBC in the Everglades is derived from the freshwater end-member, subtracting the mangrove DOC inputs from the total DOC flux yields an estimated annual DOC flux from freshwater marshes in the Shark River of $c a .1 .8 \times 10^{-3} \mathrm{Mt} \mathrm{C} \mathrm{yr}^{-1}$. On the basis of the average 8-year DOC concentrations (2004 2008, Chen et al., 2012; and 2009 2011, data presented herein) and the average of 14-year annual net surface water discharge (1996 2010) at the mouth of the Taylor River (T7 site; Koch et al., 2012), an estimated $0.46 \times 10^{-3}$ Mt carbon of DOC are released from Taylor Slough annually through the Taylor River. With an average contribution of $13.5 \%$ DBC of total DOC (derived from the slope of the linear correlation of DOC and DBC; Fig. 3.5), estimates of DBC annual fluxes of $0.24 \times 10^{-3} \mathrm{Mt} \mathrm{C}$ and $0.06 \times 10^{-3} \mathrm{Mt} \mathrm{C}$ from the Shark River and Taylor River respectively were made.

\subsubsection{Principal component analysis of BPCAs, Everglades}

Compared to other $\mathrm{BC}$ determination techniques, one major advantage of the BPCA method is its ability to reveal molecular structural information. Carboxylic groups were generated from the breakdown and oxidation of C-C links (Glaser et al., 1998). Therefore, the oxidation of more polycondensed DBC molecules will result in larger proportion of highly substituted benzene carboxylic acids (i.e., B5CA and B6CA), while less polycondensed $\mathrm{DBC}$ molecules will produce higher relative abundances of the less substituted benzene carboxylic acids (i.e., B3CA and B4CA). The aromaticity differences of $\mathrm{BC}$ could be caused by differences in combustion source materials (Dittmar \& Koch 2006), formation conditions (Glaser et al., 1998; Schneider et al., 2010), and degrees of 
degradation (Ziolkowski \& Druffel 2010). Dittmar (2008) reported a slight but significantly lower B6CA proportion of DBC from ocean offshore samples compared to the coastal samples, indicating a lower degree of condensation of DBC in the open ocean. I used the principal component analysis (PCA) to detect possible BPCA proportion pattern changes between different sites and seasons (Fig. 3.6).
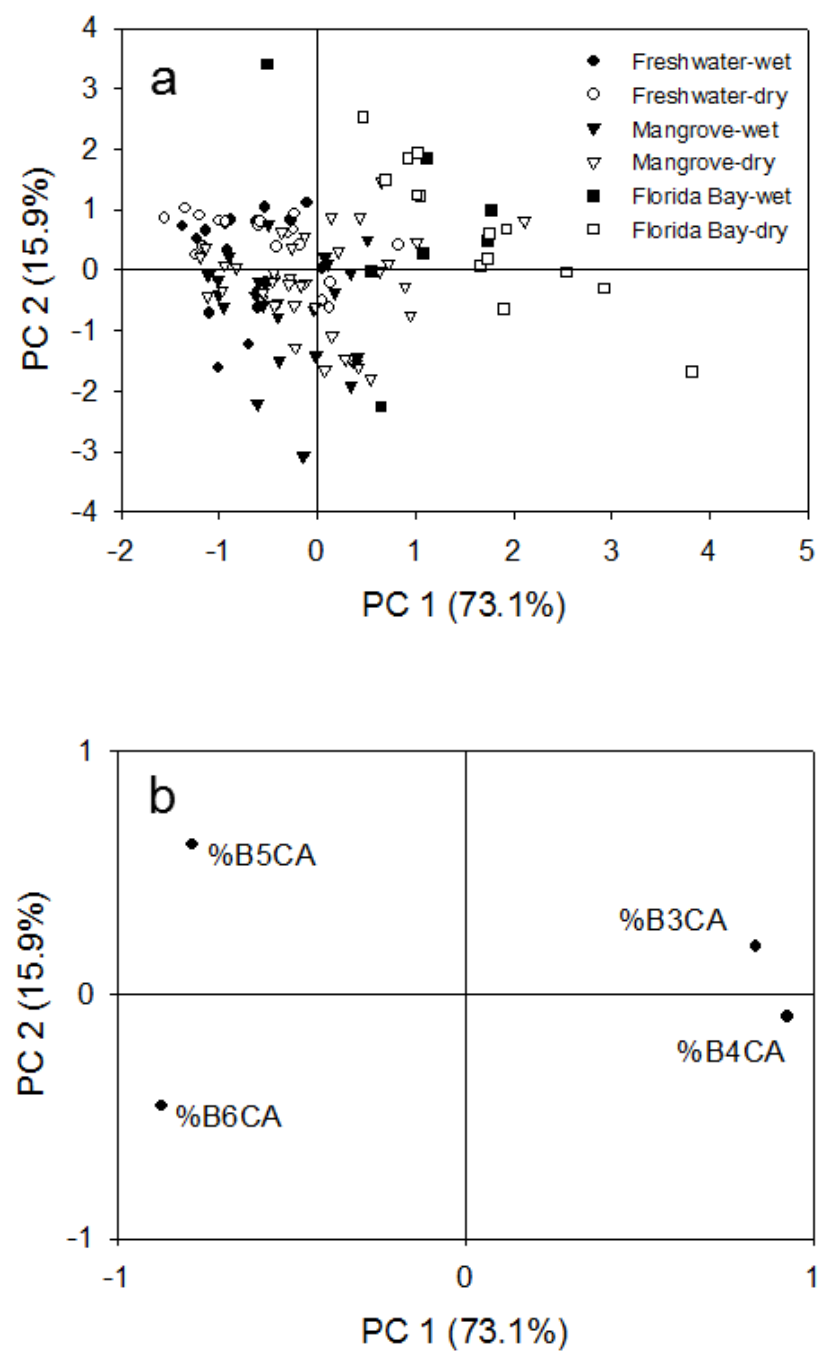

Figure 3.6 Principal component analysis for BPCA proportions of the Everglades water samples: (a) Score plot; (b) Loading plot. Freshwater sites include S2 and T2, mangrove sites include S4, S6, and T7, Florida Bay site is T10. 
Principal component 1 (PC1) is the major variable, accounting for $73.1 \%$ of the variability in this dataset. The loadings of the relative proportion of each BPCA component (Fig. 3.6b) illustrates that $\% \mathrm{~B} 3 \mathrm{CA}$ and $\% \mathrm{~B} 4 \mathrm{CA}$ are positively correlated with $\mathrm{PC} 1$ while \%B5CA and \%B6CA are negatively correlated with $\mathrm{PC} 1$. Principal component 2 (PC2) accounts for only $15.9 \%$ of the variability. No obvious difference was observed between $\% \mathrm{~B} 3 \mathrm{CA}$ and $\% \mathrm{~B} 4 \mathrm{CA}$ and only a slight difference in the distribution between \%B5CA and \%B6CA was evident along PC2. From the score plot (Fig. 3.6a), I observed similar results as those reported by Dittmar (2008): DBC from freshwater marsh sites (S2 and T2) was negatively correlated with PC1, indicating higher proportions of $\mathrm{B} 5 \mathrm{CA}$ and $\mathrm{B} 6 \mathrm{CA}$ derived from more highly poly-condensed molecular structures. In contrast, FB samples correlated positively with PC1, suggesting less polycondensed structures, yielding much higher percentages of $\mathrm{B} 3 \mathrm{CA}$ and $\mathrm{B} 4 \mathrm{CA}$. As for the seasonal changes, dry season samples (hollow symbols) shifted more to the positive PC1 values compared to wet season samples (solid symbols). The shift was not obvious for the freshwater samples and for some of the mangrove samples, but more evident for the FB samples. The DOC differences on a molecular level between freshwater samples and FB samples, as well as between wet and dry seasons, were also observed through ultrahigh resolution mass spectrometry (FT-ICR/MS) data of selective samples (Appendix 3.2).

The spatial and seasonal BPCA proportion differences observed along PC1 can be explained in two ways. One possible reason is the variations in the loading of $\mathrm{DBC}$ from different sources. Here, freshwater samples and wet season samples contain more DBC derived from local biomass burning-derived $\mathrm{BC}$, while coastal samples and dry season 
samples may have received higher contributions of anthropogenically-generated BC derived through atmospheric deposition. Such explanation is supported by the fact that biomass burning can produce a wide range of functionalized, high molecular weight polyaromatic hydrocarbons (PAHs) (Kramer et al., 2004), while fossil fuel combustionderived PAHs are mostly characterized by low molecular weight (Dittmar \& Koch, 2006; Simoneit, 2002). In fact, since the water budget and nutrient (TP) budget of Florida Bay is to a large extent controlled by atmospheric deposition (wet and dry; Nuttle et al., 2000), it is not surprising that atmospheric deposition of urban-derived combustion products may be more important in the Bay compared to the freshwater wetlands where wild fire derived $\mathrm{BC}$ sources dominate.

The other possible explanation for the reduced aromaticity along this freshwatermangrove-coastal estuarine transect is the degradation of DBC during transport. Dittmar and Koch (2006) reported a depletion of combustion-derived PAHs at the sea surface. They concluded the plausible removal process of such depletion was photo-degradation because of the reactive conjugated $\pi$-electron structure, resulting in ring cleavage and a lower aromaticity. In a recent study, photo-exposure of deep ocean water DBC (North Atlantic) reduced its abundance by 20 times after a 28-day solar irradiation period, confirming the photo-labile character of DBC in marine environments (Stubbins et al., 2012). In support of this argument, Ziolkowski and Druffel (2010) reported radiocarbon dates for $\mathrm{BC}$ in high molecular weight DOC (UDOM) suggesting that UDOM-BC from the open ocean is less aromatic and much older $\left({ }^{14} \mathrm{C}\right.$ age) than riverine UDOM-BC (i.e., river UDOM-BC is $<500{ }^{14} \mathrm{C}$ years, open ocean UDOM-BC is $18,000 \pm 3,000{ }^{14} \mathrm{C}$ years). It is possible that the DBC in Florida Bay is more aged and has been more exposed to 
sunlight compared to DBC from freshwater sites. While both explanations are plausible, the reasons for the different BPCA compositions observed in this dataset remain unresolved at this stage.

\subsubsection{Comparison of three wetland systems - Everglades, Okavango Delta and Pantanal}

Figure 3.7 shows DOC and DBC concentrations in three different wetland systems. The average DOC and DBC concentrations are both significantly higher $(\mathrm{P}<0.001)$ in the Everglades than in the other two wetlands, while the Pantanal and Okavango Delta have similar, lower DOC and DBC concentration ranges. Strong linear regression correlations between DOC and DBC concentrations were also observed for the the Pantanal and Okavango Delta. The average percent DBC in DOC (shown as the slope of regression line) was highest for the Everglades, followed by the Pantanal, and lowest for the Okavango Delta (Table 3.1). Statistically, the regression equation slope and intercept of the Pantanal is similar to the Everglades and the Okavango Delta; however, there are significant differences between the Everglades and Okavango Delta in both slope and y-intercept (95\% confidence interval, Table 3.1). The PCA distribution of BPCA relative abundance from the Pantanal and Okavango Delta are similar to those of the freshwater marshes sites in the Everglades, indicating similar sources, likely dominated by degradation products from wildfire-derived charcoal. The only wetland with an x-intercept differed from zero is the Everglades (Table 3.1), possibly caused by a DBC-free DOC pool derived from the abundant periphyton mats in the freshwater marsh areas, the mangrove fringe, and from the seagrass community in Florida Bay. Similar DBC-free DOC pools have been reported for grassland streams, and suggested to be the 
result of significant algal DOC inputs (Ding et al., 2013). Interestingly, no significant presence of periphyton has been reported for the Pantanal or the Okavango Delta, although both feature other floating plants that may contribute some DBC-free DOC to these systems.

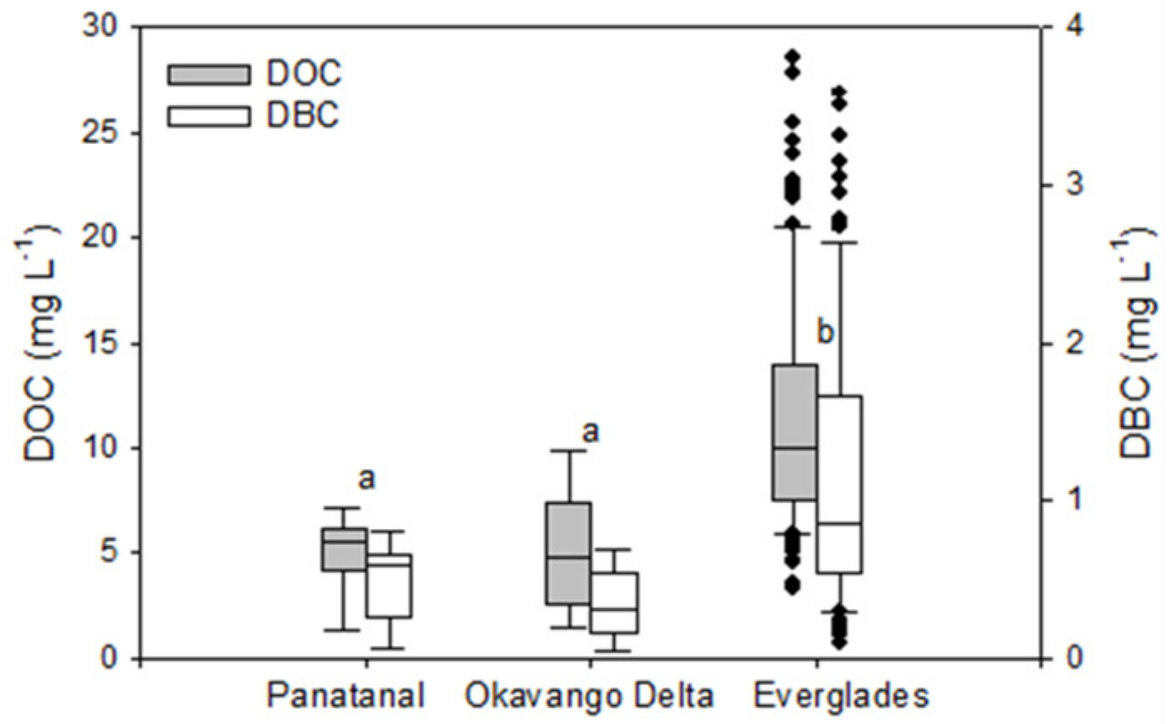

Figure 3.7 Comparison of DOC and DBC concentrations in three wetlands. Box plots labeled with the same letter stand for no significant difference between mean values while different letters stand for significant differences of mean values among sites. All statistics are derived from nonparametric significance test $(\alpha=0.05)$.

Both $\mathrm{DBC}$ concentration and composition show certain similarities as well as differences among the three wetlands. The concentration range and the DBC carbon contribution to the DOC pool (slope) were higher in the Everglades, probably caused by additional anthropogenic (urban and agricultural) $\mathrm{BC}$ sources. Compared to the other pristine wetlands, the Everglades is highly impacted as it is downstream of the agricultural area where large sugarcane fields are burned out every year right before the harvest (Fig. 3.1). The eastern Everglades are adjacent to urban areas where most of 
population and agricultural activities of South Florida are located. As a result, agricultural burning and fuel emission produced $\mathrm{BC}$ from urban areas could be transported by canal systems and the atmosphere and become important sources of BC in the Everglades, enhancing the concentration level of DBC in surface water. Additional reasons could be differences in the soil and DOM characteristics among the wetlands. Cusack et al. (2012) reported a linear correlation between soil organic carbon (SOC) and soil $\mathrm{BC}$, indicating that mineralogical interactions between soil $\mathrm{BC}$ and minerals could preserve the $\mathrm{BC}$. Therefore, the soil character differences among wetlands (e.g., organic rich peat in the Everglades vs. fine sands in the Okavango Delta; McCarthy et al., 1991) could cause differences in the retention of BC in soil. Furthermore, DOC may also play an important role in transferring $\mathrm{BC}$ to the dissovled phase on the basis of a global correlation between DOC and DBC (Jaffé et al., 2013). Therefore, DOC from higher terrestrial plants with higher aromaticity (e.g., mangrove in the Everglades) may assist the release of BC from soil. Although the above mentioned explanations are mainly speculative, and more research is needed to better understand the translocation mechanisms from soil-BC to $\mathrm{DBC}$ and the differences in DBC dynamics among wetlands, the similarity in the BPCA proportions (PCA) for DBC in the three wetlands (except for samples from FB) and the fact that a linear correlation between DOC and DBC was observed in all cases suggests many basic commonalities in the biogeochemistry of $\mathrm{BC}$ in wetlands.

\subsection{Conclusions}

This paper reports the first data of its kind on DBC levels and spatial and seasonal

dynamics in wetlands. The strong correlation observed between DOC and DBC for the 
three studied wetlands agrees with previous reports that DBC dynamics are closely linked to those of DOC (Ding et al., 2013; Dittmar et al., 2012b). In addition, the Everglades seasonal study agrees with previous reports that recent fire history does not seem to be reflected in DBC levels. On the basis of the observed linear correlation between DOC

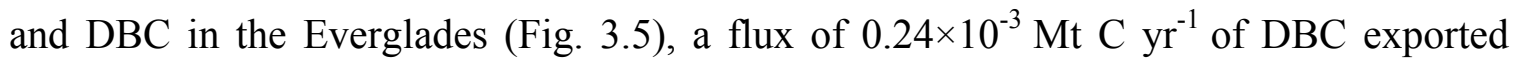

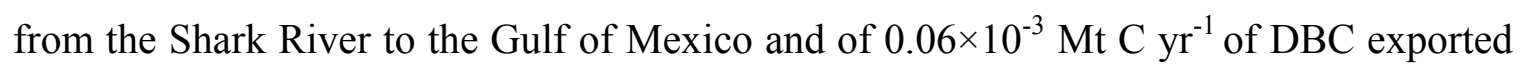
from the Taylor Slough to Florida Bay was estimated. Globally, although wetlands cover less than $2 \%$ in area among different biomes, they have been reported to export about $10 \%$ of the global total organic carbon (DOC+POC) annually (40 Mt C $\mathrm{yr}^{-1}$ out of $410 \mathrm{Mt}$ $\mathrm{C} \mathrm{yr}^{-1}$ ), showing a significantly higher organic carbon loss rate than other types of ecosystems (Schlesinger and Melack, 1981). According to the DOC/POC value summarized in Schlesinger and Melack (1981), a watershed size-weighted average DOC/POC for wetlands is $c a$. 30 , which leads to a total DOC flux from wetlands of $c a$. $39 \mathrm{Mt} \mathrm{C} \mathrm{yr}^{-1}$. This flux accounts for a significant component (15\%) of the global DOC flux of $250 \mathrm{Mt} \mathrm{C} \mathrm{yr}^{-1}$ reported by Hedges (1997). As \%DBC in wetlands (the average slope of three wetlands is 0.11 , representing $11 \%$ of DOC is DBC) is almost the same as reported global average (10.6\%; Jaffé et al., 2013), the global DBC flux from wetlands

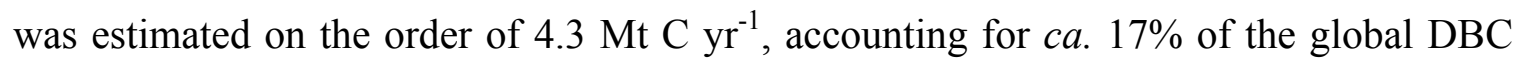
flux (25 Mt C $\mathrm{yr}^{-1}$; Jaffé et al., 2013). This indeed suggests that wetlands, especially coastal swamps and marshes, play a significant role in the global carbon cycle as an important continental-ocean carbon carrier of DBC. 
Table 3.1 Statistical comparison of linear regressions between DOC and DBC concentrations in three wetlands. Slopes (intercept) with no significant difference in $95 \%$ confidence interval were labeled with the same letter while slope (intercept) ranges with significant difference were labeled with different letters.

\begin{tabular}{ccccccc}
\hline & \multicolumn{3}{c}{ regression equation: $\mathrm{y}=\mathrm{mx}+\mathrm{n}$} & \multicolumn{3}{c}{$95 \%$ confidence interval } \\
\cline { 2 - 7 } & slope & $\mathrm{y}$-intercept & correlation & slope & $\mathrm{y}$-intercept & $\mathrm{x}$-intercept \\
& $(\mathrm{m})$ & $(\mathrm{n})$ & coefficient $\left(\mathrm{R}^{2}\right)$ & $(\mathrm{m})$ & $\mathrm{n})$ & differ from 0 \\
\hline Everglades & $0.135 \pm 0.006$ & $-0.403 \pm 0.077$ & 0.807 & $\mathrm{a}$ & $\mathrm{a}$ & yes \\
Pantanal & $0.127 \pm 0.023$ & $-0.155 \pm 0.122$ & 0.838 & $\mathrm{a}, \mathrm{b}$ & $\mathrm{a}, \mathrm{b}$ & no \\
Okavango & $0.071 \pm 0.011$ & $-0.017 \pm 0.067$ & 0.865 & $\mathrm{~b}$ & $\mathrm{~b}$ & no \\
\hline
\end{tabular}




\section{REFERENCES}

Alvarez-Salgado XA, Miller AEJ (1998) Simultaneous determination of dissolved organic carbon and total dissolved nitrogen in seawater by high temperature catalytic oxidation: conditions for precise shipboard measurements. Marine Chemistry 62(3-4): $325-333$

Baker LL, Strawn DG, Rember WC, Sprenke KF (2011) Metal content of charcoal in mining-impacted wetland sediments. Science of the Total Environment 409(3): 588-594

Beckage B, Platt WJ (2003) Predicting severe wildfire years in the Florida Everglades. Frontiers in Ecology and the Environment 1(5): 235-239

Bergamaschi BA, Krabbenhoft DP, Aiken GR, Patino E, Rumbold DG, Orem WH (2012) Tidally Driven Export of Dissolved Organic Carbon, Total Mercury, and Methylmercury from a Mangrove-Dominated Estuary. Environmental Science \& Technology 46(3): $1371-1378$

Bird MI, Moyo C, Veenendaal EM, Lloyd J, Frost P (1999) Stability of elemental carbon in a savanna soil. Global Biogeochemical Cycles 13(4): 923-932

Bottcher AB, Lzuno FT (1994) Everglades agriculture area (EAA): water, soil, crop, and environmental Management. University Press of Florida, FL

Brodowski S, Rodionov A, Haumaier L, Glaser B, Amelung W (2005) Revised black carbon assessment using benzene polycarboxylic acids. Organic Geochemistry 36(9): $1299-1310$

Cawley KM, Wolski P, Mladenov N, Jaffé R (2012) Dissolved Organic Matter Biogeochemistry Along a Transect of the Okavango Delta, Botswana. Wetlands 32(3): 475-486

Cawley KM, Yamashita Y, Jaffé R (under review) Using dissolved organic matter (DOM) optical properties to quantify mangrove inputs to the DOM pool in the Shark and Harney Rivers, Everglades National Park, Florida, USA. Estuarine, Coastal and Marine Science

Chen M, Maie N, Parish K, Jaffé R (2012) Spatial and temporal variability of dissolved organic matter quantity and composition in an oligotrophic subtropical coastal wetland. Biogeochemistry doi: 10.1007/s10533-013-9826-4

Childers DL, Boyer JN, Davis SE, Madden CJ, Rudnick DT, Sklar FH (2006) Relating precipitation and water management to nutrient concentrations in the oligotrophic "upside-down" estuaries of the Florida Everglades. Limnology and Oceanography 51(1): 602-616 
Crutzen PJ, Andreae MO (1990) biomass burning in the tropics - impact on atmospheric chemistry and biogeochemical cycles. Science 250(4988): 1669-1678

Cusack D, Chadwick OA, Hockaday WC, Vitousek PM (2012) Mineralogical controls on soil black carbon preservation. Global Biogeochemical Cycles 26: GB2019

Czimczik CI, Masiello CA (2007) Controls on black carbon storage in soils. Global Biogeochemical Cycles 21: GB3005

Deforce K, Bastiaens J, Van Neer W, Ervynck A, Lenracker A, Segant J, Crombé P (2013) Vegetation History and Archaeobotany 22(1): 51-60

Dickens AF, Gelinas Y, Masiello CA, Wakeham S, Hedges JI (2004) Reburial of fossil organic carbon in marine sediments. Nature 427(6972): 336-339

Ding Y, Yamashita Y, Dodds W, Jaffé R (2013) Dissolved black carbon in grassland streams: Is there an effect of recent fire history? Chemosphere 90(10): 2557-2562

Dittmar T (2008) The molecular level determination of black carbon in marine dissolved organic matter. Organic Geochemistry 39(4): 396-407

Dittmar T, Rezende CE, Manecki M, Niggemann J, Ovalle ARC, Stubbins A, Bernardes MC (2012a) Continuous flux of dissolved black carbon from a vanished tropical forest biome. Nature Geoscience 5(9): 618-622

Dittmar T, Koch BP (2006) Thermogenic organic matter dissolved in the abyssal ocean. Mar Chem 102(3-4): 208-217

Dittmar T, Paeng J, Gihring TM, Suryaputra IGNA, Huettel M (2012b) Discharge of dissolved black carbon from a fire-affected intertidal system. Limonology and Oceanography 57(4): 1171-1181

Duever MJ, Meeder JF, Meeder LC, McCollom JM (1994) The climate of south Florida and its role in shaping the Everglades ecosystem. In: Davis SM \& Ogden JC (eds.) Everglades: The ecosystem and its restoration. St. Lucie Press, Boca Raton, FL. p 225248

Ellery WN, McCarthy TS, Smith ND (2003) Vegetation, hydrology, and sedimentation patterns on the major distributary system of the Okavango Fan, Botswana. Wetlands 23(2): $357-375$

Flores C, Bounds DL, Ruby DE (2011) Does Prescribed Fire Benefit Wetland Vegetation? Wetlands 31(1): 35-44 
Forbes MS, Raison RJ, Skjemstad JO (2006) Formation, transformation and transport of black carbon (charcoal) in terrestrial and aquatic ecosystems. Science of the Total Environment 370(1): 190-206

Glaser B, Haumaier L, Guggenberger G, Zech W (1998) Black carbon in soils: the use of benzenecarboxylic acids as specific markers. Organic Geochemistry 29(4): 811-819

Goldberg ED (1985) Black carbon in the environment: Properties and distribution. John Wiley \& Sons, New York

Gonzalez-Perez JA, Gonzalez-Vila FJ, Almendros G, Knicker H (2004) The effect of fire on soil organic matter - a review. Environmental International 30(6): 855-870

Guggenberger G, Rodionov A, Shibistova O, Grabe M, Kasansky OA, Fuchs H, Mikheyeva N, Zrazhevskaya G, Flessa H (2008) Storage and mobility of black carbon in permafrost soils of the forest tundra ecotone in Northern Siberia. Global Change Biology 14(6): 1367-1381

Gustafsson O, Haghseta F, Chan C, MacFarlane J, Gschwend PM (1997) Quantification of the dilute sedimentary soot phase: Implications for PAH speciation and bioavailability. Environmental Science \& Technology 31(1): 203-209

Hamilton SK, Sippel SJ, Melack JM (1996) Inundation patterns in the Pantanal wetland of South America determined from passive microwave remote sensing. Archiv Fur Hydrobiologie 137(1): 1-23

Hammes K, Schmidt MWI, Smernik RJ, Currie LA, Ball WP, Nguyen TH, Louchouarn P, Houel S, Gustafsson O, Elmquist M, Cornelissen G, Skjemstad JO, Masiello CA, Song J, Peng P, Mitra S, Dunn JC, Hatcher PG, Hockaday WC, Smith DM, Hartkopf-Froeder C, Boehmer A, Luer B, Huebert BJ, Amelung W, Brodowski S, Huang L, Zhang W, Gschwend PM, Flores-Cervantes DX, Largeau C, Rouzaud JN, Rumpel C, Guggenberger G, Kaiser K, Rodionov A, Gonzalez-Vila FJ, Gonzalez-Perez JA, de la Rosa JM, Manning DAC, Lopez-Capel E, Ding L (2007) Comparison of quantification methods to measure fire-derived (black/elemental) carbon in soils and sediments using reference materials from soil, water, sediment and the atmosphere. Global Biogeochemical Cycles 21(3): GB3016

Hedges JI, Kei RG, Benner R (1997) What happens to terrestrial organic matter in the ocean? Organic Geochemistry 27(5-6): 195-212

Heinl M, Frost P, Vanderpost C, Sliva J (2007) Fire activity on drylands and floodplains in the southern Okavango Delta, Botswana. Journal of Arid Environmentals 68(1): 77-87 
Heinl M, Neuenschwander A, Sliva J, Vanderpost C (2006) Interactions between fire and flooding in a southern African floodplain system (Okavango Delta, Botswana). Landscape Ecology 21(5): 699-709

Hockaday WC, Grannas AM, Kim S, Hatcher PG (2007) The transformation and mobility of charcoal in a fire-impacted watershed. Geochimical et Cosmochimica Acta 71(14): 3432-3445

Iriarte J, Power MJ, Rostain S, Mayle FE, Jones H, Watling J, Whitney BS, McKey DB (2012) Fire-free land use in pre-1492 Amazonian savannas. Proceedings of the National Academy of Sciences of the United States of America 109(17): 6473-6478

Jaffé R, Boyer JN, Dailey SK, Maie N (2005) SFP 2002: Dissolved Organic Nitrogen in the Taylor Slough, Taylor River and Florida Bay: Molecular Biogeochemistry, Bioavailability and Potential Contribution to the Microbial Loop. In., NOAA Final Report. p NA16OP2549

Jaffé R, Ding Y, Niggemann J, Vähätalo AV, Stubbins A, Spencer RGM, Campbell J, Dittmar T (2013) Global charcoal mobilization from soils via dissolution and riverine transport to the oceans. Science 340(6130): 345-347

Kane ES, Hockaday WC, Turetsky MR, Masiello CA, Valentine DW, Finney BP, Baldock JA (2010) Topographic controls on black carbon accumulation in Alaskan black spruce forest soils: implications for organic matter dynamics. Biogeochemistry 100(1-3): $39-56$

Kim SW, Kaplan LA, Benner R, Hatcher PG (2004) Hydrogen-deficient molecules in natural riverine water samples - evidence for the existence of black carbon in DOM. Marine Chemistry 92(1-4): 225-234

Koch GR, Childers DL, Staehr PA, Price RM, Davis SE, Gaiser EE (2012) Hydrological Conditions Control P Loading and Aquatic Metabolism in an Oligotrophic, Subtropical Estuary. Estuaries and Coasts 35(1): 292-307

Kramer RW, Kujawinski EB, Hatcher PG (2004) Identification of black carbon derived structures in a volcanic ash soil humic acid by Fourier transform ion cyclotron resonance mass spectrometry. Environmental Science \& Technology 38(12): 3387-3395

Kuhlbusch TAJ, Crutzen PJ (1996) Black Carbon, the Global Carbon Cycle, and Atmospheric Carbon Dioxide. In: Levine JS (ed.) Biomass burning and Global Change. MIT Press, Campbridge, MA. p 160-169

Maie N, Boyer JN, Yang CY, Jaffé R (2006a) Spatial, geomorphological, and seasonal variability of CDOM in estuaries of the Florida Coastal Everglades. Hydrobiologia 569: $135-150$ 
Maie N, Jaffé R, Miyoshi T, Childers DL (2006b) Quantitative and qualitative aspects of dissolved organic carbon leached from senescent plants in an oligotrophic wetland. Biogeochem 78(3): 285-314

Maie N, Parish KJ, Watanabe A, Knicker H, Benner R, Abe T, Kaiser K, Jaffé R (2006c) Chemical characteristics of dissolved organic nitrogen in an oligotrophic subtropical coastal ecosystem. Geochimica et Cosmochimica Acta 70(17): 4491-4506

Maie N, Scully NM, Pisani O, Jaffé R (2007) Composition of a protein-like fluorophore of dissolved organic matter in coastal wetland and estuarine ecosystems. Water Research 41(3): 563-570

Mannino A, Harvey HR (2004) Black carbon in estuarine and coastal ocean dissolved organic matter. Limnology and Oceanography 49(3): 735-740

Marques EP, Sa LDA, Karam HA, Alvala RCS, Souza A, Pereira MMR (2008) Atmospheric surface layer characteristics of turbulence above the Pantanal wetland regarding the similarity theory. Agricultural and Forest Meteorology 148(6-7): 883-892

Masiello CA (2004) New directions in black carbon organic geochemistry. Marine Chemistry 92(1-4): 201-213

McCarthy TS, Cooper GRJ, Tyson PD, Ellery WN (2000) Seasonal flooding in the Okavango Delta, Botswana - recent history and future prospects. South African Journal of Science 96(1): 25-33

Mitra S, Bianchi TS, McKee BA, Sutula M (2002) Black carbon from the Mississippi River: Quantities, sources, and potential implications for the global carbon cycle. Environmental Science \& Technology 36(11): 2296-2302

Mladenov N, McKnight DM, Wolski P, Ramberg L (2005) Effects of annual flooding on dissolved organic carbon dynamics within a prestine wetland, the Okavango Delta of Botswana. Wetlands 25(3): 622-638

Nuttle WK, Fourqurean JW, Cosby BJ, Zieman JC, Robblee MB (2000) Influence of net freshwater supply on salinity in Florida Bay. Water Resour Res 36(7): 1805-1822

Penner JE, Eddleman H, Novakov T (1993) Towards, the development of a global inventory for black carbon emissions. Atmospheric Environment Part A-General Topics 27(8): 1277-1295

Por FD (1995) The Pantanal of Mato Grosso (Brazil): World's Largest Wetlands. Kluwer Academic, Dordrecht, Netherlands 
Ramberg L, Lindholm M, Hessen DO, Murray-Hudson M, Bonyongo C, Heinl M, Masamba W, VanderPost C, Wolski P (2010) Aquatic ecosystem responses to fire and flood size in the Okavango Delta: observations from the seasonal floodplains. Wetlands Ecology and Management 18(5): 587-595

Saunders CJ, Gao M, Lynch JA, Jaffé R, Childers DL (2006) Using soil profiles of seeds and molecular markers as proxies for sawgrass and wet prairie slough vegetation in Shark Slough, Everglades National Park. Hydrobiologia 569 (1): 475-492

Schlesinger WH, Melack JM (1981) Transport of organic carbon in the world's rivers. Tellus 33(2): 172-187

Schmidt MWI, Noack AG (2000) Black carbon in soils and sediments: Analysis, distribution, implications, and current challenges. Global Biogeochemical Cycles 14(3): 777-793

Schneider MPW, Hilf M, Vogt UF, Schmidt MWI (2010) The benzene polycarboxylic acid (BPCA) pattern of wood pyrolyzed between 200 degrees $\mathrm{C}$ and 1000 degrees C. Organic Geochemistry 41(10): 1082-1088

Schroeder W, Morisette JT, Csiszar I, Giglio L, Morton D, Justice CO (2005) Characterizing vegetation fire dynamics in Brazil through multisatellite data: Common trends and practical issues. Earth Interactions 9(13): 1-26

Simoneit BRT (2002) Molecular indicators (biomarkers) of past life. Anatomical Record 268(3): 186-195

Stubbins A, Niggemann J, Dittmar T (2012) Photo-lability of deep ocean dissolved black carbon. Biogeosciences 9(5): 1661-1670

Suman DO, Kuhlbusch TAJ, Lim B (1997) Marine sediments: a reservoir for black carbon and their use as spatial and temporal records of combustion. In: Clark JS, Cachier H, Goldammer JG \& Stock BJ (eds.) Sediment Records of Biomass Burning and Global Change. Springer Verlag, Berlin

Tzortziou M, Neale PJ, Osburn CL, Megonigal JP, Maie N, Jaffé R (2008) Tidal marshes as a source of optically and chemically distinctive colored dissolved organic matter in the Chesapeake Bay. Limnol Oceanogr 53(1): 148-159

Wade D, Ewel J, Hofstetter R (1980) Fire in south Florida ecosystems. General Technical Report SE-17, Southeastern Forest Experiment Station, Asheville

Weishaar JL, Aiken GR, Bergamaschi BA, Fram MS, Fuji R, Mopper K (2003) Evaluation of specific ultraviolet absorbance as an indicator of the chemical composition 
and reactivity of dissolved organic carbon. Envrionmental Science and Technology 37(20): 4702-4708

Winkler MG, Sanford PR, Kaplan SW (2001) Hydrology, vegetation, and climate change in the southern Everglades during the Holocene. In: Wardlaw BR (ed.) Bulletin of American Paleontology. Paleontological Research Institution, Ithaca, New York. p 57100

Wolski P, Savenije HHG (2006) Dynamics of floodplain-island groundwater flow in the Okavango Delta, Botswana. Journal of Hydrology 320(3-4): 283-301

Xu XF, Tian HQ, Pan ZJ, Thomas CR (2011) Modeling ecosystem responses to prescribed fires in a phosphorus-enriched Everglades wetland: II. Phosphorus dynamics and community shift in response to hydrological and seasonal scenarios. Ecological Modelling 222(23-24): 3942-3956

Ziolkowski LA, Druffel ERM (2010) Aged black carbon identified in marine dissolved organic carbon. Geophysical Research Letters 37: L16601 


\section{Chapter IV}

SOURCES AND DYNAMICS OF DISSOLVED BLACK CARBON IN BOREAL FOREST RIVERS AND GLACIAL STREAMS OF CENTRAL ALASKA 


\subsection{Abstract}

Boreal forests are an important source and sink for pyrogenic carbon, or black carbon (BC), as fire is very common in this type of ecosystem. However, the reported soil $\mathrm{BC}$ content in boreal forests is low, suggesting active removal processes of soil $\mathrm{BC}$, possibly through transfer to the dissolved phase. In this study, I report dissolved black carbon (DBC) concentrations from samples collected from watersheds in Alaska boreal forest streams and in glacial rivers. The DBC levels, as well as its aromaticity, in glacial rivers are much lower than those from boreal forest streams. I suggest possible source difference, namely fossil fuel vs. forest fires, as the reason for these molecular variations. The composition of $\mathrm{BC}$ oxidation products from additional samples, from geographically remote locations where atmospheric deposition of anthropogenic soot may be important, were statistically compared with the samples studied here to test this hypothesis. My results suggest that, anthropogenic $\mathrm{BC}$, associated with small soot particles, is the most likely source of DBC in some of the remote locations, including the glacial rivers and Antarctic lakes. A linear positive correlation between dissolved organic carbon (DOC) and DBC concentrations was observed for both boreal forest and glacial samples. On the basis of the global DOC flux from boreal forests, I estimate the DBC flux from boreal forests to the oceans is $c a .2 .5 \mathrm{Mt} \mathrm{C} \mathrm{yr}^{-1}$, accounting for $10 \%$ of the global riverine $\mathrm{DBC}$ flux. The ever increasing export of DOC associated DBC from high latitude boreal forests and glaciers as a result of global warming, may impact DOC quality and ultimately trophic dynamics in the marine environment. 


\subsection{Introduction}

Boreal forests are one of the largest terrestrial organic carbon reservoirs on earth and have been significantly affected by global warming over the past few decades (Serreze et al., 2000). The warming trend has led to serious consequences, among which one of the most significant is the increased forest fire frequency, especially in highlatitude regions of North America (Kasischke \& Turetsky, 2006). As a key disturbance in boreal forest ecosystem, fire can cause significant carbon loss from the ecosystem (Harden et al., 2004), change the soil organic matter content and nutrients (Neff et al., 2005), produce soot that changes local and global climate (Kim et al., 2005) and generate black carbon $(\mathrm{BC})$, a presumably biologically inert combustion complex from biomass burning and fossil fuel combustion (Goldberg, 1985; Masiello, 2004). Globally, the BC

\left. production from boreal forests is estimated at 7 to $17{\mathrm{Tg} \mathrm{C} \mathrm{yr}^{-1}}^{-1} \mathrm{Tg}=10^{12} \mathrm{~g}\right)$ of solid char residue and 2 to $2.5 \mathrm{Tg} \mathrm{C} \mathrm{yr}^{-1}$ emitted as aerosols (Preston \& Schmidt, 2006). The total charcoal storage in boreal forest soil was estimated to be $1 \mathrm{Pg} \mathrm{C}\left(1 \mathrm{Pg}=10^{15} \mathrm{~g}\right)$, amounting to $1 \%$ of total plant carbon stock in boreal forests (Ohlson et al., 2009). Quantitative assessments of soil BC in boreal regions such as the Alaska black spruce forests and Siberian scot forests have been reported (Czimczik et al., 2003; Guggenberger et al., 2008; Kane et al., 2010), the fate of this pyrogenic carbon is still unclear. Different possible scenarios for BC dynamics in boreal forest soils can be considered: (1) charcoal residues can be accumulated in soil on geological time scale as a sequestered carbon pool (Goldberg, 1985); (2) soil BC can be oxidized and translocated to the dissolved phase, to be exported by rivers (Jaffé et al., 2013) eventually entering the Arctic Ocean; (3) soil BC can be respired through microbial activity (Cheng et al., 2006), and (4) long distance 
transport and subsequent deposition of anthropogenic soot particles can contribute to the overall BC pool (Stubbins et al., 2012).

Given the fact that fire is a common occurrence in boreal forests and the refractory BC pool can be preserved on geological time scales (Goldberg, 1985), the accumulation of $\mathrm{BC}$ in boreal forest soils is expected to be significant. However, Guggenberger et al. (2008) reported that less than $3 \%$ of soil OC in a Northern Siberia forest was BC and Czimczik et al. (2003) also found very low BC storage in Siberian boreal forest soil. Re-oxidation of $\mathrm{BC}$ on surface soil by subsequent fires and in situ bio/abiotic degradation followed by mobilization to the water phase could explain the low BC stock in soil. Although dissolved BC (DBC) concentration has been measured in estuarine (Dittmar et al., 2012b), open ocean (Dittmar, 2008), riverine (Dittmar et al., 2012b; Ding et al., 2013; Jaffé et al., 2013), and wetland (Chapter IV) environments, no information of $\mathrm{DBC}$ in high latitude boreal forest watersheds and glaciers has been published.

In addition to the large charcoal residues generated by forest fires, soot is also an important combustion product and considered as the most refractory part of the $\mathrm{BC}$ continuum (Masiello, 2004). Global emission of BC to the atmosphere is estimated in the range of 12 to $24 \mathrm{TgC} \mathrm{yr}^{-1}$ (Penner et al., 1993), a larger proportion of which is generated from fossil fuel combustion compared to biomass burning (Cooke \& Wilson, 1996). Because of the smaller particle size of fossil fuel derived soot, this material can remain airborne for extended time periods (Druffel, 2004) reaching remote locations such a glaciers (Stubbins et al., 2012). For instant, for the year of 2000, the global BC emission inventory was estimated in the order of $7.5 \mathrm{Tg} \mathrm{C}$ with $4.8 \mathrm{Tg} \mathrm{C}$ derived from fossil fuel 
combustion (Bond et al., 2013). The lifetime of these BC aerosols can reach 6-8 days (Cooke \& Wilson, 1996), resulting in long distance transport and will eventually deposit by wet/dry deposition. Kim et al. (2005) reported that BC aerosols from central Alaska forest fires could be transported to the Arctic Ocean and southern Alaska Glaciers, leading to a reduction of snow/ice albedo and further melting of sea ice and glaciers. The release of dissolved organic matter (DOM) originally stored in sea ice and glaciers may eventually change the quality and quantity of DOM in the Arctic Ocean and affect marine foodwebs (Stubbins et al., 2012). Consequently, a better understanding of DBC dynamics in boreal and glacier-fed streams is critical to better constrain sources and fate of $\mathrm{BC}$ in boreal regions. Here I evaluate the DBC dynamics in boreal rivers of Alaska, and assess the differences in $\mathrm{DBC}$ sources between boreal forest streams and glacier-fed rivers in Alaska on the basis of the composition of DBC oxidation products.

\subsection{Material and methods}

\subsubsection{Site description and sample collection}

Surface water (2-6 L) samples were collected from 17 sampling sites in central Alaska in July, 2009 (Fig. 4.1), including 6 glacial streams sites (Site 1-6) and 11 boreal forest streams (Site 7-17). The boreal forest stream watersheds were centered on the Caribou-Poker Creeks Research Watershed (CPCRW, part of the Bonanza Creek LongTerm Ecological Research site), located in the Yukon-Tanana Uplands region. CPCRW is a relative pristine basin, underlain by discontinuous permafrost on mainly north-facing slopes. The average temperatures in January and July are $-22^{\circ} \mathrm{C}$ and $13^{\circ} \mathrm{C}$ respectively. The average summer precipitation is $225 \mathrm{~mm}$, and the average winter snowpack yields 
$117 \mathrm{~mm}$ water equivalent (Hinzman et al., 2003). Black spruce species, a vegetation type that is highly flammable and yields to frequent fires dominates the north-facing slopes, while paper birch species mixed with aspen species, which do not burn as readily, and some black spruce are common on most south-facing slopes. White spruce species are dominant near poorly vegetated ridge tops and in stringer forests along south-facing slopes (Fastie et al., 2002). The mosaic of plant communities and topography leads to an uneven fire regimes in this area. In the year 1999 a prescribed fire known as the FROSTFIRE experiment, was performed in a $9.7 \mathrm{~km}^{2}$ sub-basin (Site 8) watershed of CPCRW, in order to study the feedbacks from boreal fire to climate and understand the changing role of boreal forest in the earth system (Hinzman et al., 2003). Additional water samples were collected from boreal forest rivers to the North of CPCRW and from rivers fed or heavily influenced by glacial meltwater from major glaciers located on the Alaska Range. Among them, sample 5 and 6 were collected from the Tanana River drainage, a river originating in the Yukon Territory and flowing through forest and wetland biomes with a substantial base flow of ground water (Wada et al., 2011). The 17 Alaska sites were classified into four sub-groups on the basis of their different environmental settings as glacial rivers (site 1-4), glacier-influenced rivers (site 5-6), boreal forest headwater streams (site 7-13), and boreal forest rivers (site 14-17). 


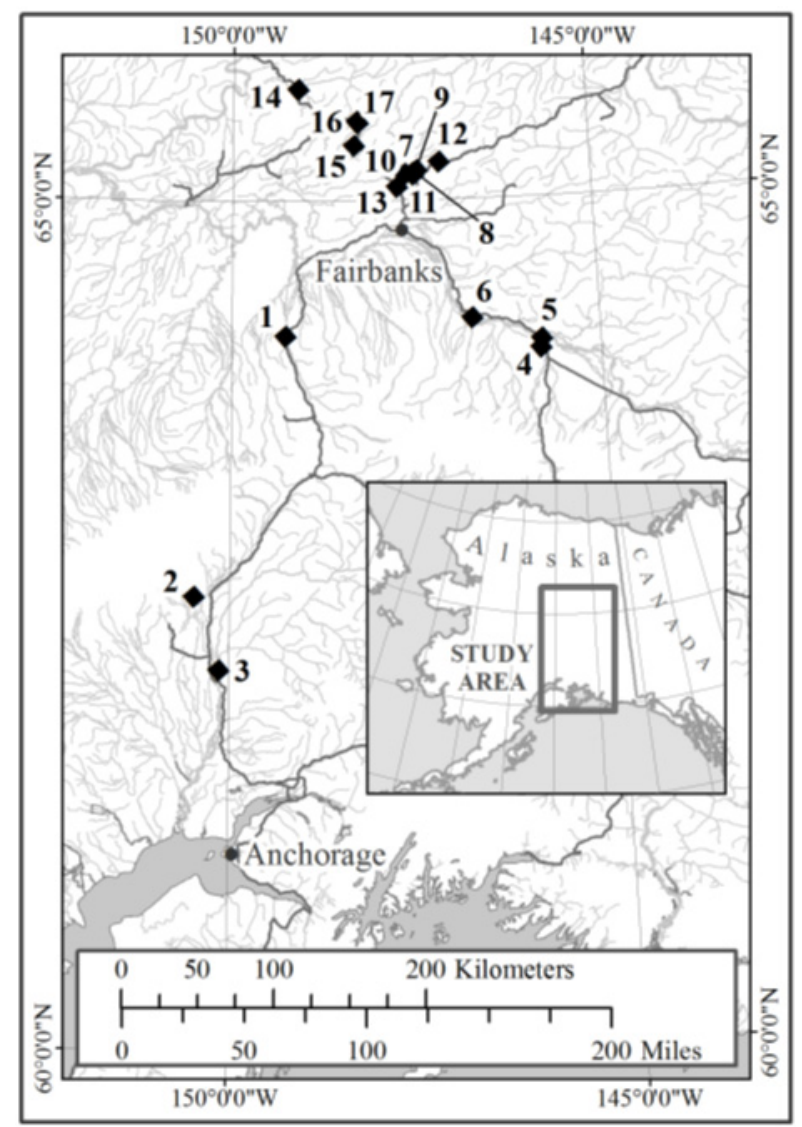

Figure 4.1 Map of Alaska sampling sites. Sites 1 to 4 are glacial fed rivers; Sites 5 and 6 are glacial influenced rivers that also receive forest and wetland discharge; Sites 7 to 17 are boreal forest streams.

Water samples were stored on ice inside pre-rinsed Nalgene plastic bottles immediately after collection and filtered through pre-combusted GF/F filters (Whatman, poresize: $0.7 \mu \mathrm{m}$ ) within 24 hours. About $60 \mathrm{~mL}$ of water sample were saved at $4{ }^{\circ} \mathrm{C}$ for dissolved organic carbon (DOC) analysis. The rest was acidified to $\mathrm{pH} 2$ with concentrated $\mathrm{HCl}(32 \%$, ACS plus grade), followed by solid phase extraction (SPE) via PPL cartridges (1g, Varian Bond Elute). Ten $\mathrm{mL} \mathrm{MeOH}$ were used to elute the DOM, including $\mathrm{DBC}$, from the cartridges. Elutes were stored at $-20{ }^{\circ} \mathrm{C}$ until $\mathrm{DBC}$ analysis. Detailed SPE procedures are described in Dittmar (2008) and Ding et al. (2013). 
Additional DBC data from the a grassland watershed (Konza Prairie; Ding et al., 2013), three wetlands (Everglades, Pantanal and Okavango Delta; Chapter IV), two coastal sites (Florida Bay and Shark Bay) as well as other remote sites including Antarctic, Arctic and Alpine lakes were included in a comparative study of BPCA relative abundances. The ecological information of Konza Prairie, three wetlands and Florida Bay can be obtained from Ding et al. (2013) and Chapter IV. Five samples were collected in Shark Bay, a shallow subtropical bay located in Western Australia with very limited human impact, in March 2011. Five to ten freeze-dried fulvic acid samples (bulk DOM extracted by XAD-resin, Aiken et al., 1992) from Antarctic, Arctic and Alpine lakes respectively were also analyzed in this study. The Antarctic samples were mostly collected from Lake Fryxell, a closed basin, permanently ice-covered lake located in the McMurdo Dry Valley. The Arctic samples were collected from several creeks and lakes in the Alaskan tundra, as part of the Arctic Long-term Ecological Research program, characterized by continuous permafrost, with a short ice-out time period during May or June. The Alpine samples were collected from two small headwater creeks, named Snake Creek and Deer Creek, in the Rocky Mountains, Colorado. Detailed site descriptions have been documented elsewhere (Cory \& McKnight, 2005; Fulton et al., 2004; McKnight et al., 1992; McKnight et al., 2001).

\subsubsection{Analytical methodology}

DOC concentrations were determined using a total organic carbon analyzer (TOC-5000A analyzer, Shimadzu) applying standard methods reported in the literature (Alvarez-Salgado \& Miller, 1998). Benzenepolycarboxylic acids (BPCAs), molecularly 
defined as oxidation products of condensed polycyclic aromatic hydrocarbon with multifunctional groups (Dittmar \& Koch, 2006), were used as markers to determine DBC concentrations. Methodological details can be obtained from Ding et al. (2013) and Dittmar (2008). The DBC concentrations were estimated applying an algorithm reported by Dittmar (2008) on the basis of the molecular structures of marine thermogenic PAH (Dittmar \& Koch, 2006).

The freeze-dried fulvic acid samples from Antarctic, Arctic and Alpine ecosystems were weighted directly before the nitric acid digestion without PPL extraction. No significant difference was found in quantity (concentrations) and quality (BPCA proportions) of DBC extracted by PPL cartridges (Dittmar et al., 2008) and XAD-resin (Aiken et al., 1992) from a comparison study using one freshwater sample, probably because both extractions are efficient techniques to isolate hydrophobic DOM and likely all DBC is in the hydrophobic components of DOM. However, this comparison study consisted of only one sample, and further studies should be done to confirm this similarity.

Statistical analyses, including regression analysis, one-way ANOVA analysis and principal component analysis (PCA), were performed by SPSS statistics 17.0 software.

\subsection{Results and discussion}

\subsubsection{Linear correlation between DOC and DBC}

The concentrations of DOC and DBC, as well as \%DBC, from each sub-group are shown in Table 4.1. Because of limited sample population in different groups, the mean and standard deviation is used for comparison instead of Student's t-test. The average 
$\mathrm{DOC}$ and $\mathrm{DBC}$ concentrations and $\% \mathrm{DBC}$ in $\mathrm{DOC}$ were the lowest for glacial river samples (site 1-4), which primarily receive input from glacier meltwater. DOC and DBC concentrations in site 5 and 6 were higher than those in glacial rivers as these receive mixed inputs from both glacial and non-glacial sources. The DOC and DBC concentrations were greater in boreal forest headwater streams and rivers compared with glacial and glacier-influenced rivers. Among them, four boreal forest rivers (sites 14-17) had significantly higher DOC and DBC concentrations, possibly caused by their larger watershed area compared to the headwater streams. The \%DBC showed a similar behavior to the $\mathrm{DOC}$ and $\mathrm{DBC}$ concentrations, with glacial sites having the lowest $\% \mathrm{DBC}$ and boreal forest rivers featuring the highest $\% \mathrm{DBC}$. There was no significant overlap in the $\mathrm{DOC}, \mathrm{DBC}$ and $\% \mathrm{DBC}$ range (Mean $\pm \mathrm{SD}$ ) among different groups.

Table 4.1 DOC and DBC concentrations and \%DBC for Alaska rivers from different environmental settings.

\begin{tabular}{ccccc}
\hline $\begin{array}{c}\text { Stream environment } \\
\text { setting }\end{array}$ & Site name & DOC & DBC & $\%$ DBC \\
\hline Glacial rivers & Site 1-4 & $(5.3 \pm 0.9) \times 10^{-1}$ & $(1.0 \pm 0.4) \times 10^{-2}$ & $1.9 \pm 0.6$ \\
Glacier-influenced rivers & Site 5-6 & $(9.6 \pm 0.0) \times 10^{-1}$ & $(3.3 \pm 0.7) \times 10^{-2}$ & $3.4 \pm 0.7$ \\
Boreal forest & Site 7-13 & $2.0 \pm 0.6$ & $(9.8 \pm 3.6) \times 10^{-2}$ & $4.9 \pm 0.7$ \\
headwater streams & & & & \\
Boreal forest rivers & Site 14-17 & $14.0 \pm 4.8$ & $(9.4 \pm 3.7) \times 10^{-1}$ & $6.7 \pm 0.8$ \\
\hline
\end{tabular}




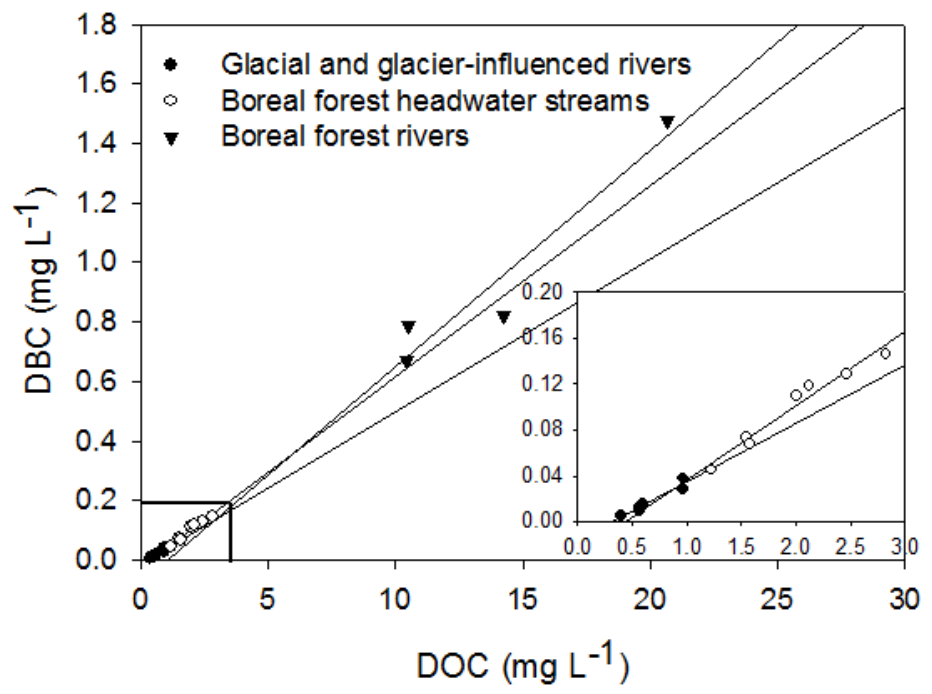

Figure 4.2 Linear regressions between DOC and DBC concentrations in sub-groups with different environment settings in Alaska. The regression equations for three environmental settings are: $\mathrm{y}=0.052 \mathrm{x}-0.0172, \mathrm{R}^{2}=0.92, \mathrm{P}<0.0001$ (glacial and glacierinfluenced rivers); $\mathrm{y}=0.0645 \mathrm{x}-0.0284, \mathrm{R}^{2}=0.96, \mathrm{P}<0.0001$ (boreal forest headwater streams); and $\mathrm{y}=0.073 \mathrm{x}-0.0806, \mathrm{R}^{2}=0.92, \mathrm{P}<0.0001$ (boreal forest rivers).

In addition to the strong influence of boreal forest ecosystems on the DOC and DBC concentrations and the \% $\mathrm{DBC}$, a strong linear correlation was found between DOC and DBC concentrations $(\mathrm{P}<0.001, \mathrm{n}=12)$, in agreement with other recent reports for other aquatic systems (Ding et al., 2013; Dittmar et al., 2012b). In fact, this trend has been suggested to be ubiquitous on a global scale (Jaffé et al., 2013). Further analysis of regression within and between sub-groups with different environment settings shown in Fig. 4.2 (glacial and glacier-influenced river sites were combined) revealed that such linear regression existed in each group $(\mathrm{P}<0.001)$ and no statistically difference were found between groups regarding to the regression slope and intercept. While it seems clear that the dynamics of DOC and DBC are coupled, the exact mechanism leading to such strong correlations is presently unclear. Possible explanations include cometabolism of soil OM and BC by soil microbes (Hockaday et al., 2007) and DOM 
induced DBC translocation by hydrophobic association (Jaffé et al., 2013). Increased leaching of soil DOM by climate and soil warming has been suggested (Goulden et al., 1998 ) and could affect soil BC in a similar way. Ultimately, it is interesting, that systems as different as high DOC boreal rivers and glacial meltwater fed rivers, fit this model.

\subsubsection{Fire impacts on $D B C$ concentrations}

Glacial river sites and glacier-influenced river sites from the Alaska Range area were expected to have a significantly lower input of forest fire derived $\mathrm{BC}$ because of the remote, high elevation of their source waters. The most likely BC source in glaciers has been shown to be from atmospheric deposition of BC aerosols (Druffel, 2004; Penner et al., 1993; Stubbins et al., 2012) from either regional forest fires or from anthropogenic combustion sources through longer airborne transport. Consequently, it is reasonable to expect that those sites had the lowest DBC concentrations (Fig. 4.2).

With respect to the boreal forest sites, not all fire records could be found, but relatively detailed fire history for the last 200-250 years in CPCRW area (site 7-13) could be retrieved from Fastie and Lloyd (2002). Site 8 in this study (named as C4 in CPCRW) was reported as having the most frequent fire events including the FROSTFIRE experiment in 1999, followed by site 7 (P6) which was used as a control in the FROSTFIRE experiment. The most recent burning at site 7 was reported for 2004 when about $50 \%$ of the catchment was impacted. A fairly severe fire occurred at site $11(\mathrm{CP})$ about 80 years ago. Not much fire activity was reported for site 9 (C2) because the catchment is dominated by birch and aspen, which do not burn readily, and the soils associated with birch and aspen tend to be poorly developed with relatively low soil OM. 
However, no obvious enhancement of DBC concentration was observed for sites that have been burned more frequent or more recent. Similar lack of correlation between fire history and DBC abundance were recently reported by Ding et al. (2013), for streams in a grassland ecosystem. Re-burning of charcoal on surface soil by subsequent fires and rapid mobilization of $\mathrm{BC}$ from the fire site shortly after burning events can both reduce the stock of soil BC, thus reducing DBC leaching (Kane et al., 2010). In addition, DBC exported presently could have been generated from historical fires that occurred decades earlier (Dittmar et al., 2012a).

\subsubsection{Assessment of DBC sources derived from benzenepolycarboxylic acid (BPCA)} composition

The relative abundances of $\mathrm{DBC}$ oxidation products, BPCAs, can be used to characterize molecular structure of DBC (Glaser et al., 1998). DBC with higher degrees of polycondensation tend to produce higher proportions of $\mathrm{B} 5 \mathrm{CA}$ and $\mathrm{B} 6 \mathrm{CA}$ oxidation products, while DBC that is less aromatic or smaller in size will produce higher proportions of B3CA and B4CA (Glaser et al., 1998). Such BPCA distribution differences could be caused by combustion conditions or fuel types such as forest fires compared to fossil fuel combustion (Schneider et al., 2010; Ziolkowski \& Druffel, 2010). The BPCA relative abundances for all studied samples were statistically evaluated using principal component analysis (PCA, Fig.4.3) where principal component 1 (PC1) and principal component 2 (PC2) account for $76.6 \%$ and $20.8 \%$ of the variability, respectively. According to the loadings (Fig. 4.3b), the \%B3CA and \%B4CA showed positive values on the $\mathrm{PC} 1$ axis, while the $\% \mathrm{~B} 5 \mathrm{CA}$ and $\% \mathrm{~B} 6 \mathrm{CA}$ were on the negative 
side. Except for \%B6CA, no other BPCAs showed significant values for PC2. As such, PC1 is a source indicator (anthropogenic vs. forest fire), while the significance of PC2 was not identified. Consequently, PC2 is not further discussed. According to PC1 the samples could be categorized into three groups in the score plot (Fig. 4.3a), corresponding to their environmental classification. The four glacial stream samples showed positive $\mathrm{PC} 1$ values indicative of much larger proportions of $\mathrm{B} 3 \mathrm{CA}$ and $\mathrm{B} 4 \mathrm{CA}$, while the boreal forest river samples were located on the negative side of PC1, indicating dominance of B5CA and B6CA. Interestingly, the two glacier-influenced river samples featured intermediate PC1 values, illustrating a mixed DBC source at these sites. Only one glacial water sample was affected by significant higher \%B6CA (PC2) compared to the other samples. The DBC concentration from this site was so low that it almost reached the detection limit of the instrument, resulting in larger instrument error because of low signal/noise ratio.

Chapter IV reported a similar BPCA based PCA plot for terrestrial and coastal DBC samples, showing a gradient along PC1. In that case, PC1 was suggested to either be indicative of source (anthropogenic deposition vs. wild fires), or derived from DBC degradation differences (likely photochemical). For the Alaska samples, a loading source difference between glacial and boreal forest watersheds, rather than degradation during fluvial transport is a more likely explanation for the DBC molecular characteristic differences. Penner et al. (1993) estimated the fossil fuel burning derived BC emission inventory and reported that fossil fuel generated $\mathrm{BC}$ was ten to hundred orders of magnitude higher in concentration than biomass burning generated $\mathrm{BC}$ in remote locations (e.g., Central North Pacific, South Pole). A recent study of Alaska glacial DOM 
using ultra-high resolution mass spectrometry and radiocarbon analysis $\left({ }^{14} \mathrm{C}\right)$ also revealed that anthropogenic aerosols were the major source of DOM in glaciers (Stubbins et al., 2012). Different from biomass burning generated charcoal, soot from fossil fuel burning is characterized by lower degree of polycondensation and size (Dittmar \& Koch, 2006), which would result in higher percentages of B3CA and B4CA oxidation products (Dittmar, 2008).
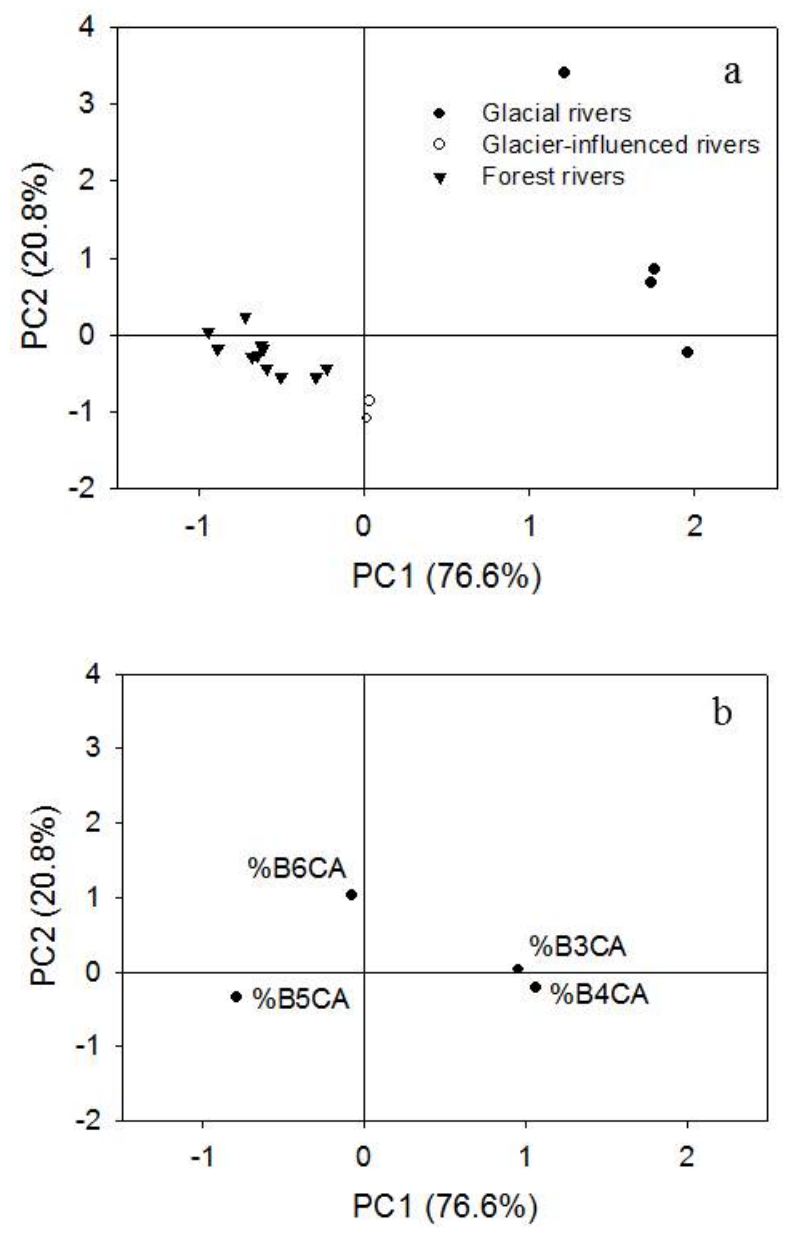

Figure 4.3 Scores (a) and loadings (b) of principal component analysis of BPCA proportions. 
To further test this hypothesis, a global PCA of BPCA proportions including previously published and unpublished $\mathrm{DBC}$ data from 11 different environments was conducted, including terrestrial, coastal marine and remote locations. The loading plot of global PCA (not shown) is very similar to that of Alaska samples (Fig. 4.3b), with PC1 and PC2 accounting for $62.5 \%$ and $28.6 \%$ of the variability respectively. Average PC1 values of samples from the same location (mean $\pm \mathrm{SD}$ ) are shown in Fig. 4.4 (for site descriptions see section 4.3.1). Samples include 5 terrestrial sites ( 3 wetlands, 1 grassland and 1 boreal forest), 2 sub-tropical coastal bays, and 4 remote sites (glacial rivers from this study, Antarctic lakes, Arctic lakes and Alpine lakes). On the basis of one-way ANOVA analysis $(\alpha=0.05)$, sites labeled with the same letter have no significant difference between mean values while different letters stand for a significant difference between mean values. Except for the Alpine and Arctic sites, the PC1 value increases from terrestrial sites to coastal sites to remote sites, indicating an increase in relative abundance of $\mathrm{B} 3 \mathrm{CA}$ and $\mathrm{B} 4 \mathrm{CA}$. It is interesting to notice that the coastal sites, composed of Florida Bay (USA) and Shark Bay (Australia), show intermediate PC1 values. As previously reported (Chapter IV) Florida Bay is a coastal environment where the water and nutrient budgets are strongly controlled by atmospheric deposition. Similar situation applies for Shark Bay. It is thus expected that these environments receive a significant $\mathrm{BC}$ contribution through atmospheric deposition (Jurado et al., 2008). Thus, although both bays receive some freshwater inputs through river discharges and runoff, the mixed source character is clear from the PC1 values. The glacial and Antarctic sites have the most positive $\mathrm{PC} 1$ values. The enhancement in $\mathrm{PC} 1$ along a terrestrial-coastal-remote transition is in accordance with an increase of anthropogenic $\mathrm{BC}$ abundance in long 
distance atmospheric transport (Penner et al., 1993). Although Alpine site and Arctic site are remote in altitude and latitude respectively, the Alpine sites are indeed small headwater streams in Alpine forest (McKnight et al., 1992) while the Arctic sites in Alaska tundra are characterized with terrestrial vegetation and subjected to relative frequent wildfire over the past two millennia (mean fire return time is 150 years; Higuera et al., 2011).Therefore, a similarity between Alpine, Arctic and other terrestrial sites is expected considering the dominant DBC sources are from wild fires.

The results presented here are in agreement with previous reports suggesting that DOM in glaciers is characterized by lower aromaticity because of the lack of vascular plant input and a primarily anthropogenic source (Hood et al., 2009, Stubbins et al., 2012).

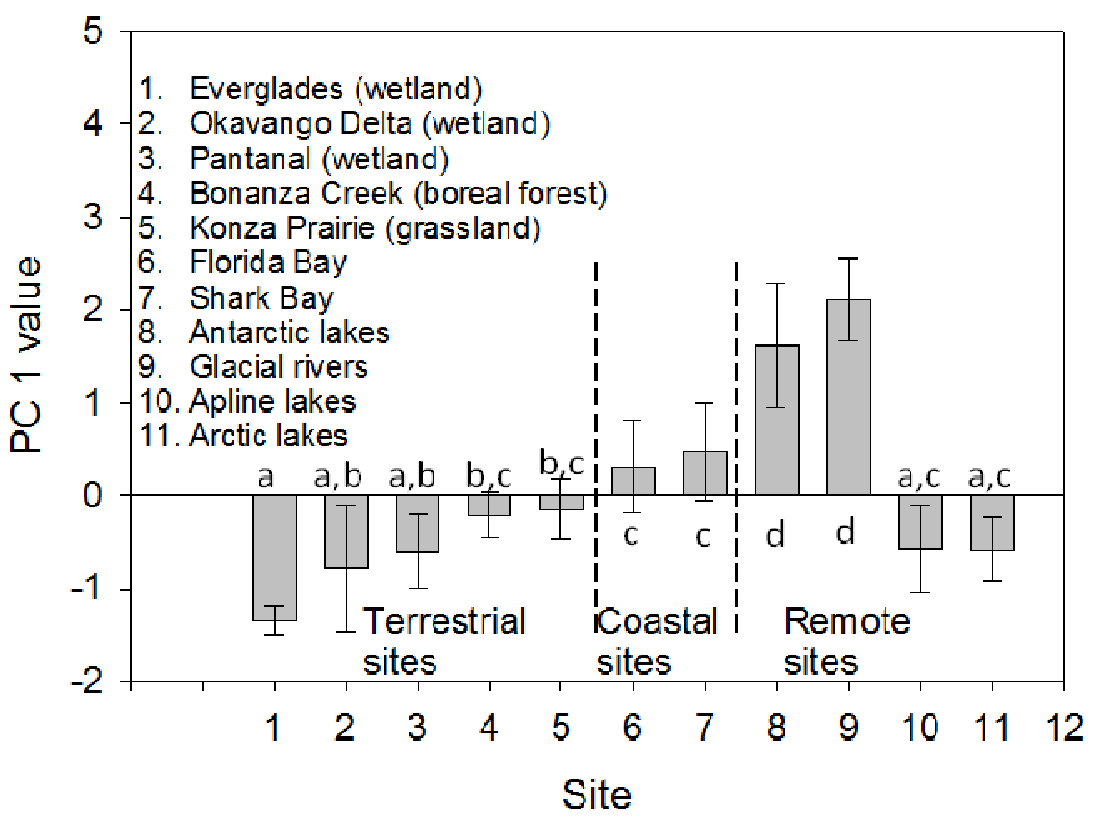

Figure 4.4 Average principal component 1 (PC1) values of samples from different environmental settings. The error bar represents the standard deviation of $\mathrm{PC} 1$ values. On the basis of one-way ANOVA analysis $(\alpha=0.05)$, sites labeled with the same letter have no significant difference between mean values while different letters stand for significant differences of mean values among sites. All populations passed the normality test and variance homogeneity test. 


\subsection{Conclusions}

Boreal forests are an important source as well as a sink for pyrogenic carbon, or BC. About one third of the net primary productivity of boreal forests is consumed by fire, contributing to $c a .3$ to $42 \%$ of global $\mathrm{BC}$ residues and $c a$. 7 to $25 \%$ of global $\mathrm{BC}$ aerosols generated annually (calculated from reported numbers in Preston and Schmidt, 2006). However, the low BC stock in boreal forest soils suggests that removal processes of soil $\mathrm{BC}$ are active in preventing its accumulation over geological time scales. The ubiquitous presence of $\mathrm{DBC}$ in boreal forest rivers and the linear correlation of $\mathrm{DBC}$ and DOC in this environment are in agreement with recent reports that DBC dynamics are coupled to DOC (Jaffé et al., 2013), and as such significant loss of soil BC from boreal forest environments is lost via translocation to the dissolved phase and subsequent export by rivers.

In contrast to boreal forest rivers, the concentrations of DOC and DBC are low in water with strong glacial influence, although a strong linear regression was also observed between DOC and DBC concentrations for these systems. On the basis of relative abundances of BC oxidation products (BPCAs), glacier and glacier melt water influenced rivers was found to be dominated by anthropogenic soot as primary source of DBC. This was also observed to be the case in other environments where $\mathrm{BC}$ sources are dominated by atmospheric deposition.

The slope of the linear regression equation between DBC and DOC shows that the average percentage of $\mathrm{DBC}$ in $\mathrm{DOC}$ is $c a .7 \%$ in Alaska boreal rivers, which is slightly lower but similar to the global riverine average of about 10.6\% (Jaffé et al., 2013). On the basis of a global total organic carbon (including DOC and particulate organic carbon, 
POC) flux of $60 \mathrm{Mt} \mathrm{C} \mathrm{yr}^{-1}\left(1 \mathrm{Mt}=10^{12} \mathrm{~g}\right)$ from boreal forests and a global average DOC/POC ratio of 1.5 (Hedges, 1997; Meybeck, 1982), the DOC flux from boreal forests on a global scale can be estimated as on the order of $36 \mathrm{Mt} \mathrm{C} \mathrm{yr}^{-1}$, and a subsequent DBC

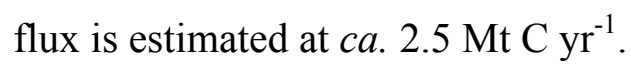

Global warming has led to higher fire frequencies and degradation of permafrost and glaciers in the high-latitude boreal forest areas (Kasischke \& Turetsky, 2006). On the other hand, $\mathrm{BC}$ aerosol from such fires can cause positive feed-backs to global warming and further accelerate permafrost and glaciers degradation (Bond et al., 2013). Since climate change is predicted to increase DOM export from the terrestrial environments to the coastal ocean (Whitehead et al., 2009), global DBC export will also increase. The annual contribution from boreal regions represents about $10 \%$ of the annual global riverine DBC contribution to oceanic environments (Jaffé et al., 2013). It is at this point unknown how much of this DBC load is anthropogenic in nature and derived from glacier melt water. The presence of $\mathrm{DBC}$ in remote environments indeed reflects the global impact of human activities and points towards a positive feedback between $\mathrm{BC}$ emissions and accelerated global warming. 


\section{REFERENCES}

Aiken GR, McKnight DM, Thorn KA, Thurman EM (1992) Isolation of hydrophilic organic-acids from water using nonionic macroporous resins. Organic Geochemistry 18(4): $567-573$

Alvarez-Salgado XA, Miller AEJ (1998) Simultaneous determination of dissolved organic carbon and total dissolved nitrogen in seawater by high temperature catalytic oxidation: conditions for precise shipboard measurements. Marine Chemistry 62(3-4): $325-333$

Bond TC, Doherty SJ, Fahey DW, Forster PM, Berntsen T, DeAngelo BJ, Flanner MG, Ghan S, Kärcher B, Koch D, Kinne S, Kondo Y, Quinn PK, Sarofim MC, Schultz MG, Schulz M, Venkataraman C, Zhang H, Zhang S, Bellouin N, Guttikunda SK, Hopke PK, Jacobson MZ, Kaiser JW, Klimont Z, Lohmann U, Schwarz JP, Shindell D, Storelvmo T, Warren SG, Zender CS (2013) Bounding the role of black carbon in the climate system: A scientific assessment. Journal of Geophysical Research-Atmospheres: in press, doi: 10.1002/jgrd.50171

Cooke WF, Wilson JJN (1996) A global black carbon aerosol model. Journal of Geophysical Research 101(D14): 19395-19409

Cory RM, McKnight DM (2005) Fluorescence spectroscopy reveals ubiquitous presence of oxidized and reduced quinones in dissolved organic matter. Environmental Science \& Technology 39(21): 8142-8149

Czimczik CI, Preston CM, Schmidt MWI, Schulze ED (2003) How surface fire in Siberian Scots pine forests affects soil organic carbon in the forest floor: Stocks, molecular structure, and conversion to black carbon (charcoal). Global Biogeochemical Cycles 17(1): GB1956

Ding Y, Yamashita Y, Dodds W, Jaffé R (2013) Dissolved black carbon in grassland streams: Is there an effect of recent fire history? Chemosphere 90(10): 2257-2562

Dittmar T (2008) The molecular level determination of black carbon in marine dissolved organic matter. Organic Geochemistry 39(4): 396-407

Dittmar T, Rezende CE, Manecki M, Niggemann J, Ovalle ARC, Stubbins A, Bernardes MC (2012a) Continuous flux of dissolved black carbon from a vanished tropical forest biome. Nature Geoscience 5(9): 618-622

Dittmar T, Koch B, Hertkorn N, Kattner G (2008) A simple and efficient method for the solid-phase extraction of dissolved organic matter (SPE-DOM) from seawater. Limnology and Oceanography-Methods 6: 230-235 
Dittmar T, Koch BP (2006) Thermogenic organic matter dissolved in the abyssal ocean. Marine Chemistry 102(3-4): 208-217

Dittmar T, Paeng J, Gihring TM, Suryaputra IGNA, Huettel M (2012b) Discharge of dissolved black carbon from a fire-affected intertidal system. Limonology and Oceanography 57(4): 1171-1181

Druffel ERM (2004) Comments on the importance of black carbon in the global carbon cycle. Marine Chemistry 92(1-4): 197-200

Fastie CL, Lloyd AH, Doak P (2003) Fire history and postfire forest development in an upland watershed of interior Alaska. Journal of Geophysical Research-Atmospheres 108(D1): 8150

Fulton JR, McKnight DM, Foreman CM, Cory RM, Stedmon C, Blunt E (2004) Changes in fulvic acid redox state through the oxycline of a permanently ice-covered Antarctic lake. Aquatic Sciences 66(1): 27-46

Glaser B, Haumaier L, Guggenberger G, Zech W (1998) Black carbon in soils: the use of benzenecarboxylic acids as specific markers. Organic Geochemistry 29(4): 811-819

Goldberg ED (1985) Black carbon in the environment: Properties and distribution. John Wiley \& Sons, New York

Goulden ML, Wofsy SC, Harden JW, Trumbore SE, Crill PM, Gower ST, Fries T, Daube BC, Fan SM, Sutton DJ, Bazzaz A, Munger JW (1998) Sensitivity of boreal forest carbon balance to soil thaw. Science 279(5348): 214-217

Guggenberger G, Rodionov A, Shibistova O, Grabe M, Kasansky OA, Fuchs H, Mikheyeva N, Zrazhevskaya G, Flessa H (2008) Storage and mobility of black carbon in permafrost soils of the forest tundra ecotone in Northern Siberia. Global Change Biology 14(6): $1367-1381$

Harden JW, Neff JC, Sandberg DV, Turetsky MR, Ottmar R, Gleixner G, Fries TL, Manies KL (2004) Chemistry of burning the forest floor during the FROSTFIRE experimental burn, interior Alaska, 1999. Global Biogeochemical Cycles 18(3): 14

Higuera PE, Chipman ML, Barnes JL, Urban MA, Hu FS (2011) Variability of tundra fire regimes in Arctic Alaska: millennial-scale patterns and ecological implications. Ecological Applications 21(8): 3211-3226

Hinzman LD, Fukuda M, Sandberg DV, Chapin FS, Dash D (2003) FROSTFIRE: An experimental approach to predicting the climate feedbacks from the changing boreal fire regime. Journal of Geophysical Research-Atmospheres 108(D1): 8153 
Hockaday WC, Grannas AM, Kim S, Hatcher PG (2007) The transformation and mobility of charcoal in a fire-impacted watershed. Geochimica Et Cosmochimica Acta 71(14): 3432-3445

Hood E, Fellman J, Spencer RGM, Hernes PJ, Edwards R, D'Amore D, Scott D (2009) Glaciers as a source of ancient and labile organic matter to the marine environment. Nature 462(7276): 1044-U1100

Jaffé R, Ding Y, Niggemann J, Vähätalo AV, Stubbins A, Spencer RGM, Campbell J, Dittmar T (2013) Global charcoal mobilization from soils via dissolution and riverine transport to the oceans. Science 340(6130): 345-347

Jurado E, Dachs J, Duarte CM, Simo R (2008) Atmospheric deposition of organic and black carbon to the global oceans. Atmospheric Environment 42(34): 7931-7939

Kane ES, Hockaday WC, Turetsky MR, Masiello CA, Valentine DW, Finney BP, Baldock JA (2010) Topographic controls on black carbon accumulation in Alaskan black spruce forest soils: implications for organic matter dynamics. Biogeochemistry 100(1-3): $39-56$

Kasischke ES, Turetsky MR (2006) Recent changes in the fire regime across the North American boreal region - Spatial and temporal patterns of burning across Canada and Alaska. Geophysical Research Letters 33(9): L09703

Kim Y, Hatsushika H, Muskett RR, Yamazaki K (2005) Possible effect of boreal wildfire soot on Arctic sea ice and Alaska glaciers. Atmospheric Environment 39(19): 3513-3520 Masiello CA (2004) New directions in black carbon organic geochemistry. Marine Chemistry 92(1-4): 201-213

Masiello CA (2004) New directions in black carbon organic geochemistry. Marine Chemistry 92(1-4): 201-213

McKnight DM, Bencala KE, Zellweger GW, Aiken GR, Feder GL, Thorn KA (1992) Sorption of dissolved organic-carbon by hydrous aluminum and iron-oxides occurring at the confluence of deer creek with the snake river, summit county, colorado. Environmental Science \& Technology 26(7): 1388-1396

Neff JC, Harden JW, Gleixner G (2005) Fire effects on soil organic matter content, composition, and nutrients in boreal interior Alaska. Canadian Journal of Forest Research-Revue Canadienne De Recherche Forestiere 35(9): 2178-2187

Ohlson M, Dahlberg B, Okland T, Brown KJ, Halvorsen R (2009) The charcoal carbon pool in boreal forest soils. Nature Geoscience 2(10): 692-695 
Penner JE, Eddleman H, Novakov T (1993) Towards, the development of a global inventory for black carbon emissions. Atmospheric Environment Part a-General Topics 27(8): 1277-1295

Preston CM, Schmidt MWI (2006) Black (pyrogenic) carbon: a synthesis of current knowledge and uncertainties with special consideration of boreal regions. Biogeosciences 3(4): $397-420$

Schneider MPW, Hilf M, Vogt UF, Schmidt MWI (2010) The benzene polycarboxylic acid (BPCA) pattern of wood pyrolyzed between 200 degrees $\mathrm{C}$ and 1000 degrees $\mathrm{C}$. Organic Geochemistry 41(10): 1082-1088

Serreze MC, Walsh JE, Chapin FS, Osterkamp T, Dyurgerov M, Romanovsky V, Oechel WC, Morison J, Zhang T, Barry RG (2000) Observational evidence of recent change in the northern high-latitude environment. Climatic Change 46(1-2): 159-207

Stubbins A, Hood E, Raymond PA, Aiken GR, Sleighter RL, Hernes PJ, Butman D, Hatcher PG, Striegl RG, Schuster P, Abdulla HAN, Vermilyea AW, Scott DT, Spencer RGM (2012) Anthropogenic aerosols as a source of ancient dissolved organic matter in glaciers. Nature Geoscience 5(3): 198-201

Wada T, Chikita KA, Kim Y, Kudo I (2011) Glacial Effects on Discharge and Sediment Load in the Subarctic Tanana River Basin, Alaska. Arctic Antarctic and Alpine Research 43(4): 632-648

Whitehead PG, Wilby RL, Battarbee RW, Kernan M, Wade AJ (2009) A review of the potential impacts of climate change on surface water quality. Hydrological Sciences Journal-Journal Des Sciences Hydrologiques 54(1): 101-123

Ziolkowski LA, Druffel ERM (2010) Aged black carbon identified in marine dissolved organic carbon. Geophysical Research Letters 37: L16601 


\section{Chapter V}

GLOBAL CHARCOAL MOBILIZATION FROM SOILS VIA DISSOLUTION AND

SUBSEQUENT RIVERINE TRANSPORT TO THE OCEANS

(This chapter is modified from Jaffé et al., 2013, Science) 


\subsection{Abstract}

Global biomass burning generates 40-250 million tons of charcoal every year, part of which is preserved for millennia in soils and sediments. Here I have quantified dissolution products of charcoal in a wide range of rivers worldwide, and show that globally a major portion of the annual charcoal production is lost from soils via dissolution and subsequent transport to the ocean. The global flux of soluble charcoal accounts to $26.5 \pm 1.8$ million tons per year, which is $\sim 10 \%$ of the global riverine flux of dissolved organic carbon (DOC). I suggest the mobilization of charcoal and DOC out of soils is mechanistically coupled. This study closes a major gap in the global charcoal budget, and provides critical information in the context of geoengineering.

\subsection{Introduction}

Charcoal, or Black Carbon (BC), is a molecularly diverse organic product of incomplete combustion of biomass and fossil fuels (Baldock et al., 2002; Goldberg, 1985; Schneider et al., 2010). It is ubiquitous in the environment, where it slowly decomposes (Zimmerman, 2010), but part of it is preserved for thousands of years (Masiello and Druffel, 1998). Global biomass burning generates 40-250 Mt BC per year (Kuhlbusch and Crutzen, 1996), and 5-40\% of total soil organic carbon is estimated to be BC (Cusack et al., 2012; Hammes et al., 2007; Masiello and Druffel, 2003; Skjemstad et al., 2002). The global BC stock in sediments, soils and waters combined is 300-500 Gt carbon (Hockaday et al., 2007).

$\mathrm{BC}$ has been considered as extraordinarily stable in the environment. However, current production rates exceed estimates on decomposition rates. According to this 
mismatch, there should be more BC than total organic carbon in soils (Masiello, 2004; Schmidt, 2004). This paradox indicates that a relatively labile BC pool must exist, allowing for significant losses from soils. Measurements of BC age in boreal forest soils of $c a .652$ years (Ohlson et al., 2009) agree with reported BC degradation rates on centennial time scales (Czimczik et al., 2003; Hockaday et al., 2007), suggesting that microbial degradation and erosion of $\mathrm{BC}$ may be more significant than previously believed. A meta-analysis of the current knowledge on black carbon degradation in soils (Singh et al., 2012) indicates turnover times of less than 100 years. Alternatively, multiple pools of black carbon were suggested in the same study (Singh et al., 2012) with about half of the black carbon turning over in 3 years, while the other half may persist in soils over millennia. This range of reactivity is probably a function of charring temperature and source material, but also environmental factors such as soil properties and fauna play a role in BC decomposition (Czimczik and Masiello, 2007; Nguyen and Lehmann, 2010; Singh et al., 2012).

In addition to complete oxidation into $\mathrm{CO}_{2}$ and particle erosion (Mitra et al., 2002), BC can also be mobilized from soils in dissolved form as dissolved BC (DBC; Dittmar et al., 2012a, b; Hockaday et al., 2007; Mitra et al., 2002). A recent study showed that even decades after major slash-and-burn, DBC was efficiently mobilized in large quantities from the soils of a former tropical forest biome in Brazil (Dittmar et al., 2012b). The fact that $>2 \%$ of the marine DOC pool has a heat-induced molecular signature (Dittmar et al., 2009) also points toward considerable fluxes of DBC from land to ocean. If $\mathrm{BC}$ 'dissolution' in soils is an important translocation process in terrestrial systems, the transfer of this material to marine environments may be critical in 
establishing global mass balances for BC (Dittmar et al., 2009; Dittmar et al., 2012b). However, few data on DBC loads are available for rivers (Ding et al., 2013; Dittmar et al., 2012a, b; Mannino and Harvey, 2004), and this quantitative information is too limited to reliably estimate land-ocean fluxes on a global scale.

The objective of this study was to provide a first estimate of the global flux of DBC from land to ocean through rivers. For this purpose I determined the concentration of DBC in rivers globally (Fig. 5.1), across a wide range of sizes from major rivers to headwater streams and wetland watersheds, and geographically from the arctic to the southern mid-latitudes. Furthermore, I experimentally studied the translocation of soil BC to the dissolved phase and propose mechanisms for this process.

DBC was determined on a molecular level as the sum of polycyclic aromatic carbon (Dittmar et al., 2008). This polycyclic aromatic fraction forms at highest temperatures (Hammes et al., 2007) and is among the most stable components of charred biomass. It is also the fraction of black carbon that is found dissolved throughout the deep ocean (Dittmar et al., 2009). The limitation of our analytical window to polycyclic aromatic carbon implies that the global DBC flux calculations reported here are conservative underestimates and comprise a lower limit of the actual fluxes. I studied 174 freshwater samples in order to assess the average and variability of DBC and DOC concentrations on a globally representative scale (Fig. 5.1). Sampling was not intended to resolve seasonal or site-specific features, such as climate, elevation, or vegetation. Replicate samples from the same locations were averaged to avoid domination of the statistics by only a few sampling locations, thus reducing the overall dataset to 109 data points. Each data point represents a distinct main stem, tributary or wetland system from 
27 different river systems and wetlands. These samples include 15 of the largest rivers worldwide such as the Amazon, Congo and major Arctic Rivers provided by A. Vähätalo (University of Helsinki, Helsinki, Finland), A. Stubbins (Skidaway Institute of Oceanography, GA, USA), RGM. Spencer (Woods Hole Research Center, MA, USA). All reported DBC and DOC are original, except those from Apalachicola River (Florida; Dittmar et al., 2012a), Paraíba do Sul River (Brazil; Dittmar et al., 2012b) and Konza Prairie (Kansas; Ding et al., 2013) for which published concentrations were included in the data analysis.

\subsection{Methods}

\subsubsection{Water sample collection and analysis}

A total of 174 surface water samples were collected from 27 different river systems and wetlands (Fig. 5.1). Water samples were filtered immediately through precombusted glass fiber filters (Whatman GF/F, nominal pore size: $0.7 \mu \mathrm{m}$ ), acidified to $\mathrm{pH}=2$ with concentrated $\mathrm{HCl}$ (analytical quality) and stored at $4{ }^{\circ} \mathrm{C}$ until analysis and sample preparation in the home laboratories. Samples of ten major rivers (Congo River, Mekong River, Mississippi River, Parana River, St Lawrence River, Amazon River, Danube River, Ganges-Brahmaputra River, Yangtze River, Lena River), collected during peak flow, were filtered after a few weeks in transit to the laboratory. The DBC measurements of these samples were not compromised by the delay in filtration considering that only $3-4 \%$ of the biologically recalcitrant DOC was lost during the transport. After solid phase extraction of DBC, the benzenepolycarboxylic acids (BPCAs) method was used for DBC quantification (Dittmar, 2008). 
Two different digestion and detection systems were used: About half of the samples were oxidized under $160^{\circ} \mathrm{C}$ for 6 hours and quantified by a high performance liquid chromatography coupled with a photodiode array detector (HPLC-PDA) at Florida International University (FIU), while the other half of samples were oxidized under 170 ${ }^{\circ} \mathrm{C}$ for 9 hours and quantified by an ultrahigh performance liquid chromatography coupled with a photodiode array detector (UPLC-PDA) at the University of Oldenburg. The same standards were used in the two systems for comparison, and an inter-laboratory comparison on selected samples did not show differences between the two analytical systems (Fig. 5.2). DOC concentrations were measured through Shimadzu TOC analysers (Pt catalysed high temperature combustion) at both universities. DOC analyses were validated on a daily basis with deep-sea reference material.

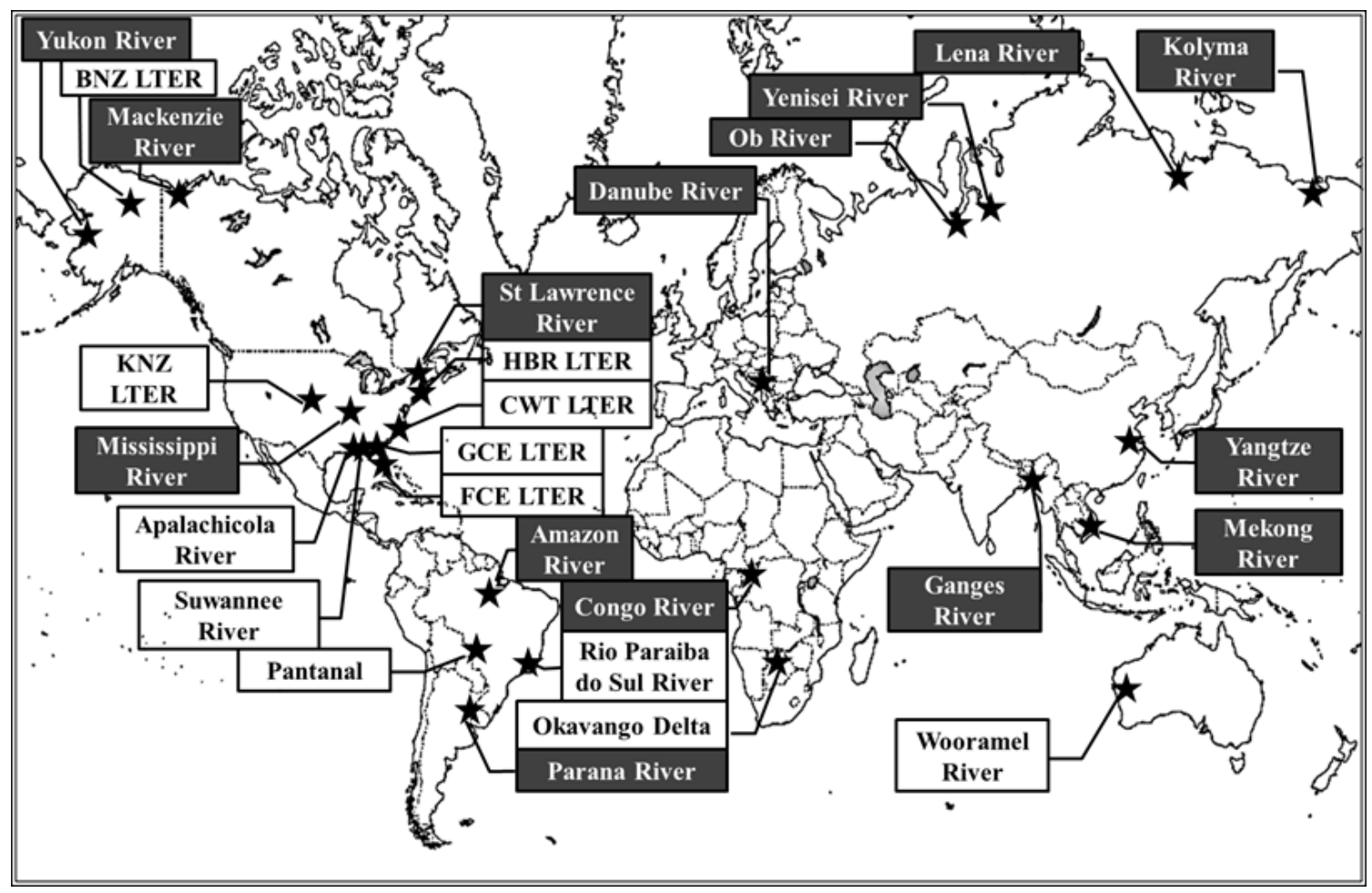

Figure 5.1 Map for global freshwater DBC sampling sites. Major world river sites are shown in grey boxes. White boxes show all other sites including minor to intermediate rivers, headwater streams and wetland associated streams. 


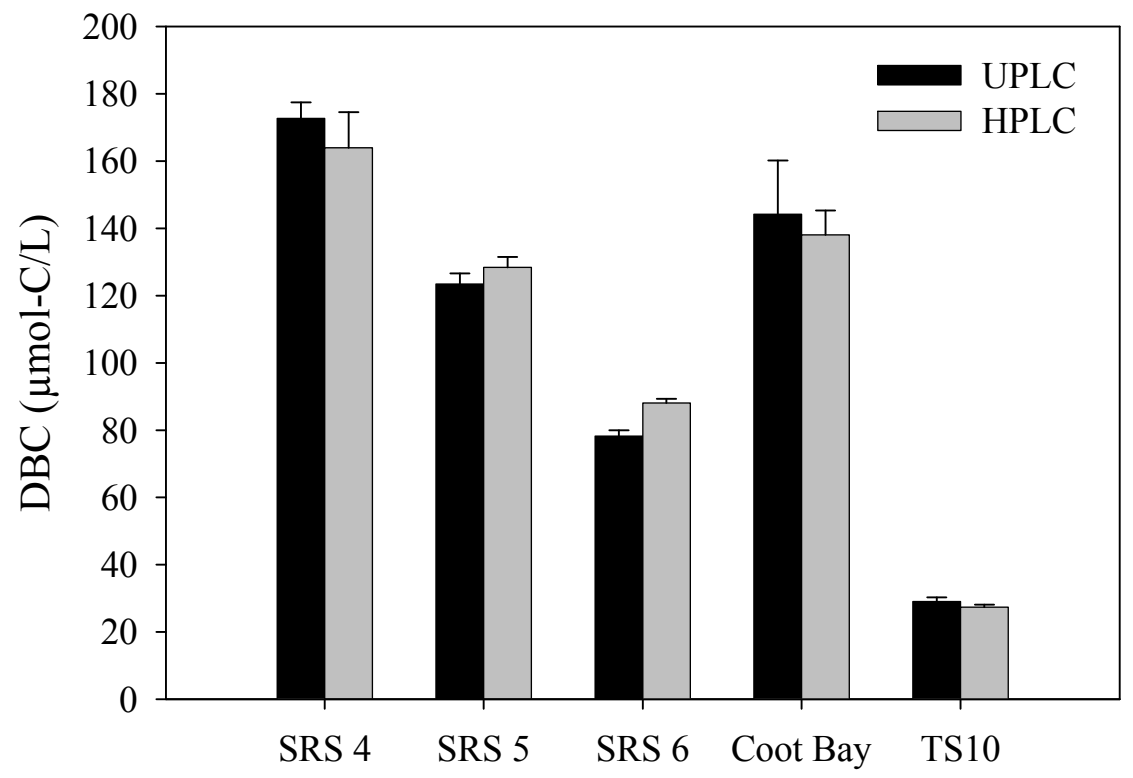

Figure 5.2 Inter-laboratory comparison of DBC quantification. Five selected samples were processed and analyzed in duplicates in both laboratories (error bars present deviation of the mean).

\subsubsection{Classification of water samples and statistical analysis}

Twenty (20) samples from Paraíba do Sul River, 9 samples from Suwannee River, 20 samples from Shark River slough and 20 samples from Taylor Slough in the Florida Coastal Everglades (FCE LTER) were each averaged separately before integrating them into the large database, because of the high sampling frequency at these locations. This reduced the total number of data points to 109 . The samples were further classified into two major categories as shown in Fig 5.1 and Fig. 5.3. The major world river sites, indicated in grey boxes in Fig. 5.1 and marked as black dots in Fig. 5.3, include the Rivers Congo, Mekong, Mississippi, Parana, St Lawrence, Amazon, Danube, Ganges-Brahmaputra, Yangtze, Kolyma, Lena, Mackenzie, Ob, Yenisei and Yukon. The remaining rivers are minor to intermediate rivers, headwater streams and wetland 
associated streams. These sites are depicted in white boxes in Fig. 5.1 and marked as grey dots in Fig. 5.3, and include samples from six different Long-Term Ecological Research (LTER) sites (BNZ-Bonanza Creek, CWT-Coweeta, FCE-Florida Coastal Everglades, GCE-Georgia Coastal Ecosystems, HBR-Hubbard Brook, KNZ-Konza Prairie), two river dominated estuaries (Apalachicola River and Suwannee River) in North America, two sites in South America (Pantanal wetland and Paraíba do Sul River), one site in Southern Africa (Okavango Delta) and one site in Western Australia (Wooramel River).

For additional statistical analysis, the samples were classified into five categories: major rivers (same as above), intermediate rivers, headwater streams, glacial streams and wetland influenced streams. Since it is unclear whether DOC or DBC is the independent variable, a quadratic regression instead of a normal linear regression analysis was applied. The quadratic regression analysis (DBC versus DOC concentrations) revealed that, within a 95\% confidence interval, the slopes for the different groups were indistinguishable among these various aquatic systems (Table 5.1). The only slope that differed was that of the streams fed by glaciers located on the Alaska Range, which contained the least terrigenous DOC and where $\mathrm{BC}$ has been suggested to be primarily of anthropogenic sources (Stubbins et al., 2012). All regression analyses were performed both with DOC as the determinant and via geometric mean regression. Both approaches yielded the same results within the confidence margins. All regressions presented in this paper passed a normality test (Shapiro-Wilk-test) on a significance level of $\mathrm{p}<0.0001$. 
Table 5.1 Regression analysis of DOC and DBC from different environments. (n: sample number; a: the slope of the quadratic regression equation; $b$ : the $y$-intercept for the quadratic regression equation; SD: standard deviation).

\begin{tabular}{|c|c|c|c|c|c|c|c|c|}
\hline \multirow{2}{*}{$\begin{array}{c}\text { Environmental } \\
\text { type }\end{array}$} & \multicolumn{8}{|c|}{ Quadratic regression } \\
\hline & & Normality & $\mathrm{n}$ & ouption & $\mathrm{a}-\mathrm{SD}$ & $\mathrm{a}+\mathrm{SD}$ & b-SD & $\mathrm{b}+\mathrm{SD}$ \\
\hline \multirow[t]{2}{*}{ Major rivers } & & Yes & 11 & $\mathrm{DBC}=0.108 \times \mathrm{DOC}-0.089$ & 0.102 & 0.114 & -0.107 & -0.070 \\
\hline & Arctic area & Yes & 26 & $\mathrm{DBC}=0.103 \times \mathrm{DOC}-0.039$ & 0.099 & 0.107 & -0.077 & 0.017 \\
\hline Intermediate & Peat influenced & Yes & 24 & $\mathrm{DBC}=0.125 \times \mathrm{DOC}+0.470$ & 0.111 & 0.141 & -0.393 & 0.540 \\
\hline \multirow[t]{2}{*}{ rivers } & Wetland influenced & Yes & 40 & $\mathrm{DBC}=0.106 \times \mathrm{DOC}-0.198$ & 0.094 & 0.120 & -0.297 & 0.078 \\
\hline & Other mid-size & No* & 16 & $\mathrm{DBC}=0.072 \times \mathrm{DOC}-0.052$ & 0.067 & 0.077 & -0.086 & -0.020 \\
\hline \multicolumn{9}{|l|}{ Headwater } \\
\hline streams & & Yes & 24 & $\mathrm{DBC}=0.096 \times \mathrm{DOC}-0.137$ & 0.072 & 0.141 & -0.115 & -0.107 \\
\hline Glacial streams & & Yes & 6 & $\mathrm{DBC}=0.055 \times \mathrm{DOC}-0.021$ & 0.048 & 0.064 & -0.025 & -0.017 \\
\hline
\end{tabular}

*Nonparametric regression analysis (Spearman test) was used, and $\mathrm{P}<0.0001$.

Two-tailed test was used for significant test, with $\alpha=0.05$. All P values of regression analysis were $<0.0001$. 


\subsubsection{Soil incubation experiment}

Three different types of surface soil were used in the soil leaching experiment. The PA2 soil sample was provided by Dr. Johannes Lehmann (Cornell University), collected from the remnants of a historic charcoal blast furnace (Greenwood Furnace) located in Huntingdon (PA, USA). The soil is very dark in color and contains large amounts of $\mathrm{BC}$ because it was collected from the place where workers temporally stored the charcoal (Cheng et al., 2008a). The BC deposited in soil is known to be produced during a relative short period around 1870s (Warren, 1973), and it is relative homogenous in structure due to its generation from specific hardwood sources and under uniform charring conditions. The process used was similar to $\mathrm{BC}$ produced by modern pyrolysis (Cheng et al., 2008b). This charcoal blast furnace site was abandoned in 1904, so the BC in soil is over 100 years old. The soil was determined to be high in C content $(520 \mathrm{~g} / \mathrm{kg})$ and low in $\mathrm{pH}$ value (4.8). The mass of sand, silt and clay per kilogram of soil was found to be $53 \%, 23 \%, 24 \%$ respectively. The rest of soil properties, mean annual temperature and mean annual precipitation information can be obtained from Cheng et al. (2008a, b).

The HBR soil sample was collected near the Hubbard Brook LTER site in New Hampshire (http://www.lternet.edu/sites/hbr/), dominated by a mixed hardwood forest ( $80 \%$ red spruce-balsam fir and $20 \%$ northern hard woods), and is pristine from human habitation or forest harvest. A big natural fire was reported in 1820, and no fires have been observed since then. As a result, the charcoal generated is $c a$. 190 years old. Pieces of charcoal were recovered by hand from a root crater resulting from a fallen tree. Soil depth was about 4-6 inches. The surface soil collected was brown in color and contained significant vegetative remains as leaf litter and roots. No other soil properties were 
measured or reported. The SRS2 surface soil from the Everglades was used to represent soils contain a mix of old and recently produced BC. Detailed in site ecology, vegetation and soil properties were described in Chapter III.

All three soil samples were air dried first and dried in the oven $\left(60^{\circ} \mathrm{C}\right)$ until the mass was constant. Soils were then homogenized by agate mortar and pestle and pass through a $1 \mathrm{~mm}$ sieve. About $0.8 \mathrm{~g}$ of PA2 and HBR and about $0.4 \mathrm{~g}$ of SRS2 soil samples were accurately weighted (precision: $0.1 \mathrm{mg}$ ) and transferred to pre-acid and based cleaned $250 \mathrm{~mL}$ brown Nalgene bottles. One hundred (100) $\mathrm{mL}$ of MilliQ water, with $0.05 \%(\mathrm{w} / \mathrm{v}) \mathrm{NaN}_{3}$ as microbial inhibitor, was added into each bottle for incubation. Triplicated samples at four time series points $(6 \mathrm{~h}, 24 \mathrm{~h}, 48 \mathrm{~h}$ and $72 \mathrm{~h})$ were prepared for each soil types. MilliQ water only was used as the time 0 sample (initial time point); additional triplicated MilliQ water was stored in Nalgene bottles and analyzed at the final time point $(72 \mathrm{~h})$ as the blank. After MilliQ was added, incubation bottles were tightly capped and shaken in an auto-shaker in room temperature $\left(\sim 23^{\circ} \mathrm{C}\right)$ before analyzed.

\subsubsection{Char incubation experiment}

An aged wood char sample (HBR char mentioned in section 5.3.3) was gently brushed to remove attached soil particles, pulverized and homogenized with an agate mortar and pestle, and sieved (US standard No. 18). For comparison, a fresh wood char reference sample was used, which is distributed by M. Schmidt and colleagues (University of Zurich, Switzerland, http://www.geo.unizh.ch/phys/bc). Both pulverized char samples were incubated both in DOC-free water and water containing $4 \mathrm{mg}^{-1}$ terrigenous DOC. The DOC used for incubation was collected from a freshwater canal in 
the Everglades (Hillsboro Canal), which has been characterized as mostly of terrestrial/soil origin (Yamashita et al., 2010). Prior to incubation, the water was filtered through Whatman GF/F glass fibre filters followed by GVWP membrane filters (Durapore ${ }^{\circledR}$, pore size: $0.22 \mu \mathrm{m}$ ) to remove microorganisms. About $40 \mathrm{mg}$ of aged or fresh char were accurately weighted (precision: $0.001 \mathrm{mg}$ ) and transferred to a $1 \mathrm{~L}$ brown bottle, with an addition of $100 \mathrm{~mL}$ pure water or DOC-enriched water. All bottles were stored at room temperature (about $23{ }^{\circ} \mathrm{C}$ ) and shaken by an auto-shaker. After 24 hours, the aqueous solutions were filtered through GF/F filters and analysed for DBC and DOC. DBC concentrations in the experiment were corrected for the DBC concentration of the added terrigenous DOC. Pure and DOC-enriched water without added char were used as blanks and controls. All incubations were performed in triplicate to determine methodological reproducibility. The short incubation experiment was intended to exclude any significant microbial activity derived dissolution, and instead was focused on the physical translocation caused by associations between BC and DOC.

\subsection{Results and Discussion}

\subsubsection{Estimation of global riverine DBC flux to the oceans}

The DBC concentrations varied strongly among the freshwater systems, ranging from $1.94 \times 10^{-3}$ to $2.77 \mathrm{mg} \mathrm{C} \mathrm{L}^{-1}$ (average \pm standard deviation: $0.48 \pm 0.55 \mathrm{mg} \mathrm{C} \mathrm{L}^{-1}$ ). DBC comprised from $0.1 \%$ to $17.5 \%$ of DOC (average \pm standard deviation: $7.1 \pm 3.6 \%$ ). Despite this apparent variability, DBC and DOC concentrations were highly significantly correlated $\left(\mathrm{R}^{2}=0.88, \mathrm{n}=109, \mathrm{p}<0.0001\right)$. Recent case studies that examined the relationship between DOC and DBC (Ding et al., 2013; Dittmar et al., 2012a) as well as 
soil BC and soil organic matter (Cusack et al., 2012; Glaser et al., 2003) are consistent with this observation. Because the abundance distribution for DOC and DBC concentrations were not normally distributed, I grouped the samples according to their DOC concentrations into 15 groups for further statistical analysis (Fig. 5.3). The slope of the resulting regression indicates that the global DOC pool contains $10.6 \% \mathrm{DBC}( \pm 0.7 \%$, on a $95 \%$ confidence level, $\mathrm{n}=15$ ). The intercept of the regression was not significantly different from zero. If the original un-grouped data are used for the regression, the resulting slope and intercept are statistically not different, but the estimates for the error margins (confidence intervals) are lower because of the higher number of data points ( $\mathrm{n}=$ 109). The major world river samples perfectly followed the regression of the whole data set, suggesting that "natural averaging" occurs in big watersheds.

I took advantage of this highly significant relationship between DBC and DOC concentrations to convert published data for global river loads of DOC into DBC loads.

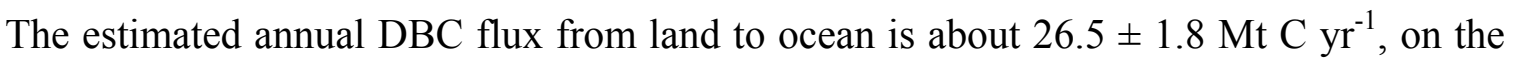
basis of a flux of riverine DOC of $250 \mathrm{Mt} \mathrm{C} \mathrm{yr}^{-1}$ (Hedges et al., 1997). The global DOC flux contains considerably large margins of uncertainty, but as refinements of global DOC flux estimates will become available, updates on global DBC fluxes can be easily made on the basis of the observed relationship between DOC and DBC. 


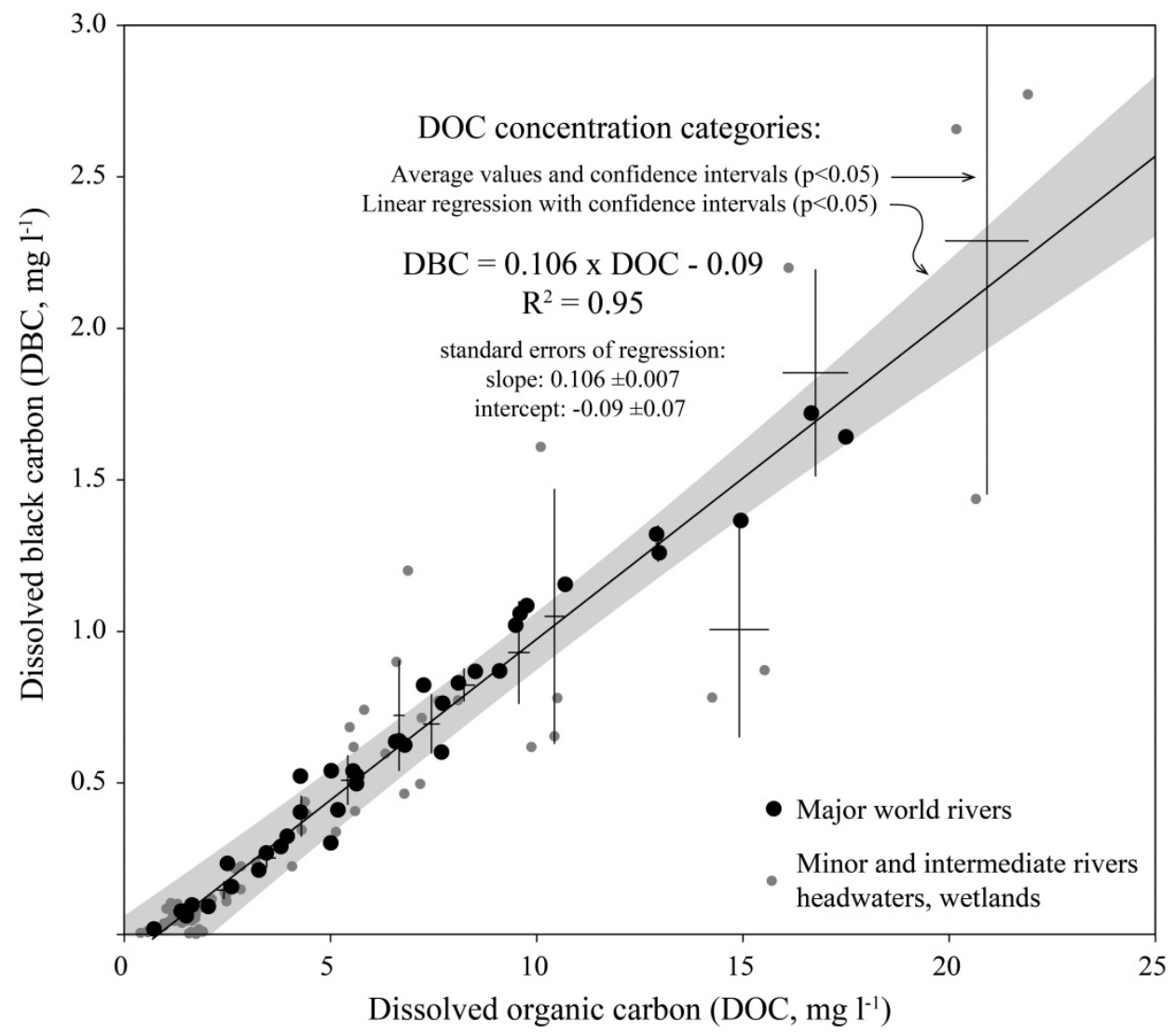

Figure 5.3 DOC versus DBC concentrations of global rivers. The regression parameters are for the average values of 15 DOC concentration categories (crosses). Regression on the raw data yield the same slope and intercept, but the confidence intervals are smaller because of the apparent larger number of samples (from Jaffé et al., 2013)

\subsubsection{Soil and char incubations: possible soil BC translocation mechanisms}

While an expectable wide range of variability among individual rivers was observed, the global relationship between DOC and DBC concentrations appears enigmatic on a first view. The linear correlation between DOC and DBC suggests that (a) the diagenetic processes driving the release of DOC and DBC are coupled, and/or (b) DOC is directly involved in the physical translocation process of soil BC to DBC. Here proofs of concept is provided for the proposed mechanisms by: (a) incubating three soil samples containing different char in water for 72 hours and determining the release of 
DOC and DBC from soil to the water column (testing the co-translocation hypothesis); (b) incubating two different wood chars in water for 72 hours and determining the release of DBC with and without the presence of riverine DOC (testing the DOC-assisted translocation hypothesis).

In the soil incubation, the HBR sample released the most DOC after 72 hours, which is almost as much as three times of that released from SRS2 sample, and PA2 sample released the least amount (Fig. 5.4a). As for the DBC, HBR soil released significant higher DBC amount than the other two soil samples, while PA2 soil and SRS2 sediment released similar amounts of DBC per gram of soil samples (Fig. 5.4b). DOC and DBC concentrations were strongly correlated during the whole incubation (Fig. 5.5), indicating a coupling in the release process of DOC and DBC. It is clear that over this short-term experiment, and under abiotic conditions $\left(\mathrm{NaN}_{3}\right)$, the release of both DOC and DBC is primarily related to a physical leaching process. However, for this to occur, soil $\mathrm{OM}$ and soil $\mathrm{BC}$ need to have previously undergone microbial oxidation and enhance their solubility to be translocated from the soil to the dissolved phase. In this respect, while the generation of DOC from soil OM is a well-established process (Chantigny, 2003 and references therein), both abiotic and biotic processes have been suggested to be crucial in the oxidation of soil BC (Cheng et al., 2006; Zimmerman, 2010). Soil fungi were found also to be able to oxidize, depolymerize and dissolve recalcitrant macromolecules in wood, coal and humic substances (Hockaday et al., 2007). For instant, non-lignolytic fungi can oxidize polyaromatic hydrocarbon (PAH), which shares a common structural elements with $\mathrm{BC}$, via extracellular dioxygenase (Hockaday et al., 2007); and ligninolytic basidiomycetes (wood and leaf-litter-decaying fungi) were found 
to have the ability to degrade low-rank coal (Hofrichter et al., 1999). As a result, at least portions of the soil $\mathrm{BC}$ can be degraded along with other non-BC soil $\mathrm{OM}$ to produce water-soluble molecules. At the meantime, charcoal can also increase DOC in soil pore water (Beesley \& Dickinson 2011; Lin et al., 2012), possible by promoting microorganism growth and the concurrent increase in enzyme production (Hamer et al., 2004).
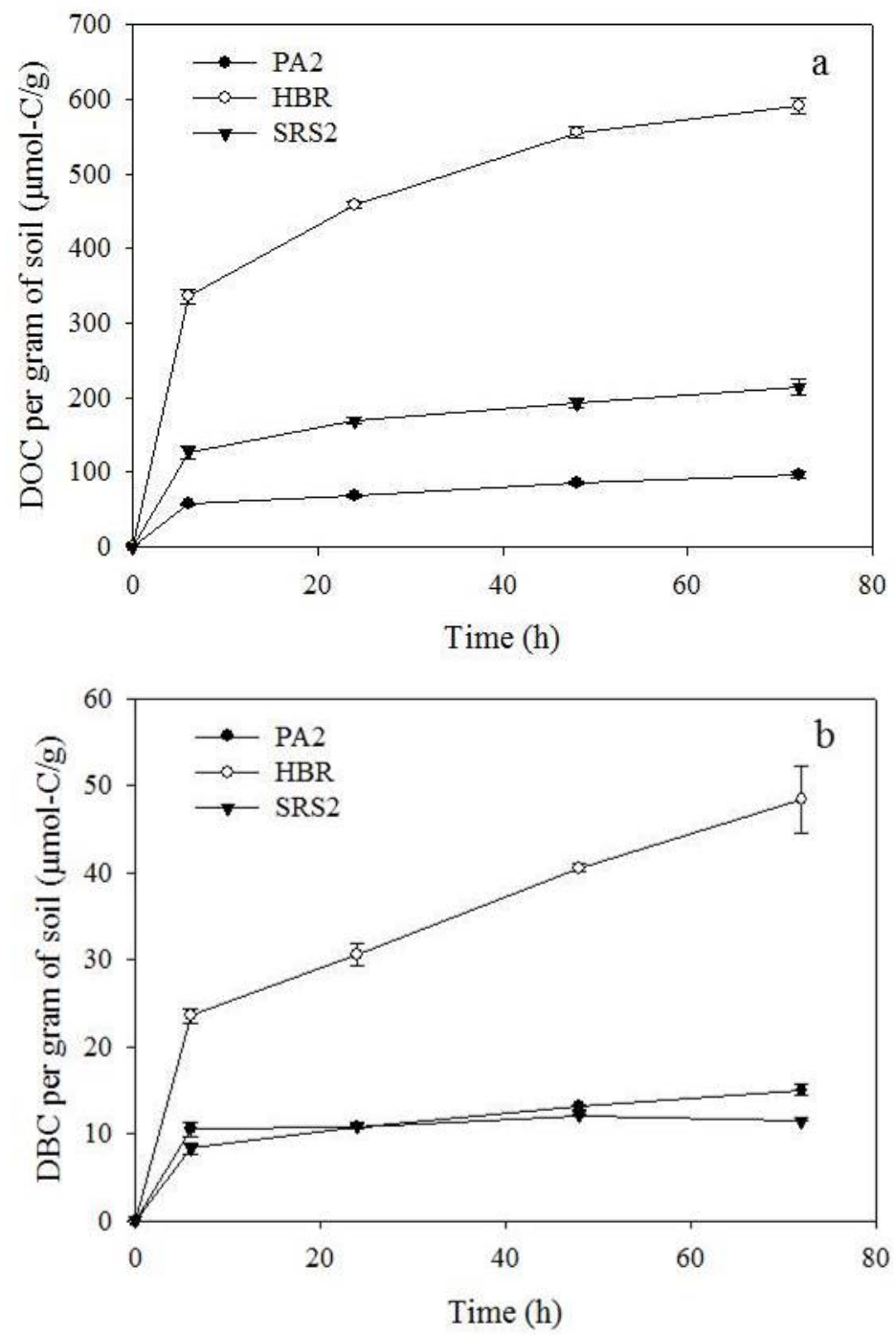

Figure 5.4 72-hour changes of DOC (a) and DBC (b) amounts released from unit gram of different types of soil. Time serious samples were collected at $0,6,24,48$ and 72 hour. 
The trend lines showing the release of DOC and DBC from soils in Fig.5.4 suggest that while the release patterns were similar, differences in the quantitative aspects imply that the factors controlling the storage and leaching processes are different between the samples. However, a clear linear relationship between leached DOC and DBC was also apparent, but the slopes of this relationship were highly variable between the soils samples. The change in DBC with increase in DOC was highest for the PA2 soil sample, which is probably a result of the unusually high $\mathrm{BC}$ content in the soils from historic charcoal blast furnace. This rate of increase (slope) was followed by that for the HBR sample, and was lowest for the SRS2 sample. The exact reasons for these differences are unclear at this time and likely dependent on the soil BC content, BC age and degree of oxidation, the characteristics of the soil mineral matrix, and the quality of the released DOC.

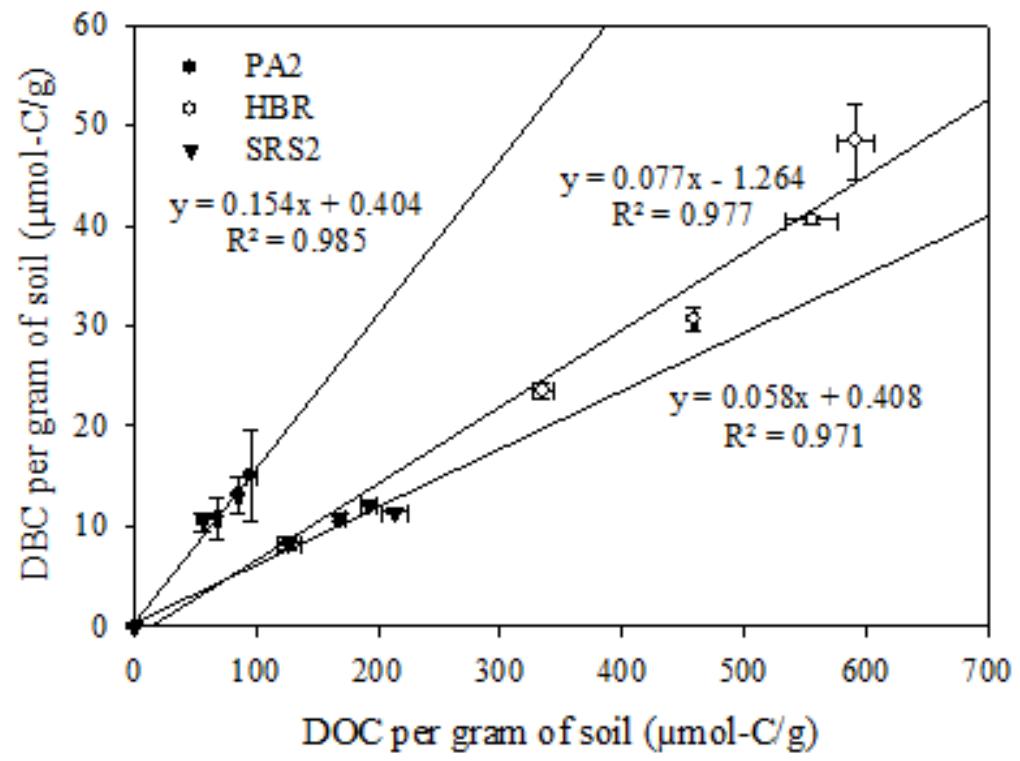

Figure 5.5 Correlation between DOC and DBC released from unit gram of different types of soil. 
In the char incubation, two wood chars vastly different in nature were tested. One was a fresh laboratory-generated reference material (http://www.geo.unizh.ch/phys/bc), the other aged natural wood char ( $c a .190$ years old). The whole incubation lasted for 72 hours, but the DOC and DBC amounts leached out from char reached the maximum during the first 24 hours. The slight decrease of DOC and DBC after 24 hours is probably due to a sorption of DOC and DBC on the plastic bottles, or on the char. The exact reason for the slight concentration reduction is unclear, but was insignificant to final results, and DOC and DBC concentrations at the $24 \mathrm{~h}$ were used (Fig. 5.6). The experiments performed in pure water resulted in the generation of DOC and DBC for both chars, but the aged char had a slightly enhanced yield. When both chars were incubated with natural DOC solution, the release of DOC and DBC was not affected for the fresh char, while the aged char released doubled DOC and three times more DBC with the addition of DOC solution than without (Fig. 5.6). In the presence of additional DOC, significantly more DOC and DBC was released from the aged compared to the young charcoal, which is consistent with a recent study (Abiven et al., 2011). These results indicate that not only the age (i.e., degree of weathering), but also the presence of DOC has an important effect on the release of DBC from charcoal. Although the molecular structures of DBC compounds are not completely known, they are commonly molecularly defined as condensed aromatic ring structures (Dittmar, 2008). These compounds are likely highly functionalized with hydroxyl and carboxylic groups on their periphery (Hockaday et al., 2007; Dittmar et al., 2006), conferring them some limited aqueous solubility. However, estimated log Kow values for two possible DBC structures (Chapter I, Fig. 1.4) estimated via an exposure assessment tool named EPI Suite ${ }^{\mathrm{TM}}$, provided online by the U.S. 
Environmental Protection Agency, were between 8 to 8.5 , indicating the water solubility of DBC is extremely low (on the order of ng per liter). Since dissolved organic matter (DOM) is amphiphilic complex, consisting of both hydrophilic and hydrophobic components, it is possible that $\mathrm{DBC}$ is strongly associated with the hydrophobic component of DOM. Such hydrophobic associations have been reported between DOM and hydrophobic organic pollutants, where the presence of DOM serves as a mobilizing agent for otherwise insoluble compounds (Kim and Kwon, 2010). Alternative, highly aromatic, polar BC oxidation products may also strongly bind to mineral surfaces in soil (Cusack et al., 2012; Hockaday et al., 2007) and only become mobilized by DOC via exchange reactions on the mineral surface. As such, molecular characteristics of the "mobilizing reagent" DOM may also be critical in this process. It is possible that DOC can mobilize those $\mathrm{BC}$ components that are not too strongly bound to mineral surfaces or that are too hydrophobic to be dissolved and can only be mobilized through interactions with DOC.

Charcoal has been described as having generically sorptive characteristics, not only for both polar and nonpolar compounds (e.g., humic acid extracts and sugars), but also for enzymes that are important in microbial processes in soils (Lehmann et al., 2011 and references therein). The release of DOC during the leaching experiments suggests that charcoal may generate DOC from the charcoal itself (as soluble non-DBC combustion products), and that this release, as the case of $\mathrm{DBC}$, is enhanced by the presence of natural DOC in the water. However, further detailed studies on this subject are needed to clarify the physical-chemical processes that control this carbon release. 

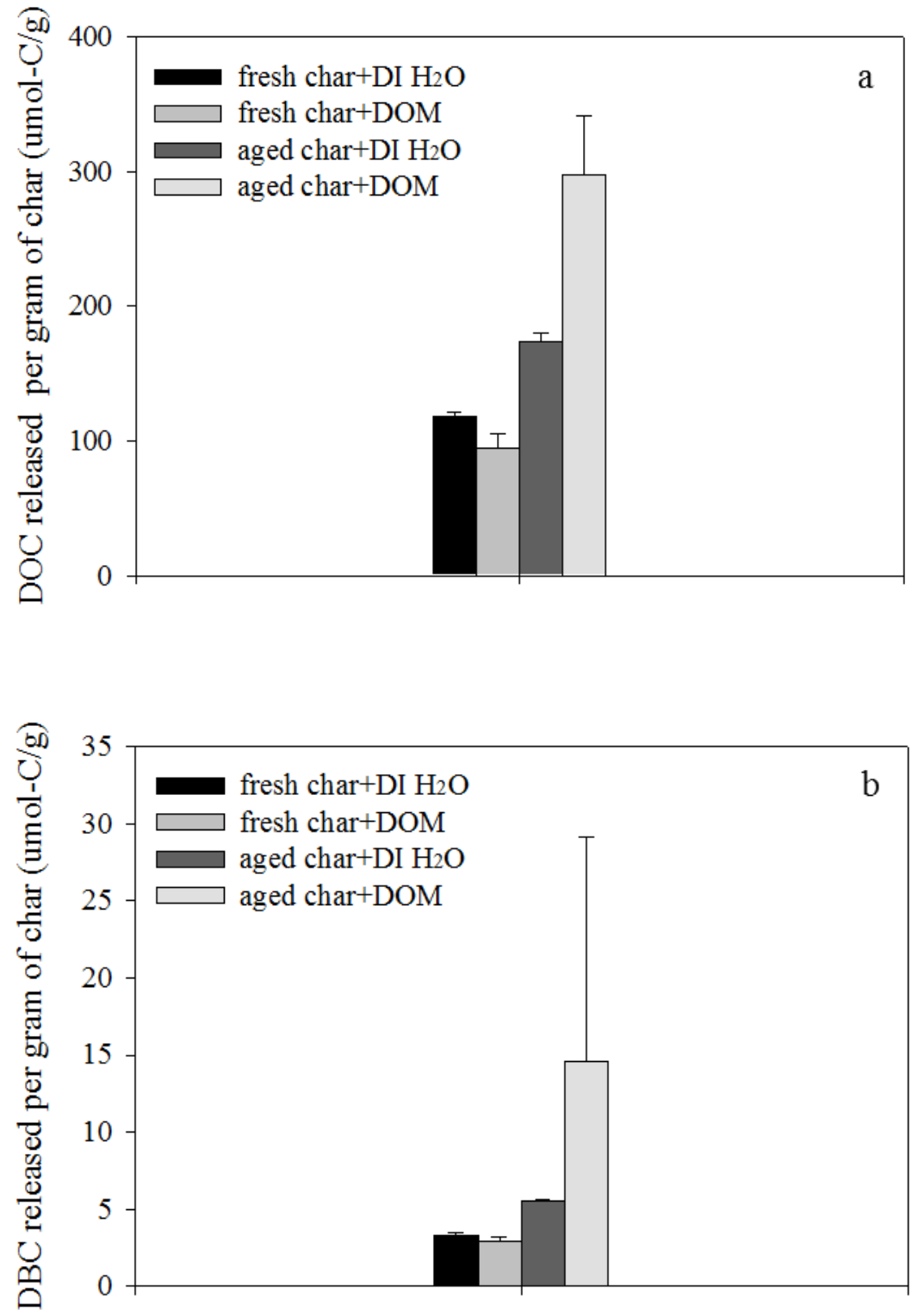

Figure 5.6 C-normalized DOC (a) and DBC (b) amounts of leachate per unit gram of fresh and aged chars incubated with DI $\mathrm{H}_{2} \mathrm{O}$ and DOM solution.

\subsection{Conclusions}

In conclusion, this study reports on the globally ubiquitous presence of $\mathrm{DBC}$ in freshwater environments. About $10 \%$ of riverine DOC is pyrogenic, based on which 26.5 $\pm 1.8 \mathrm{Mt}$ carbon of $\mathrm{DBC}$ enter the oceans every year as a critical component of the global 
carbon cycle. This flux comprises a significant fraction of the annual production of charcoal from vegetation fires (40-250 Mt carbon per year BC; Kuhlbusch and Crutzen, 1996). Although other soil processes such as microbial oxidation into $\mathrm{CO}_{2}$, erosion and re-burning also contribute to the losses of soil $\mathrm{BC}$, this study shows that the DOC pool is an important environmental intermediate for both transfer and storage of BC.

DOC and DBC fluxes in rivers appear strongly coupled. With continued global climate change, and predicted increments in DOC export from terrestrial environments to the oceans, the flux of DBC is expected to increment equivalently. While bio-char applications to soils have been proposed as an effective means of carbon sequestration to off-set a significant portion of anthropogenic $\mathrm{CO}_{2}$ emissions (Lehmann et al., 2006), this activity is likely to further enhance the translocation and export of $\mathrm{DBC}$ to marine systems. The environmental consequences of such notable DBC exports on marine communities are presently unknown, but may be reflected in the reduction of DOC bioavailability and associated effects on microbial loop dynamics and aquatic food webs. The results suggest that applying existing knowledge on DOC production, storage, and movement in soils to ensure that bio-char applications are implemented sustainably and managed in ways to minimize riverine DBC fluxes. 


\section{REFERENCES}

Abiven S, Hengartner P, Schneider MPW, Singh N, Schmidt MWI (2011) Pyrogenic carbon soluble fraction is larger and more aromatic in aged charcoal than in fresh charcoal. Soil Biology \& Biochemistry 43(7): 1615-1617

Baldock JA, Smernik RJ (2002) Chemical composition and bioavailability of thermally, altered Pinus resinosa (Red Pine) wood. Organic Geochemistry 33(9): 1093-1109

Beesley L, Dickinson N (2011) Carbon and trace element fluxes in the pore water of an urban soil following greenwaste compost, woody and biochar amendments, inoculated with the earthworm Lumbricus terrestris. Soil Biology \& Biochemistry 43(1): 188-196

Chantigny MH (2003) Dissolved and water-extractable organic matter in soils: a review on the influence of land use and mangement practices. Geoderma 113(3-4): 357-380

Cheng CH, Lehmann J, Engelhard MH (2008a) Natural oxidation of black carbon in soils: Changes in molecular form and surface charge along a climosequence. Geochimica Et Cosmochimica Acta 72(6): 1598-1610

Cheng CH, Lehmann J, Thies JE, Burton SD (2008b) Stability of black carbon in soils across a climatic gradient. Journal of Geophysical Research-Biogeosciences 113: G02027

Cheng CH, Lehmann J, Thies JE, Burton SD, Engelhard MH (2006) Oxidation of black carbon by biotic and abiotic processes. Organic Geochemistry 37(11): 1477-1488

Cusack D, Chadwick OA, Hockaday WC, Vitousek PM (2012) Mineralogical controls on soil black carbon preservation. Global Biogeochemical Cycles 26: GB2019

Czimczik CI, Masiello CA (2007) Controls on black carbon storage in soils. Global Biogeochemical Cycle 21: GB003005

Czimczik CI, Preston CM, Schmidt MWI, Schulze ED (2003) How surface fire in Siberian Scots pine forests affects soil organic carbon in the forest floor: Stocks, molecular structure, and conversion to black carbon (charcoal). Global Biogeochemical Cycles 17(1): GB1956

Ding Y, Yamashita Y, Dodds W, Jaffé R (2013) Dissolved black carbon in grassland streams: Is there an effect of recent fire history? Chemosphere 90(1): 2557-2562

Dittmar T (2008) The molecular level determination of black carbon in marine dissolved organic matter. Organic Geochemistry 39(4): 396-407

Dittmar T, Koch BP (2006) Thermogenic organic matter dissolved in the abyssal ocean. Marine Chemistry 102(3-4): 208-217 
Dittmar T, Koch BP, Hertkorn N, Kattner G (2008) A simple and efficient method for the solid-phase extraction of dissolved organic matter (SPE-DOM) from seawater. Limnology and Oceanography: Methods 6: 230-235

Dittmar T, Paeng J (2009) A heat-induced molecular signature in marine dissolved organic matter. Nature Geoscience 2(3): 175-179

Dittmar T, Paeng J, Gihring TM, Suryaputra IGNA, Huettel M (2012a) Discharge of dissolved black carbon from a fire-affected intertidal system. Limonology and Oceanography 57(4): 1171-1181

Dittmar T, Rezende CE, Manecki M, Niggemann J, Ovalle ARC, Stubbins A, Bernardes MC (2012b) Continuous flux of dissolved black carbon from a vanished tropical forest biome. Nature Geoscience 5(9): 618-622

Glaser B, Amelung W (2003) Pyrogenic carbon in native grassland soils along a climosequence in North America. Global Biogeochemistry Cycle 17: gb002019

Goldberg ED (1985) Black carbon in the environment: Properties and distribution. John Wiley \& Sons, New York

Hamer U, Marschner B, Brodowski S, Amelung W (2004) Interactive priming of black carbon and glucose mineralisation. Organic Geochemistry 35(7): 823-830

Hammes K, Schmidt MWI, Smernik RJ, Currie LA, Ball WP, Nguyen TH, Louchouarn P, Houel S, Gustafsson O, Elmquist M, Cornelissen G, Skjemstad JO, Masiello CA, Song J, Peng P, Mitra S, Dunn JC, Hatcher PG, Hockaday WC, Smith DM, Hartkopf-Froeder C, Boehmer A, Luer B, Huebert BJ, Amelung W, Brodowski S, Huang L, Zhang W, Gschwend PM, Flores-Cervantes DX, Largeau C, Rouzaud JN, Rumpel C, Guggenberger G, Kaiser K, Rodionov A, Gonzalez-Vila FJ, Gonzalez-Perez JA, de la Rosa JM, Manning DAC, Lopez-Capel E, Ding L (2007) Comparison of quantification methods to measure fire-derived (black/elemental) carbon in soils and sediments using reference materials from soil, water, sediment and the atmosphere. Global Biogeochemical Cycles 21(3): GB3016

Hedges JI, Kei RG, Benner R (1997) What happens to terrestrial organic matter in the ocean? Organic Geochemistry 27(5-6): 195-212

Hockaday WC, Grannas AM, Kim S, Hatcher PG (2007) The transformation and mobility of charcoal in a fire-impacted watershed. Geochimica et Cosmochimica Acta 71(14): 3432-3445

Hofrichter M, Ziegenhagen D, Sorge S, Ullrich R, Bublitz F, Fritsche W (1999) Degradation of lignite (low-rank coal) by ligninolytic basidiomycetes and their manganese peroxidase system. Applied Microbiology and Biotechnology 52(1): 78-84 
Kim SJ, Kwon JH (2010) Determination of Partition Coefficients for Selected PAHs between Water and Dissolved Organic Matter. Clean-Soil Air Water 38(9): 797-802

Kuhlbusch TAJ, Crutzen PJ (1996) Black Carbon, the Global Carbon Cycle, and Atmospheric Carbon Dioxide. In: Levine JS (ed.) Biomass burning and Global Change. MIT Press, Campbridge, MA. p 160-169

Lehmann J, Gaunt J, Rondon M (2006) Bio-char sequestration in terrestrial ecosystems-a review. Mitigation and Adaption Strategies for Global Changes. 11: 403-427

Lehmann J, Rillig MC, Thies J, Masiello CA, Hockaday WC, Crowley D (2011) Biochar effects on soil biota-A review. Soil Biology and Biochemistry 43(9): 1812-1836

Lin Y, Munroe P, Joseph S, Henderson R, Ziolkowski A (2012) Water extractable organic carbon in untreated and chemical treated biochars. Chemosphere 87(2): 151-157

Mannino A, Harvey HR (2004) Black carbon in estuarine and coastal ocean dissolved organic matter. Limnology and Oceanography 49(3): 735-740

Masiello CA (2004) New directions in black carbon organic geochemistry. Marine Chemistry 92(1-4): 201-213

Masiello CA, Druffel ERM (1998) Black carbon in deep-sea sediments. Science 280(5371): 1911-1913

Masiello CA, Druffel ERM (2003) Organic and black carbon C-13 and C-14 through the Santa Monica Basin sediment oxic-anoxic transition. Geophysical Research Letters 30(4): 1185

Mitra S, Bianchi TS, McKee BA, Sutula M (2002) Black carbon from the Mississippi River: Quantities, sources, and potential implications for the global carbon cycle. Environmental Science \& Technology 36(11): 2296-2302

Nguyen BT, Lehmann J, Hockaday WC, Joseph S, Masiello CA (2010) Temperature Sensitivity of Black Carbon Decomposition and Oxidation. Environmental Science \& Technology 44(9): 3324-3331

Ohlson M, Dahlberg B, Okland T, Brown KJ, Halvorsen R (2009) The charcoal carbon pool in boreal forest soils. Nature Geoscience 2(10): 692-695

Schmidt MWI (2004) Biogeochemistry: Carbon budget in the black. Nature 427(6972): 305-307 
Schneider MPW, Hilf M, Vogt UF, Schmidt MWI (2010) The benzene polycarboxylic acid (BPCA) pattern of wood pyrolyzed between 200 degrees C and 1000 degrees C. Organic Geochemistry 41(10): 1082-1088

Singh N, Abiven S, Torn MS, Schmidt MWI (2012) Fire-derived organic carbon in soil turns over on a centennial scale. Biogeosciences 9(8): 2847-25857

Skjemstad JO, Reicosky DC, Wilts AR, McGowan JA (2002) Charcoal carbon in US agricultural soils. Soil Science Society of America Journal 66(4): 1249-1255

Stubbins A, Hood E, Raymond PA, Aiken GR, Sleighter RL, Hernes PJ, Butman D, Hatcher PG, Striegl RG, Schuster P, Abdulla HAN, Vermilyea AW, Scott DT, Spencer RGM (2012) Anthropogenic aerosols as a source of ancient dissolved organic matter in glaciers. Nature Geoscience 5(3): 198-201

Warren K (1973) The American Steel Industry, 1850-1970. Oxford University Press, London

Yamashita Y, Scinto LJ, Maie N, Jaffé R (2010) Dissolved Organic Matter Characteristics Across a Subtropical Wetland's Landscape: Application of Optical Properties in the Assessment of Environmental Dynamics. Ecosystems 13(7): 1006-1019

Zimmerman AR (2010) Abiotic and Microbial Oxidation of Laboratory-Produced Black Carbon (Biochar). Environmental Science \& Technology 44(4): 1295-1301 
Chapter VI

DISSOLVED BLACK NITROGEN (DBN) IN FRESHWATER ENVIRONMENTS:

SOURCE AND LAND TO OCEAN FLUX ASSESSMENT 


\subsection{Abstract}

Biomass burning results in the formation and accumulation of pyrogenic products such as black carbon and black nitrogen in soils. The ubiquitous presence of pyrogenic products in natural dissolved organic matter (DOM) and potential implications in global carbon cycling have recently been reported. However, little is known about the environmental dynamics or the importance in the global nitrogen cycle of dissolved black (heterocyclic aromatic) nitrogen (DBN). Here I report the coupling between DBN and dissolved black carbon (DBC) in ultrafiltered DOM from headwater streams, suggesting similar sources, and show that DOC plays an important role in the translocation of soil$\mathrm{BN}$ to the dissolved phase. I also propose a global estimate of riverine DBN flux to the oceans $\left(0.7 \mathrm{Mt} \mathrm{N} \mathrm{yr}^{-1}\right)$. This portion of the dissolved organic nitrogen pool, which is likely recalcitrant, may affect the biogeochemical cycling of $\mathrm{N}$ and potentially the microbial community structure in aquatic environments.

\subsection{Introduction}

Nitrogen $(\mathrm{N})$ is one of the most important elements controlling the cycling of organic matter in the biosphere (Paul \& Clark, 1996; Porter, 1975). The concentrations of both inorganic and organic $\mathrm{N}$ are closely related to biological productivity in terrestrial and aquatic environments (Knicker, 2004), and dissolved organic nitrogen (DON) can make up a major portion of the total $\mathrm{N}$ pool in many aquatic systems (Boyer et al., 1997; Davis et al., 2001; Jeff et al., 2012; Krupka, 1989; Wangersky, 1993). While DON is critical in fueling the microbial loop (Amon et al., 2001; Boyer et al., 1997; Parker, 2005), and a major component of it is in the presumably bio-labile amide- $\mathrm{N}$ form (Maie 
et al., 2006b and references therein), DON has also been reported as being biologically refractory in the deep ocean (Aluwihare et al., 2005). N-stabilization through soil-organic matter interaction (conventionally believed as "humification processes"; Schmidt et al., 2011) is one important pathway to stabilize organic $\mathrm{N}$ in soils and sediments, and this process is controlled by diverse environmental factors and biogeochemical processes (Knicker, 2004 and references therein). The result of such processes is the formation of carboxyl-containing macromolecular $\mathrm{N}$ products, with $80-90 \%$ of the detected $\mathrm{N}$ assigned to amide/peptide structures (Knicker \& Ludemann, 1995).

Biomass burning has been suggested as another important contributor to potentially refractory organic-N in soils (Almendros et al., 2003; Knicker et al., 1996). Since the frequency of wild-fires worldwide has been increasing as a consequence of climate change (Kasischke \& Turetsky, 2006), the effects of fire on soil organic matter are of particular interest to many soil scientists. Previous ${ }^{15} \mathrm{~N}$ NMR spectroscopic studies showed that pyromorphic soil humus after fires contained rearranged macromolecules that were highly aromatic (Almendros et al., 2003), where nitrogen was mostly in the form of heterocyclic aromatic N (Knicker et al., 1996). Such heterocyclic aromatic N, or "black nitrogen" (BN), in charred residues was shown to be derived from heat-induced transformations of peptides rather than selective enrichment of heat stable pyrrolic-N (Almendros et al., 2003). In fact, the presence of heterocyclic aromatic $\mathrm{N}$ was reported to be unique to fire influenced soils (Knicker et al., 2005) and could influence the lability of SON.

Recently, X-ray photoelectron spectroscopy (XPS) has been applied to the identification of BN in soil humic acids (Abe and Watanabe, 2004; Abe et al., 2005). 
This non-destructive and semi-quantitative technique can differentiate $\mathrm{N}$ species into three groups based on the chemical shift of the binding energy: aromatic $\mathrm{N}$ (including pyridine, imine, and aniline derivatives), peptide/amide $\mathrm{N}$ (including pyrrole, secondary and tertiary amines), and primary amine $\mathrm{N}$ (Abe and Watanabe, 2004). Compared to ${ }^{15} \mathrm{~N}$ NMR, Abe et al. (2005) reported a strong similarity between the percentages of the XPS detected aromatic $\mathrm{N}$ group and ${ }^{15} \mathrm{~N}$ NMR detected heterocyclic $\mathrm{N}$ group for eight soil humic acid samples. The results suggested that the abundance of aniline and imine $\mathrm{N}$ compounds were insignificant in the aromatic $\mathrm{N}$ group detected by XPS and that the majority of $\mathrm{N}$ species in this group consisted of heterocyclic aromatic $\mathrm{N}$ (Abe et al., 2005). The only natural existing amino acid included in the same aromatic $\mathrm{N}$ group is histidine (Abe and Watanabe, 2004), but considering its natural abundance in soil and water, interferences should be subtle. Although other aromatic N, such as imidazole or indole fragments in humic substances, may also contribute to the aromatic $\mathrm{N}$ pool, humification processes produced $\mathrm{N}$-compounds are usually in form of peptide/amide $\mathrm{N}$ (Knicker \& Ludemann, 1995). Thus most $\mathrm{N}$ species in this group should sill be heterocyclic aromatic $\mathrm{N}$ which are generated under thermal alteration (Knicker et al., 1996). Considering the above facts, while the quantification of BN by XPS might be slightly overestimated, it should still reflect an appropriate estimate.

Heterocyclic aromatic $\mathrm{N}$ was also detected in dissolved organic matter (DOM) by XPS, and suggested to be responsible in reducing the bioavailability of DON in wetlands (Maie et al., 2006b). These authors reported a significant portion (as high as 25\%) of heterocyclic aromatic $\mathrm{N}$ in DON of the Florida Coastal Everglades (FCE) system, an oligotrophic coastal wetland with frequent seasonal fires. Other aquatic systems, in 
particular headwater streams across a wide range of climatic regions, also showed the presence of dissolved heterocyclic aromatic N, or "dissolved black nitrogen" (DBN) in DOM (Jaffé et al., 2012), suggesting that DBN, similarly to dissolved black carbon (DBC), may be ubiquitous in the aquatic environment. Since DOM has also been reported to contain DBC, a well-known combustion-derived product (e.g., Ding et al., 2013; Dittmar \& Koch, 2006; Dittmar \& Paeng, 2009), it was proposed that DBN may also be derived from fires (Jaffé et al., 2012; Maie et al., 2006b). In this study, DOC, DBN and DBC levels in a set of ultrafiltered samples from diverse aquatic environments were compared to test this hypothesis, and to provide an estimate of the global DBN export from land to the oceans.

\subsection{Materials and methods}

\subsubsection{Sampling locations}

Ultrafiltered DOM (UDOM) samples collected from different biomes from a wide climatic range in North America and previously characterized on the molecular level were used in this study (Fig. 6.1). Detailed sampling locations, preparation of UDOM samples, as well as molecular characteristics, were described in Jaffé et al. (2012). Sites include the tundra (ARC), taiga (BNZ), sub-Alpine (NWT), grassland prairie (KNZ), Eastern deciduous forest (CWT) and tropical rainforest (LUQ) biomes.

Six bulk DOM samples from a subtropical wetland ecosystem (Florida Coastal Everglades, FCE) where high DBN abundance had been previously reported (Maie et al., 2006) were collected along a transect from freshwater marsh (SRS2), through the mangrove transition ecotone (Coot Bay, SRS4 and 5), to the coastal mangrove estuary 
(SRS6), and a costal bay (Florida Bay). Detailed site information of SRS2, 4-6 and Florida Bay are described in Childers et al. (2006) and on the FCE-LTER website (http://fcelter.fiu.edu). Coot Bay is a brackish enclosed bay in the mangrove fringe of southern Everglades National Park.

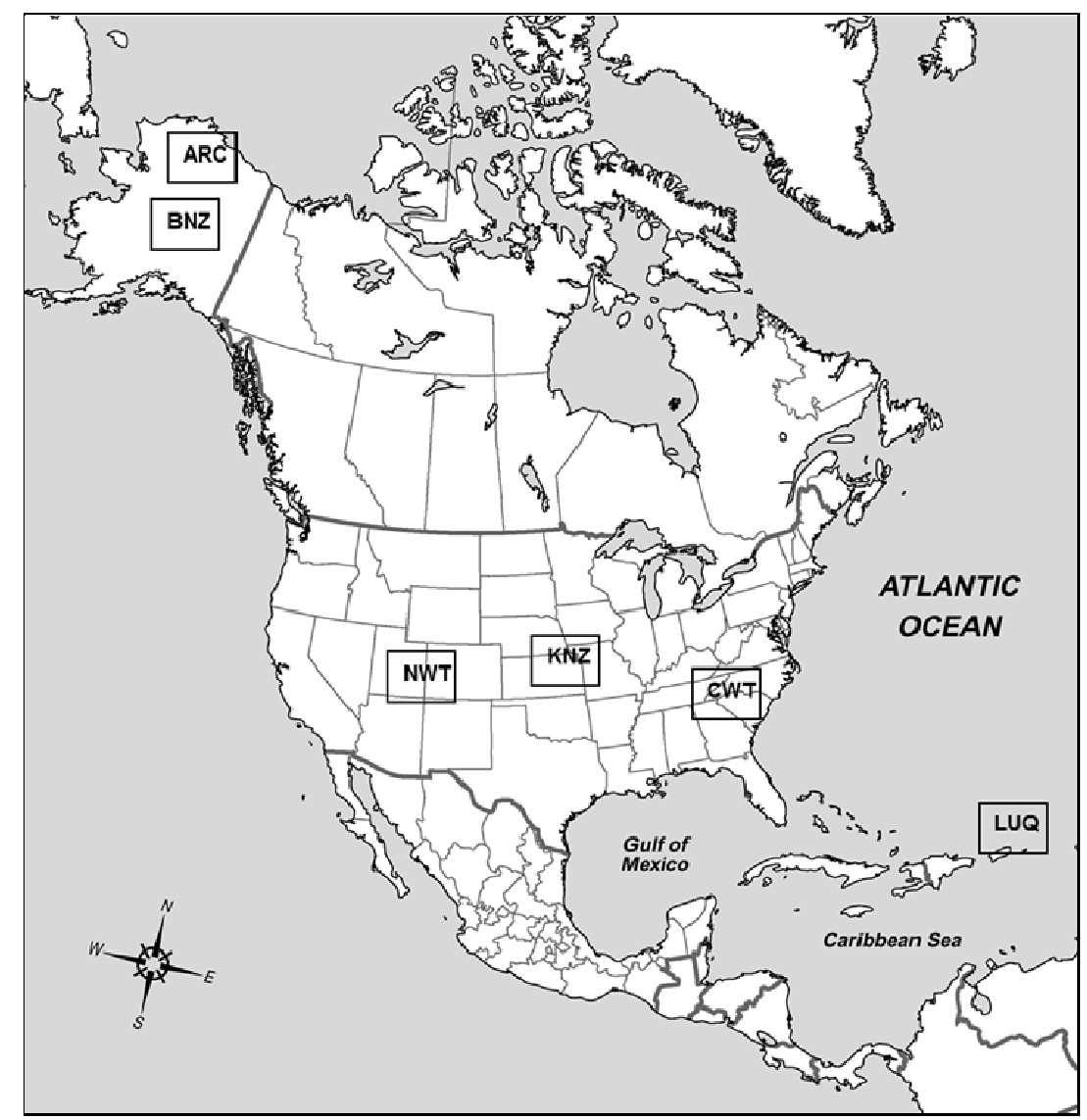

Figure 6.1 A map shows the UDOM samples collected from six different LTER sites across climatic regions of North America (from Jaffé et al., 2012).

\subsubsection{Sample preparation}

Sample preparation of UDOM ( $>1 \mathrm{kDa})$ samples have been described by Jaffé et al. (2012). For the bulk samples from the FCE, 2.5 L of surface water from six FCE sites were collected in acid cleaned glass bottles, stored on ice before transferring to the lab 
and filtered immediately through pre-combusted GF/F filters (pore size: $0.7 \mu \mathrm{m}$ ). About $60 \mathrm{~mL}$ of filtered samples were saved for the dissolved organic carbon (DOC) analysis, while the remaining was acidified to $\mathrm{pH} 2$ and extracted by solid phase extraction (SPE) via Varian Bond Elut PPL cartridges, and quantitatively eluted with MeOH (Ding et al., 2013; Dittmar et al., 2008).

\subsubsection{DBN analysis: X-ray photoelectron spectroscopy}

The percentage of ultrafiltered DBN (\%UDBN) was determined by XPS (Abe \& Watanabe, 2004). The XPS-N1s spectra (ESCA-3300, Shimadzu, Japan) were deconvoluted into three major $\mathrm{N}$ species according to different binding energies as aromatic $\mathrm{N}$, peptide/amide $\mathrm{N}$, and primary amine $\mathrm{N}$. The aromatic $\mathrm{N}$ group, which has been described in the introduction as primarily consisting of heterocyclic aromatic $\mathrm{N}$, is considered here as an estimate of UDBN group. The area ratio between aromatic $\mathrm{N}$ peak and the total area were defined as \%UDBN (Fig. 6.2). UDBN concentrations were determined on the basis of \%UDBN and UDON values which were derived from reported $\mathrm{C} / \mathrm{N}$ ratios and UDOC concentrations (Jaffé et al., 2012). For the bulk FCE samples, PPL extracts were evaporated to dryness under a gentle stream of high purity nitrogen, re-dissolved in carbon-free deionized water, frozen, freeze dried and ground. The freeze-dried PPL samples were analyzed similarly as the UDOM samples (Jaffé et al., 2012), but only \%DBN data were obtained. 


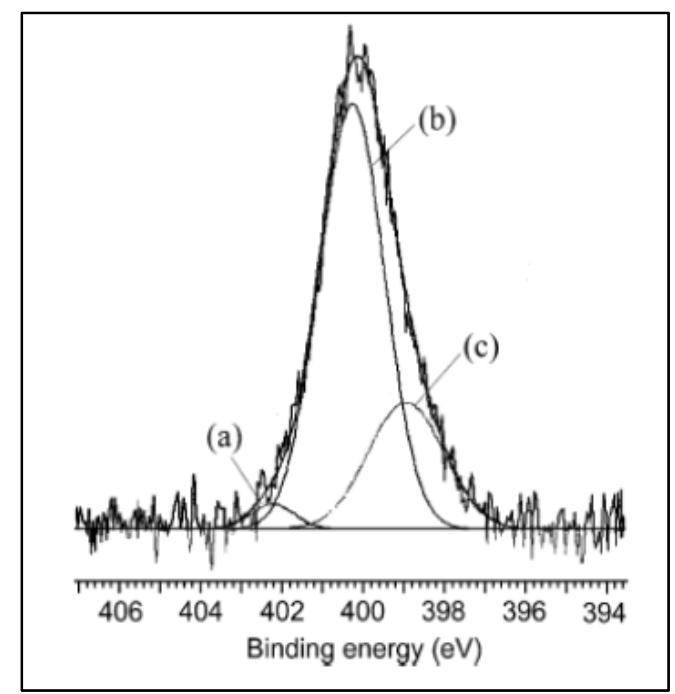

Figure 6.2 An example of a XPS-N1s spectrum: (a) primary amine $\mathrm{N}$ group, (b) peptide/amide $\mathrm{N}$ group, and (c) aromatic $\mathrm{N}$ group (from Maie et al., 2006b). The majority of $\mathrm{N}$ species in aromatic $\mathrm{N}$ group is heterocyclic aromatic $\mathrm{N}$.

\subsubsection{DBC analysis: BPCA method}

The ultrafiltered DBC (UDBC) and bulk DBC, structurally defined as the condensed polyaromatic moieties in UDOM, were determined by the benzenepolycarboxylic acid (BPCA) method, a sensitive and unambiguous technique developed by Dittmar (2008) and optimized by Ding et al. (2013). Aliquots of dried UDOM powers, or $\mathrm{MeOH}$ elute of DOM, were quantitatively transferred into $2 \mathrm{~mL}$ glass ampules, and dissolved in $0.5 \mathrm{~mL}$ concentrated $\mathrm{HNO}_{3}(65 \%)$. MeOH elutents were dried under $\mathrm{N}_{2}$ gas before applying the concentrated acid. The ampules were sealed and slowly heated to $160{ }^{\circ} \mathrm{C}$ and kept for 6 hours in a temperature programmed GC oven (Ding et al., 2013). After digestion, the nitric acid was evaporated in a sand bath under $\mathrm{N}_{2}$ stream and the oxidation products were re-dissolved in a quaternary amine buffer, followed by separation and quantification via a $\mathrm{C}_{18}$ column equipped in a high-performance liquid chromatography (HPLC) system (Dittmar et al., 2008). 


\subsubsection{DOC analysis}

DOC was determined on a Shimadzu TOC-5000 analyzer (Shimadzu Scientific Instruments, Columbia, USA) equipped with a platinum catalyst and an infrared detector. About $0.1 \mathrm{mg}$ powdered UDOM was accurately weighed (precision: $0.001 \mathrm{mg}$ ) and redissolved in $4 \mathrm{~mL}$ carbon-free Milli-Q water (Millipore) before the DOC analysis. Bulk water DOM and UDOM solutions were acidified with $0.01 \mathrm{~N} \mathrm{HCl}$ and sparged with carbon-free compressed air to remove inorganic carbon content before injecting into the TOC analyzer.

\subsubsection{Statistical analysis}

All data sets passed the normality test prior to the regression analyses performed by SPSS 17.0.

\subsection{Results and discussion}

\subsubsection{Potential source for $D B N$}

Values for bulk DOC, UDBC and UDBN concentrations ranged from 0.77 to 4.01 $\mathrm{mg} \mathrm{C} \mathrm{L}{ }^{-1}, 2.3 \times 10^{-3}$ to $4.9 \times 10^{-2} \mathrm{mg} \mathrm{C} \mathrm{L}{ }^{-1}$, and $1.7 \times 10^{-3}$ to $1.1 \times 10^{-2} \mathrm{mg} \mathrm{N} \mathrm{L}^{-1}$, respectively. In general, sites with higher bulk DOC (UDOC) concentrations also have higher $\% \mathrm{DBN}(\% \mathrm{UDBN})$ and $\% \mathrm{DBC}(\% \mathrm{UDBC})$. In fact, \%DBN (\%UDBN) and $\% \mathrm{DBC}$ (\%UDBC) were statistically correlated within group (Fig. 6.3; $\mathrm{P}=0.016, \mathrm{n}=6$ for UDOM group; $\mathrm{P}=0.036, \mathrm{n}=6$ for DOM group). However, a significant difference in the slope of this correlation between the UDOM and bulk DOM samples was observed, indicating DBN and DBC in different DOM fractions have different molecular weight distributions. 
While these differences are most likely the result of methodological differences during sample preparation, samples from different locations are compared in this dataset thus introducing additional variables. It seems likely that DBN molecules are more enriched in the higher molecular weight $(>1 \mathrm{kDa})$ UDOM samples, while a large portion of DBC molecules are presented in lower molecular weight $(<1 \mathrm{kDa})$ bulk DOM samples. Although detailed molecular characteristics of DBN are lacking, this result is in agreement with reported low DBC abundance in marine UDOM, probably because of DBC degradation and/or a preferentially association with the lower molecular weight fraction of DOM (Ziolkowski \& Druffel, 2010). However, the exact reasons behind the observed differences remain unclear at this point.

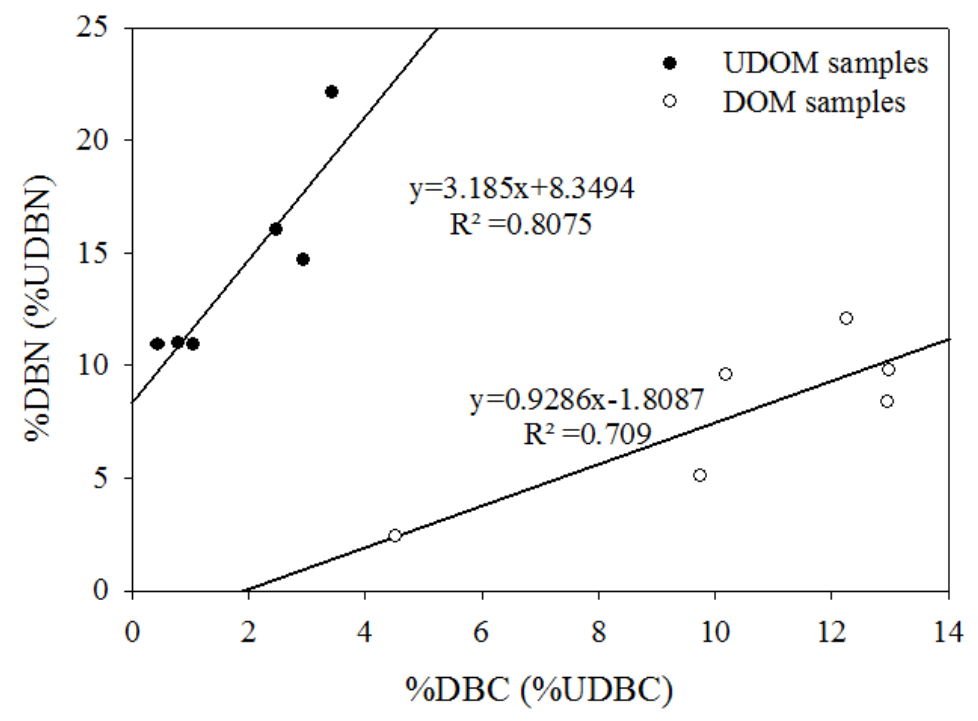

Figure 6.3 Linear correlations between \%DBC (\%UDBC) and \%DBN (\%UDBN) in both UDOM samples and DOM samples suggesting same combustion source for BC and BN.

The linear correlation between the UDBC and UDBN concentrations of biome samples was also statistically significant (Fig. $6.4 \mathrm{a} ; \mathrm{P}=0.004, \mathrm{n}=6$ ), indicating a coupling 
of the two parameters. Because the DBN concentrations are not available for the FCE samples except for one freshwater site (SRS4), the correlation between DBC and DBN concentrations of bulk DOM samples is not reported here.
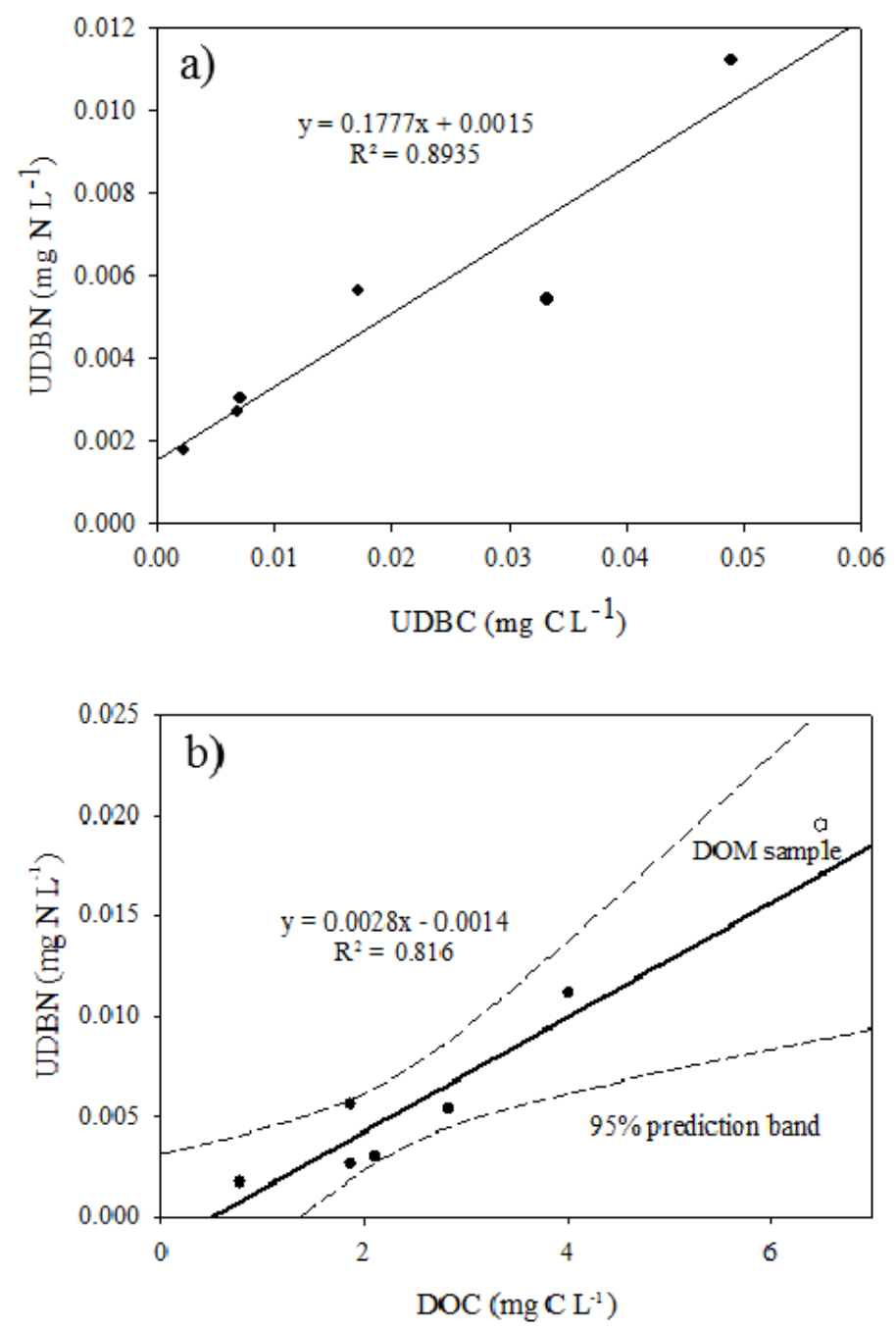

Figure 6.4 Linear correlations between UDBC and UDBN concentrations (a) and linear correlations between bulk DOC and UDBN concentrations (black circles), including one bulk DOM sample (open circle, SRS4) from the Everglades (b).

Although heterocyclic aromatic $\mathrm{N}$ in soil was reported to be a unique biomarker for the effect of fire on soil organic matter (Knicker, 2004; Knicker, 2007), the sources of 
heterocyclic aromatic $\mathrm{N}$ in the dissolved phase have not been constrained. However, the strong correlation between UDBC and UDBN observed in this study suggests that the source and translocation processes of soil $\mathrm{BC}$ and $\mathrm{BN}$ to the dissolved phase are most likely coupled. In addition, the fact that this linear correlation is derived from samples from vastly different aquatic systems suggests that the co-generation of DBC and DBN from soils exposed to biomass burning may be a ubiquitous phenomenon and of global significance.

\subsubsection{Controlling factors for DBN environmental dynamics}

In a recent study on the relationship between biomass burning and freshwater DBC concentrations, recent fire history was found to be less important in controlling the DBC dynamics than the factors that control DOC dynamics, suggesting coupled soil-towater translocation mechanisms and/or a physicochemical association between DOC and DBC (Ding et al., 2013). Such correlations have been reported to be significant both in other regional studies (Dittmar et al., 2012b) and on a global scale (Jaffé et al., 2013). Thus, similar coupling between DOC and DBN can be expected since DBC and DBN likely share a common source (biomass burning) and molecular features (i.e., polycyclic aromatic structures). Indeed, the regression analysis proves that bulk DOC and UDBN concentrations are strongly linearly correlated (Fig. $6.4 \mathrm{~b} ; \mathrm{P}=0.014, \mathrm{n}=6$ ), indicating that the environmental factors control the DOC dynamics are also the ones that determine the UDBN dynamics. 


\subsubsection{Estimate of global riverine DBN flux to the oceans}

The strong linear regression between bulk DOC and UDBN features an $\mathrm{x}-$ intercept which is not significantly differed from zero, and a slope representing the ratio between UDBN and DOC (0.28\%; Fig. 6.4b). This slope value (UDBN as \% of DOC) is much lower than that reported \% DBC in DOC for regional studies (3.2\%-8.1\%; Ding et al., 2013; Dittmar et al., 2012b) or the global average of 10.6\% (Jaffé et al., 2013). On

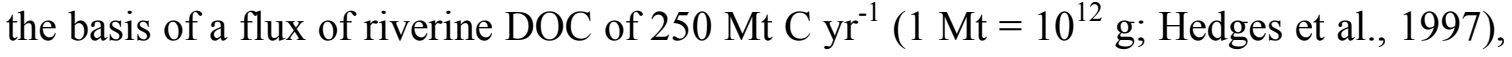
an estimate of riverine UDBN flux to oceans is $0.7 \mathrm{Mt} \mathrm{N} \mathrm{yr}^{-1}$. This accounts for $c a .2 \%$ of the annual riverine DON land to the sea flux (36 Mt N yr ${ }^{-1}$; Schlesinger, 1997) and $c a$. $7 \%$ of the annual preserved $\mathrm{N}$ in marine sediment (10.5 $\mathrm{Mt} \mathrm{N} \mathrm{yr}^{-1}$; Schlesinger, 1997). It is important to point out, that this estimate is derived from a set of headwater streams that have intermediate to low DOC concentrations, and does not include data from large rivers representing extensive watersheds. On a global scale however, the slopes of the linear correlation between DBC and DOC for headwater streams and that for larger world rivers were not significantly different (Jaffé et al., 2013), and thus, watershed size may not be as critical in estimating flux values for DBN. More importantly, bulk DBN fluxes may be higher than those estimated here for UDBN since the DBN content in the low molecular weight fraction of DOM was not determined. Consequently, the global riverine DBN flux derived from UDBN flux might be underestimated.

An additional analysis of a bulk DOM sample from the FCE (SRS4) with known DBN concentration, where high UDBN concentrations had previously been reported (Maie et al., 2006b), showed that the DOC and DBN concentrations fell within the $95 \%$ confidence interval of the DOC vs. UDBN regression line (Fig. 6.4b). Although limited 
to one determination, this result suggests the majority of DBN is recovered in the UDOM fraction, On the other hand, using the aromatic N determined by XPS as representative of the UDBN might result in a slightly overestimation since this technique cannot exclude possible interferences from imidazole or indole fragments. However, such contributions were also suggested to be subtle (see above) and likely insignificant. Therefore, while the accuracy of the estimated riverine DBN flux reported herein may be subject to some variability, its order of magnitude should be accurate and of great significance in the global nitrogen cycle.

\subsection{Conclusions}

BN in soil is an indicator of exposure to biomass burning (Knicker, 2007). While the conceptual model of soil char accumulation on the basis of the presumed refractory nature of BC has recently been challenged (Ding et al., 2013; Dittmar et al., 2012a), and losses because of translocation from soil to aqueous have been shown to be much more important than previously believed (Jaffé et al., 2013), it is expected that losses from soil $\mathrm{BN}$ to the aquatic phase in the form of $\mathrm{DBN}$ followed by riverine export may be significant as well. The linear correlation between UDBC and UDBN suggests that DBC and DBN are likely of the same combustion origin and the ubiquitous presence of $\mathrm{BN}$ in the dissolved phase represents the translocation and loss of soil $\mathrm{BN}$ from terrestrial to aquatic environments. Similar to BC (Forbes et al., 2006), BN can ultimately be exported to the marine environment and become part of the marine DON pool. On the basis of the significant linear correlation between DOC and UDBN among diverse aquatic ecosystems, the estimate of the annual DBN export (UDBN flux) to the oceans is on the 
order of $0.7 \mathrm{Mt} \mathrm{N} \mathrm{yr}^{-1}$. Such pyrogenic DON may be more recalcitrant than the bulk DON and thus accumulate in oceanic systems. While little is known about the reactivity of DBN, and although the DBN flux is one to two orders of magnitude lower than the global estimate for DBC (Jaffé et al., 2013), the contribution of riverine DBN to the refractory DON pool in the oceans needs to be assessed in more detail, as it may modify microbial loop dynamics and affect the biogeochemical cycling of $\mathrm{N}$ in aquatic environments. However, the available database on DBN is highly limited at this point, and further studies are needed to constrain the importance of DBN in the global nitrogen cycle. 


\section{REFERENCES}

Abe T, Watanabe A (2004) X-ray photoelectron spectroscopy of nitrogen functional groups in soil humic acids. Soil Science 169(1): 35-43

Abe T, Maie N, Watanabe A (2005) Investigation of humic acid $\mathrm{N}$ with X-ray photoelectron spectroscopy: Effect of acid hydrolosis and comparison with $15 \mathrm{~N}$ cross polarization/magic angle spinning nuclear magnetic resonace spectroscopy. Organic Geochemistry 36(11): 1490-1497

Almendros G, Knicker H, Gonzalez-Vila FJ (2003) Rearrangement of carbon and nitrogen forms in peat after progressive thermal oxidation as determined by solid-state C13 and N-15-NMR spectroscopy. Organic Geochemistry 34(11): 1559-1568

Aluwihare LI, Repeta DJ, Pantoja S, Johnson CG (2005) Two chemically distinct pools of organic nitrogen accumulate in the ocean. Science 308(5724): 10071010

Amon RMW, Fitznar HP, Benner R (2001) Linkages among the bioreactivity, chemical composition, and diagenetic state of marine dissolved organic matter. Limnology and Oceanography 46(2): 287-297

Boyer JN, Fourqurean JW, Jones RD (1997) Spatial characterization of water quality in Florida Bay and Whitewater Bay by multivariate analyses: Zones of similar influence. Estuaries 20(4): 743-758

Davis SE, Childers DL, Day JW, Rudnick DT, Sklar FH (2001) Nutrient dynamics in vegetated and unvegetated areas of a southern Everglades mangrove creek. Estuarine Coastal and Shelf Science 52(6): 753-768

Ding Y, Yamashita Y, Dodds W, Jaffé R (2013) Dissolved black carbon in grassland streams: Is there an effect of recent fire history? Chemosphere 90(1): 2557-2562

Dittmar, T (2008) The molecular level determination of black carbon in marine dissolved organic matter. Organic Geochemistry 39(4): 396-407

Dittmar T, Rezende CE, Manecki M, Niggemann J, Ovalle ARC, Stubbins A, Bernardes MC (2012a) Continuous flux of dissolved black carbon from a vanished tropical forest biome. Nature Geoscience 5(9): 618-622

Dittmar T, Koch B, Hertkorn N, Kattner G (2008) A simple and efficient method for the solid-phase extraction of dissolved organic matter (SPE-DOM) from seawater. Limnology and Oceanography-Methods 6: 230-235 
Dittmar T, Paeng J (2009) A heat-induced molecular signature in marine dissolved organic matter. Nature Geoscience 2(3): 175-179

Dittmar T, Paeng J, Gihring TM, Suryaputra IGNA, Huettel M (2012b) Discharge of dissolved black carbon from a fire-affected intertidal system. Limonology and Oceanography 57(4): 1171-1181

Forbes MS, Raison RJ, Skjemstad JO (2006) Formation, transformation and transport of black carbon (charcoal) in terrestrial and aquatic ecosystems. Science of the Total Environment 370(1): 190-206

Hedges JI, Keil RG, Benner R (1997) What happens to terrestrial organic matter in the ocean? Organic Geochemistry 27(5-6): 195-212

Jaffé R, Ding Y, Niggemann J, Vähätalo AV, Stubbins A, Spencer RGM, Campbell J, Dittmar T (2013) Global charcoal mobilization from soils via dissolution and riverine transport to the oceans. Science 340(6130): 345-347

Jaffé R, Yamashita Y, Maie N, Cooper WT, Dittmar T, Dodds WK, Jones JB, Myoshi T, Ortiz-Zayas JR, Podgorski DC, Watanabe A (2012) Dissolved organic matter in headwater streams: compositional variability across climatic regions of North America. Geochimica et Cosmochinica Acta 94: 95-108

Jeff S, Hunter K, Vandergucht D, Hudson J (2012) Photochemical mineralization of dissolved organic nitrogen to ammonia in prairie lakes. Hydrobiologia 693(1): 71-80

Kasischke ES, Turetsky MR (2006) Recent changes in the fire regime across the North American boreal region - Spatial and temporal patterns of burning across Canada and Alaska. Geophysical Research Letters 33(9): L09703

Knicker H (2004) Stabilization of N-compounds in soil and organic-matter-rich sediments - what is the difference? Marine Chemistry 92(1-4): 167-195

Knicker H (2007) How does fire affect the nature and stability of soil organic nitrogen and carbon? A review. Biogeochemistry 85(1): 91-118

Knicker H, Almendros G, GonzalezVila FJ, Martin F, Ludemann HD (1996) C-13- and N-15-NMR spectroscopic examination of the transformation of organic nitrogen in plant biomass during thermal treatment. Soil Biology \& Biochemistry 28(8): 1053-1060

Knicker H, Gonzalez-Vila FJ, Polvillo O, Gonzalez JA, Almendros G (2005) Fireinduced transformation of $\mathrm{C}$ - and $\mathrm{N}$-forms in different organic soil fractions from a Dystric Cambisol under a Mediterranean pine forest (Pinus pinaster). Soil Biology \& Biochemistry 37(4): 701-718 
Knicker H, Ludemann HD (1995) N-15 and C-13 CPMAS and solution NMR-studies of N-15 enriched plant-material during 600 days of microbial-degradation. Organic Geochemistry 23(4): 329-341

Maie N, Knicker H, Watanabe A, Kimura M (2006a) Heterocyclic N in the highly humified humic acids extracted from the subsoil of paddy fields and surface ando soils. Organic Geochemistry 37(1): 12-19

Maie N, Parish KJ, Watanabe A, Knicker H, Benner R, Abe T, Kaiser K, Jaffé R (2006b) Chemical characteristics of dissolved organic nitrogen in an oligotrophic subtropical coastal ecosystem. Geochimica et Cosmochimica Acta 70(17): 4491-4506

Maie N, Pisani O, Jaffé R (2008) Mangrove tannins in aquatic ecosystems: Their fate and possible influence on dissolved organic carbon and nitrogen cycling. Limnology and Oceanography 53(1): 160-171

Parker AE (2005) Differential supply of autochthonous organic carbon and nitrogen to the microbial loop in the Delaware Estuary. Estuaries 28(6): 856-867

Paul EA, Clark MJ (1996) Soil Microbiology and Biochemistry. Academic Press, San Diego

Porter LK (1975) Nitrogen transfer in ecosystems. In: Paul EA, McLaren AD (eds.), Soil Biochemistry. Marcel Dekker, New York. p 1-30

Schlesinger WH (1997) Biogeochemistry: An Analysis of Global Change. Academic Press, San Diego

Schmidt MWI, Torn MS, Abiven S, Dittmar T, Guggenberger G, Janssenes IA, Kleber M, Kogel-Knabber I, Lehmann J, Manning DAC, Nannipieri P, Rasse DP, Weiner S, Trumbore SE (2011) Persistence of soil organic matter as in ecosystem property. Nature 478(7367): 49-56

Ziolkowski LA, Druffel ERM (2010) Aged black carbon identified in marine dissolved organic carbon. Geophysical Research Letters 37: L16601 
Chapter VII

CONCLUSIONS 
Humans have been generating (i.e., burning firewood) and utilizing (i.e., applying biochar as fertilizer for agricultural use) black carbon (BC) from ancient times. However, it was not until recent decades that scientists have started to understand the recalcitrant nature of this pyrogenic product and realized the important role it might play in the global carbon cycling and climate change. The number of studies on $\mathrm{BC}$, even challenged by the lack of proven and reliable analytical techniques, has been increasing dramatically in the past few decades, especially in soil and atmospheric sciences. As BC budgets have more accurately been constrained, estimating the loss of $\mathrm{BC}$ from terrestrial soils environments has remained an enigmatic and somewhat controversial task. The confirmation of the existence and ubiquity of $\mathrm{BC}$ in the dissolved form has provided evidence that $\mathrm{BC}$ is less refractory than previously believed. Still, little is known about the environmental dynamics of DBC and other combustion products such as DBN, and the environmental drivers and biogeochemical mechanisms controlling their fate and transport are only now being identified.

Considering biomass burning is likely the major sources of DBC, the first question brought about is whether DBC levels reflect local burning history and fire frequency. In Chapter II, the DBC concentrations from a freshwater grassland ecosystem (Konza Prairie) were determined, where a series of watersheds have been subject to different burn frequencies in the past four decades. No correlation was found between DBC concentration, and neither fire frequency nor time since last burn. This suggests that DBC may not be a good proxy for recent fire history. The specific environmental factors in this grassland prairie, such as the very frequent burning and a quick washout of soil early in the wet season, can lead to a lack of soil BC accumulation after each prescribed 
fire. Furthermore, the recalcitrant nature of DBC indicates a longer time scales (possibly decades to centuries) may be needed for the dissolution/translocation processes to be significant. Thus the export of DBC from watersheds is likely a reflection of historical instead of recent burning. On the basis of the strong linear correlation observed between $\mathrm{DBC}$ and DOC, the annual DBC flux from grasslands to the oceans was estimated at 0.14 $\operatorname{MtC~yr}{ }^{-1}\left(1 \mathrm{Mt}=10^{12} \mathrm{~g}\right)$.

To further test the correlation between DBC and fire history, and to determine if similar linear correlation between DOC and DBC also exist in other aquatic biomes, a two-year DBC dynamic study was performed in a coastal wetland with known fire regime (Chapter III). The two-year temporal and spatial dynamic study of DBC and DOC from this freshwater-mangrove-coast transect (also as a frequent fire-no fire transect) indeed confirmed that recent fire frequency was not the factor controlling the DBC dynamic in this coastal wetland system. The DBC dynamics were again found to be strongly correlated to DOC dynamics, regardless of the temporal and spatial variations among sites. A further comparative study between the Everglades and other two inland wetlands (the Pantanal and Okavango Delta) showed similar correlations between DOC and $\mathrm{DBC}$, suggesting that the dissolution mechanisms of soil OC and $\mathrm{BC}$ were strongly coupled also in wetlands. The key environmental factors determining the DOC dynamics (e.g., hydrology, microbial activity, mineral binding) should consequently also be critical in controlling DBC dynamics. Similarly, an annual DBC flux from wetlands worldwide was estimated (4.3 Mt C $\mathrm{yr}^{-1}$ ), which is much higher than the grassland flux since wetlands export more DOM annually. 
Although $\mathrm{BC}$ is assumed to be primarily derived from biomass burning, other sources such as fossil fuel combustion may be important regionally. In agreement, the work presented here shows that the chemical structure of DBC (derived from BPCA distribution) was not found to be uniform among all water samples analyzed. Principal component analysis (PCA) of the relative abundance of benzenepolycarboxylic acids (BPCAs), the DBC digestions products that reflect molecular aromaticity, shows that locations which receive significant atmospheric inputs, such as coastal samples from the Florida Bay, were more enriched in low aromatic DBC molecules while terrestrial DBC samples (e.g., from the Everglades and the other inland wetlands) share similar, more aromatic structures (Chapter III). Other remote locations such as Shark Bay, Australia, showed similar molecular patterns as those observed for Florida Bay. This molecular level discrimination of DBC indicates differences in source strength and/or the degree of degradation of the DBC. To further investigate this phenomenon, samples from geographically remote locations, and which are likely to receive high relative contributions from atmospheric deposition (vs. wild fires) such as aquatic systems in Antarctic, the Arctic, Alpine lakes and glacial rivers were analyzed. The PCA analysis of BPCA relative abundances revealed that while terrestrial DBC (e.g., grassland, wetlands, or forests) was enriched in B5CA and B6CA, Antarctic and glacial rivers DBC samples were enriched in $\mathrm{B} 3 \mathrm{CA}$ and $\mathrm{B} 4 \mathrm{CA}$, indicative of lowest aromaticity. This data suggests that locations not prone to forest fires, and which are strongly influenced by atmospheric deposition, generate DBC that is mainly anthropogenically derived.

As the coupling between DOC and DBC was noticed in all regional studies, a more comprehensive study was conducted to verify this strong regression on a global 
scale (Chapter V), including ten of the world's largest rivers (e.g., Congo River, Mississippi River, Amazon River, etc.), six large Arctic rivers (e.g., Yukon, Lena, Ob, etc.) and other intermediate to small watersheds, covering all continents expect for Antarctica. Subcategorized into four groups (major rivers, intermediate rivers, headwater streams and glacial streams), the ubiquitous regressions between DOC and DBC from each environmental group were statistically compared (i.e., the slope and intercept of the correlation equation), and the slopes were found indistinguishable among groups. A global statistic model between DOC and DBC was built and the regression suggested that $10.6( \pm 0.7) \%$ of DOC was actually combustion derived. On the basis of a reported

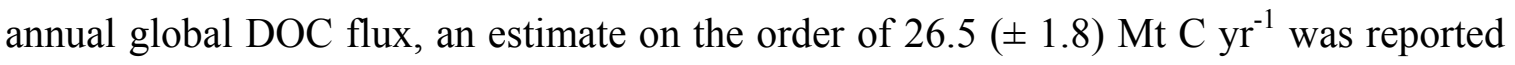
as the annual riverine $\mathrm{DBC}$ flux to the oceans. The theory behind this strong correlation still remains unclear, but preliminary soil incubation and char incubation experiments indicated two possible hypotheses: co-generation and co-translocation mechanisms and/or a physicochemical association between DOC and DBC.

Finally, another possible biomass burning generated byproduct, dissolved black nitrogen (DBN) was determined from a set of samples across climatic regions in North America. The ubiquitous presence of DBN in different freshwater biomes and the strong cross-correlation between $\mathrm{DBC}, \mathrm{DBC}$ and $\mathrm{DOC}$ indicate that $\mathrm{DBN}$ and $\mathrm{DBC}$ are probably from the same source (biomass combustion), and DBN dynamics, similarly to DBC, are also coupled to the DOC. A conservative estimate of global DBN flux to the oceans was $0.7 \mathrm{Mt} \mathrm{N} \mathrm{yr}^{-1}$.

In summary, the ubiquitous presence of DBC in all aquatic environments indeed confirms that DOM is an important intermediate, as well as a significant sink, in the 
global $\mathrm{BC}$ cycle. With continued global climate change, the flux of $\mathrm{DBC}$ is expected to increase as DOC export from terrestrial environments to the oceans is predicted to rise. This activity is likely to further enhance the translocation and export of the sequestered $\mathrm{BC}$ (e.g., biochar accumulated in soil/sediment) to marine systems in form of DBC. The environmental consequences of such notable DBC exports on marine communities are presently unknown, but may be reflected in the reduction of DOC bioavailability and associated effects on microbial loop dynamics and aquatic food webs. The mechanisms behind the environmental coupling between DOC and DBC need further studies; however, the estimate value of global riverine DBC flux utilizing its linear correlation with DOC is of great significance in the global BC cycle. 
APPENDICES 


\section{Appendix 2.1}

The oxidation efficiencies of commercially available activated charcoal (Calgon Co.) using three different oxidation conditions. $\mathrm{C}$ recovery $=$ mol-C of all BPCAs $/$ mol-C of fullerene subjected to oxidation

\begin{tabular}{lccc}
\hline & $160^{\circ} \mathrm{C}, 6 \mathrm{~h}$ & $170^{\circ} \mathrm{C}, 9 \mathrm{~h}$ & $180^{\circ} \mathrm{C}, 8 \mathrm{~h}$ \\
\hline$\% \mathrm{~B} 3 \mathrm{CA}$ & $0.07 \pm 0.00$ & $0.07 \pm 0.01$ & N.D. ${ }^{*}$ \\
$\% \mathrm{~B} 4 \mathrm{CA}$ & $0.37 \pm 0.07$ & $0.14 \pm 0.14$ & $0.38 \pm 0.09$ \\
$\% \mathrm{~B} 5 \mathrm{CA}$ & $4.33 \pm 0.09$ & $4.30 \pm 0.08$ & $4.48 \pm 0.10$ \\
$\% \mathrm{~B} 6 \mathrm{CA}$ & $95.21 \pm 0.10$ & $95.31 \pm 0.20$ & $95.10 \pm 0.06$ \\
$\mathrm{C}$ recovery & $(10.32 \pm 0.29) \%$ & $(10.07 \pm 0.35) \%$ & $(8.44 \pm 0.33) \%$ \\
\hline
\end{tabular}

$*$ N.D. $=$ not detected 


\section{Appendix 2.2}

BPCA standards stability test results. Five different concentration levels of mixed standards $(25 \mu \mathrm{M}, 50 \mu \mathrm{M}, 100 \mu \mathrm{M}, 200 \mu \mathrm{M}$ and $500 \mu \mathrm{M})$ were oxidized at $160{ }^{\circ} \mathrm{C}$ for 6 hours. Mean recovery was calculated for the individual BPCA STD from five different concentration levels, and SD was used as error bar.

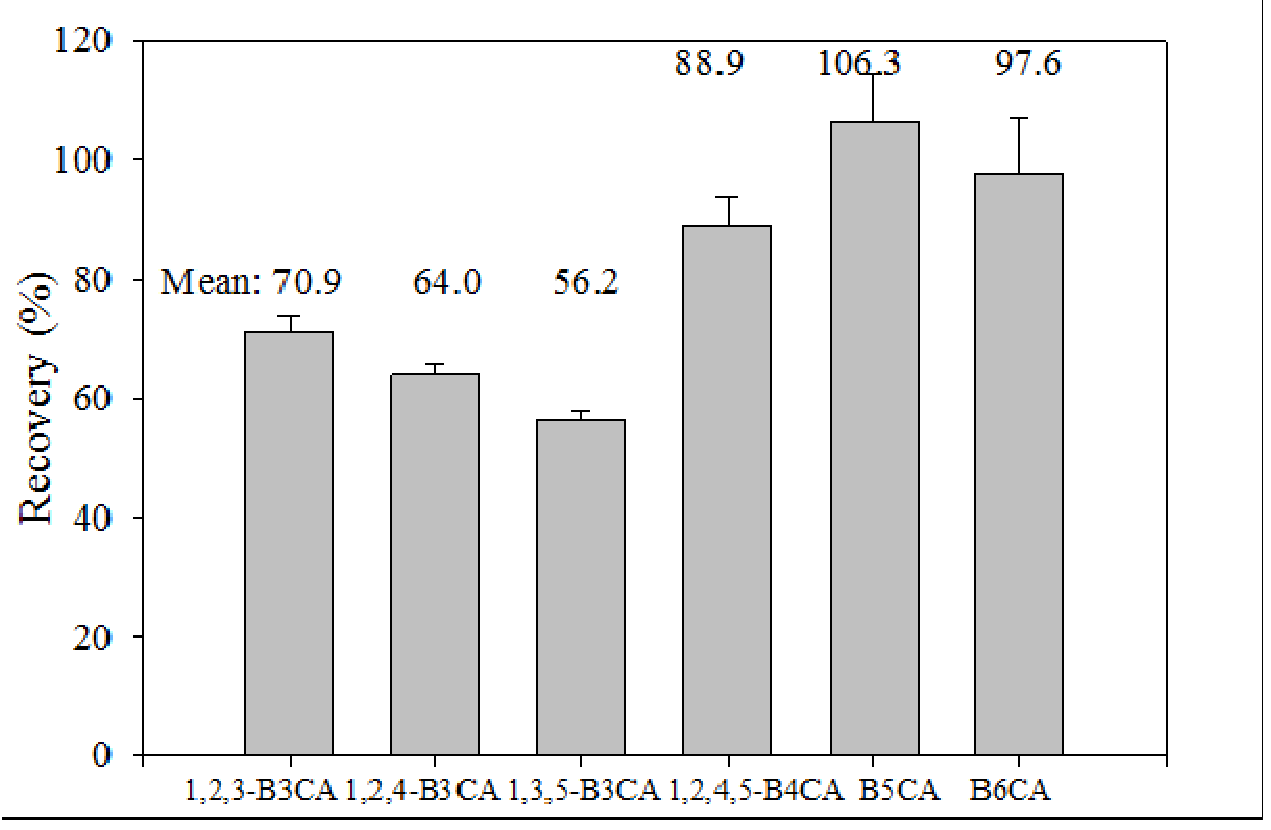




\section{Appendix 2.3}

BPCA Carbon yields from oxidations of a real DOM sample (Taylor Slough, FL) at four different temperatures $\left(140^{\circ} \mathrm{C}, 150^{\circ} \mathrm{C}, 160^{\circ} \mathrm{C}\right.$ and $\left.170^{\circ} \mathrm{C}\right)$ for 8 hours.

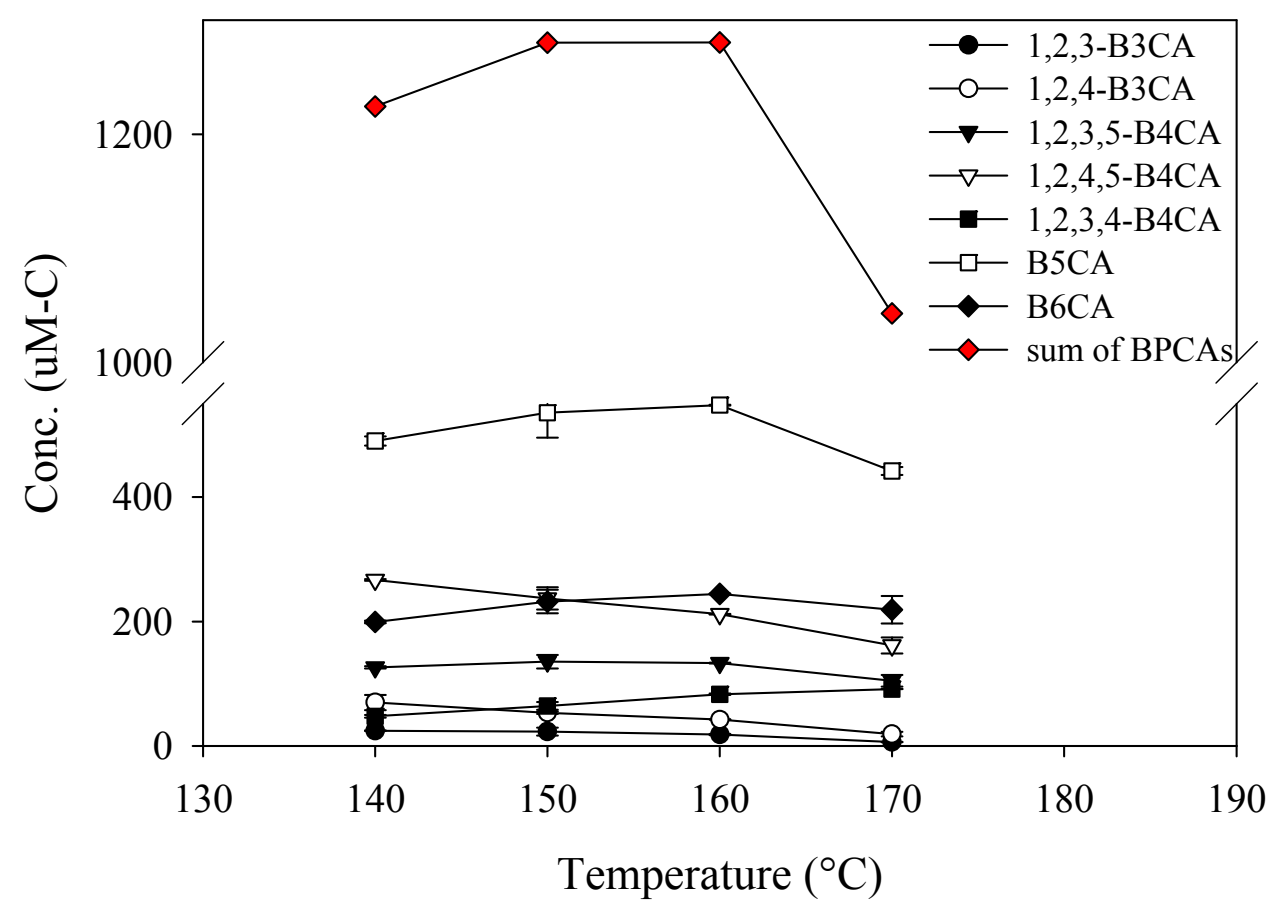


Appendix 2.4

DOC concentrations, DBC concentrations, \%DBC in DOC, relative abundance of BPCAs, and fire regimes in Konza Prairie.

\begin{tabular}{|c|c|c|c|c|c|c|c|c|c|}
\hline & $\begin{array}{c}\text { DOC } \\
\left(\mathrm{uM} \mathrm{l}^{-1}\right)\end{array}$ & $\begin{array}{c}\mathrm{DBC} \\
\left(\mathrm{uM} \mathrm{l}^{-1}\right)\end{array}$ & $\begin{array}{c}\% \mathrm{DBC} \\
(\%)\end{array}$ & $\begin{array}{c}\% \mathrm{~B} 3 \mathrm{CA} \\
(\%)\end{array}$ & $\begin{array}{c}\% \mathrm{~B} 4 \mathrm{CA} \\
(\%)\end{array}$ & $\begin{array}{c}\% \mathrm{~B} 5 \mathrm{CA} \\
(\%)\end{array}$ & $\begin{array}{c}\% \mathrm{~B} 6 \mathrm{CA} \\
(\%)\end{array}$ & $\begin{array}{l}\text { Burn return time } \\
(\mathrm{yr})\end{array}$ & $\begin{array}{c}\text { Time since last burn } \\
\text { (yr) }\end{array}$ \\
\hline N1B & 1.60 & 0.046 & 2.91 & 6.17 & 36.48 & 34.20 & 23.14 & 1.00 & 0.20 \\
\hline $\mathrm{N} 2 \mathrm{~A}$ & 1.73 & 0.065 & 3.75 & 7.28 & 38.45 & 43.53 & 10.74 & 2.00 & 0.20 \\
\hline N2B & 1.64 & 0.047 & 2.88 & 8.61 & 38.92 & 42.34 & 10.13 & 2.00 & 0.20 \\
\hline $\mathrm{K} 2 \mathrm{~A}$ & 1.48 & 0.045 & 3.05 & 7.38 & 38.49 & 42.75 & 11.39 & 2.00 & 0.20 \\
\hline K4A & 2.01 & 0.084 & 4.15 & 6.71 & 34.59 & 44.71 & 13.99 & 4.00 & 1.00 \\
\hline $\mathrm{N} 4 \mathrm{C}$ & 1.49 & 0.048 & 3.23 & 9.15 & 37.45 & 42.02 & 11.38 & 4.00 & 0.10 \\
\hline N4D & 1.41 & 0.042 & 3.01 & 8.09 & 40.07 & 43.58 & 8.26 & 4.00 & 1.00 \\
\hline $\mathrm{N} 20 \mathrm{~A}$ & 1.65 & 0.055 & 3.31 & 6.61 & 37.75 & 43.71 & 11.92 & 20.00 & 4.00 \\
\hline N20B & 1.72 & 0.054 & 3.15 & 7.83 & 38.52 & 44.70 & 8.95 & 20.00 & 3.00 \\
\hline $\mathrm{K} 20 \mathrm{~A}$ & 1.40 & 0.040 & 2.85 & 7.13 & 41.56 & 41.19 & 10.13 & 20.00 & 5.00 \\
\hline 20B & 2.48 & 0.106 & 4.26 & 7.33 & 32.20 & 45.91 & 14.56 & 20.00 & 5.00 \\
\hline
\end{tabular}


Appendix 3.1

Measurements of different parameters and the relative abundance of BPCAs for surface water samples from six sites in the FCE. All measurements were reported as Mean $\pm \mathrm{SD}$ of data collected through a two-year monthly sampling.

\begin{tabular}{cccccccc}
\hline & & $\mathrm{S} 2$ & $\mathrm{~S} 4$ & $\mathrm{~S} 6$ & $\mathrm{~T} 2$ & $\mathrm{~T} 7$ & $\mathrm{~T} 10$ \\
\hline DOC $\left(\mathrm{mg} \mathrm{L}^{-1}\right)$ & & $20.26 \pm 4.87$ & $14.59 \pm 2.35$ & $8.75 \pm 2.04$ & $7.61 \pm 2.03$ & $12.59 \pm 4.43$ & $7.03 \pm 1.63$ \\
DBC $\left(\mathrm{mg} \mathrm{L}^{-1}\right)$ & & $2.59 \pm 0.61$ & $1.83 \pm 0.24$ & $0.92 \pm 0.25$ & $0.75 \pm 0.22$ & $0.90 \pm 0.42$ & $0.28 \pm 0.09$ \\
\%DBC & & $12.93 \pm 1.89$ & $12.77 \pm 2.60$ & $10.24 \pm 3.05$ & $10.00 \pm 2.08$ & $7.13 \pm 1.88$ & $3.98 \pm 1.18$ \\
Salinity (\%o) & & 0 & $7.37 \pm 7.25$ & $24.24 \pm 5.68$ & 0 & $14.26 \pm 10.75$ & $37.36 \pm 4.49$ \\
\hline \%B3CA & wet season & $4.74 \pm 1.46$ & $4.53 \pm 0.57$ & $4.97 \pm 1.74$ & $5.27 \pm 1.38$ & $6.08 \pm 2.75$ & $8.91 \pm 5.07$ \\
& dry season & $4.92 \pm 1.25$ & $4.25 \pm 0.66$ & $5.18 \pm 1.11$ & $5.71 \pm 1.50$ & $6.02 \pm 1.48$ & $8.65 \pm 2.65$ \\
& overall & $4.84 \pm 1.31$ & $4.43 \pm 0.61$ & $5.10 \pm 1.36$ & $5.52 \pm 1.43$ & $6.05 \pm 2.05$ & $8.75 \pm 3.60$ \\
\hline \%B4CA & wet season & $29.93 \pm 1.61$ & $30.67 \pm 1.24$ & $34.58 \pm 1.75$ & $33.06 \pm 1.36$ & $35.74 \pm 3.52$ & $38.41 \pm 2.94$ \\
& dry season & $30.63 \pm 1.91$ & $31.72 \pm 2.02$ & $34.63 \pm 1.57$ & $33.52 \pm 1.71$ & $37.27 \pm 2.70$ & $40.89 \pm 3.42$ \\
& overall & $30.33 \pm 1.78$ & $31.27 \pm 1.75$ & $34.61 \pm 1.61$ & $33.31 \pm 1.54$ & $36.63 \pm 3.09$ & $39.98 \pm 3.41$ \\
\hline \%B5CA & wet season & $46.65 \pm 1.73$ & $46.56 \pm 0.59$ & $43.35 \pm 2.00$ & $45.81 \pm 2.24$ & $43.12 \pm 1.98$ & $42.69 \pm 5.20$ \\
& dry season & $47.25 \pm 1.82$ & $46.11 \pm 1.28$ & $44.27 \pm 1.72$ & $45.41 \pm 2.12$ & $43.83 \pm 1.69$ & $42.34 \pm 4.01$ \\
& overall & $46.99 \pm 1.76$ & $46.30 \pm 1.03$ & $43.91 \pm 1.86$ & $45.59 \pm 2.13$ & $43.53 \pm 1.81$ & $42.46 \pm 4.36$ \\
\hline \%B6CA & wet season & $18.68 \pm 1.26$ & $18.24 \pm 1.67$ & $17.10 \pm 1.39$ & $15.86 \pm 1.68$ & $15.05 \pm 4.39$ & $10.00 \pm 3.28$ \\
& dry season & $17.20 \pm 1.34$ & $17.81 \pm 1.36$ & $15.92 \pm 1.40$ & $15.35 \pm 1.29$ & $12.88 \pm 2.96$ & $8.12 \pm 1.11$ \\
& overall & $17.84 \pm 1.47$ & $18.00 \pm 1.45$ & $16.45 \pm 1.60$ & $15.58 \pm 1.46$ & $13.91 \pm 3.80$ & $8.80 \pm 2.28$ \\
\hline
\end{tabular}


Appendix 3.2

DISSOLVED BLACK CARBON CHARACTERIZATION BY FT-ICR/MS

\section{Introduction}

Principal component analysis (PCA) of two year monthly samples from the Florida Everglades Ecosystem (FCE) reveals a significant difference in relatively abundance of dissolved black carbon (DBC) oxidation products, benzenepolycarboxylic acids (BPCAs), between freshwater and coastal samples and between wet and dry season samples. I hypothesize that this BPCA composition difference is caused by variations in the loading of $\mathrm{BC}$ from different sources, where freshwater samples and wet season samples contain more DBC derived from biomass burning, while coastal samples and dry season samples have more anthropogenically generated DBC derived from atmospheric deposition through long distance transport. However, in addition to the BPCA molecular distributions, no additional molecular level information is available to confirm my hypothesis.

Fourier transform ion cyclotron resonance mass spectrometry (FT-ICR/MS) is a cuttingedge analytical technique that has been increasingly used in molecular characterization of DOM, such as humic acids (Stenson et al. 2002), fulvic acids (Stenson et al. 2003), condensed aromatic compounds (Hertkorn et al. 2006; Kramer et al. 2004), riverine and marine DOM (Dittmar \& Paeng 2009; Sleighter \& Hatcher 2008), and can provide detailed chemical formula and structural information. The most useful visualized tool to integrate FT-ICR/MS data is the van Krevelen diagram (Fig. A3.2.1), with the molar $\mathrm{O} / \mathrm{C}$ ratio on the $\mathrm{x}$-axis and molar $\mathrm{H} / \mathrm{C}$ ratio on the y-axis. In van Krevelen diagrams, different types of compounds (tannins, lipids, proteins, condensed hydrocarbons, etc.) cluster in a specific area according to their distinctive $\mathrm{O} / \mathrm{C}$ and 
$\mathrm{H} / \mathrm{C}$ ratios, and $\mathrm{BC}$ is usually characterized as low $\mathrm{H} / \mathrm{C}$ ratio and low $\mathrm{O} / \mathrm{C}$ ratio. Schmitt-Kopplin et al. (2011) separated the BC cluster into three subcategories: polyphenyl, linear polyaromatic and condensed polyaromatic (Fig. A3.2.2) This categorization offers the possibility to characterize DBC from different sources or formed under different conditions, and as such DBC with different BPCA relative abundance would present different chemical composition distributions in van Krevelen diagrams. The freshwater samples and wet season samples with relatively high $\mathrm{B} 5 \mathrm{CA}+\mathrm{B} 6 \mathrm{CA}$ are expected to have more condensed polyaromatic $\mathrm{BC}$ subcategory compared to the coastal samples and dry season samples that contain relatively high $\mathrm{B} 3 \mathrm{CA}+\mathrm{B} 4 \mathrm{CA}$ abundance. This preliminary study will be the first of its kind and potentially offer an insight into the biogeochemistry of DBC.

\section{Material and methods}

Five solid phase extraction elutes from the monthly FCE samples (Chapter III) were selected, including two Florida Bay (FB) sample (site T10) collected in dry season and one collected in wet season, two freshwater samples (site T2 and S2) collected in wet season. One to three (1-3) $\mathrm{mL}$ of $\mathrm{MeOH}$ elutes were dried under high purity $\mathrm{N}_{2}$ gas in small pre-combusted glass bottles and the final mass of DOM for each sample was about 2-4 mg. The dried DOM samples were shipped to National High Magnetic Field Laboratory located in Florida State University, Tallahassee, FL. FT-ICR mass spectra were acquired with a home-built 9.4 T FTICR mass spectrometer. Data were collected and processed by a modular ICR data acquisition system (MIDAS). Detailed instrument setting and method description of FI-ICR/MS can be retrieved from Tremblay et al. (2007). 


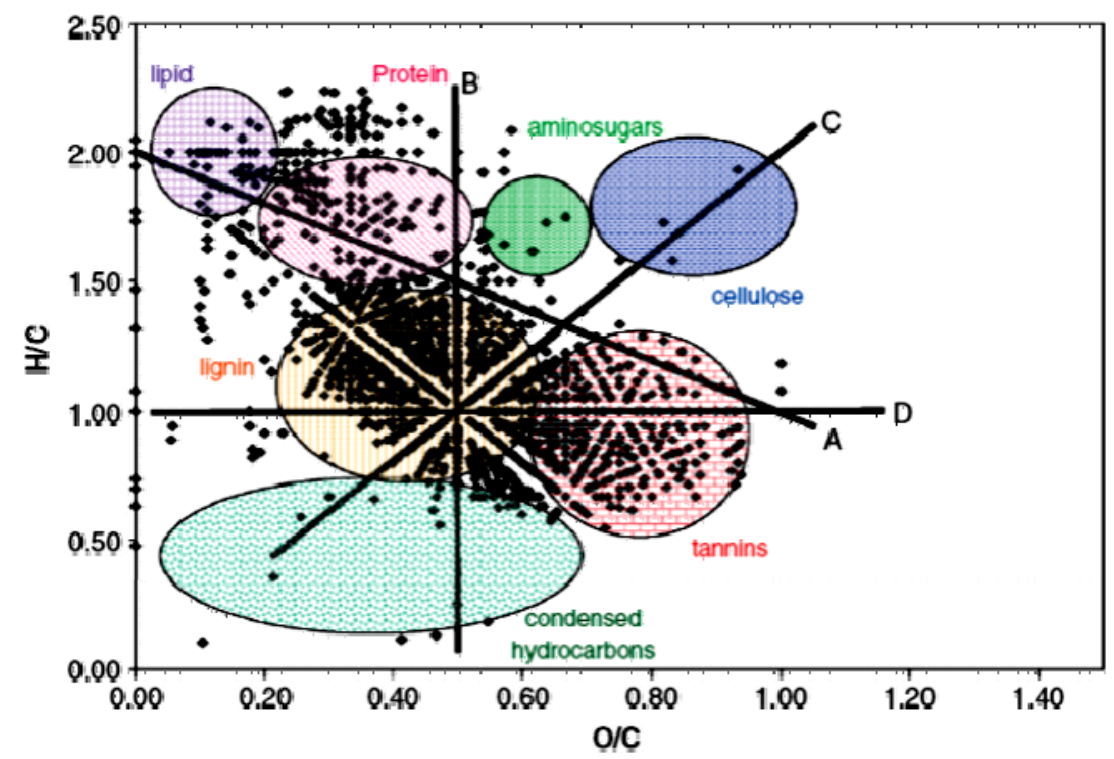

Figure A3.2.1 The traditional van Krevelen Diagram of DOM (from Sleight and Hatcher, 2007). The distinctive lines in the plot denote the following chemical reactions:

A. methylation/demethylation, or alkyl chain elongation

B. hydrogenation/dehydrogenation, C. hydration/condensation, D. oxidation/reduction

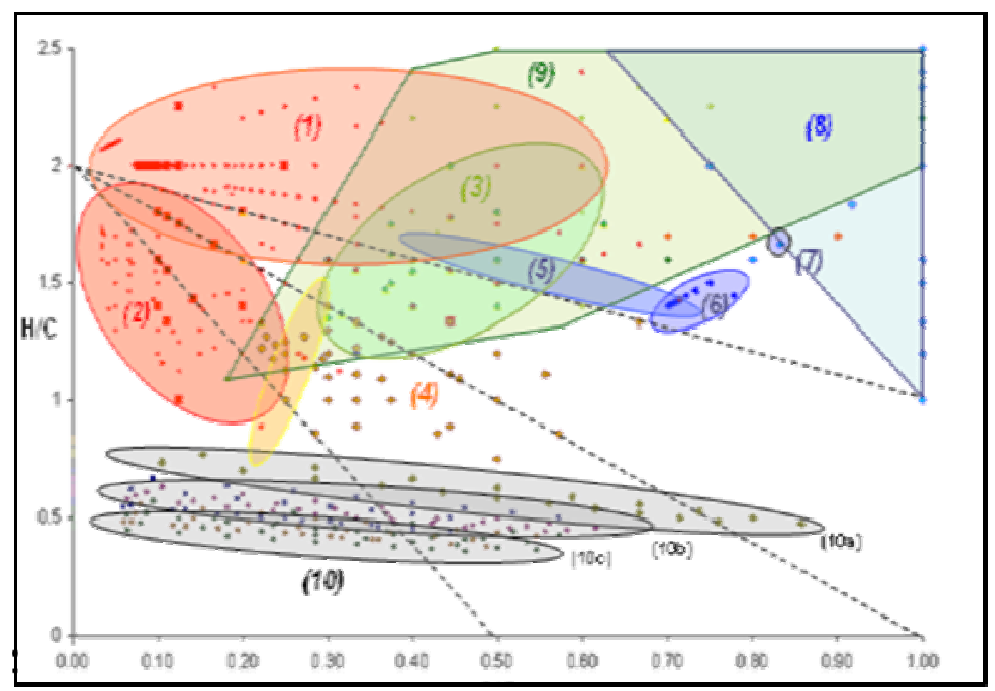

Figure A3.2.2 The van Krevelen Diagram from Schmitt-Kopplin et al. (2011): (1) fatty acids, (2) oxidized terpenoids, (3) oxidation products of VOC, (4) aromatic acids lignins, (5) oxocarboxylic acids, (6) methyl glyoxan, (7) levoglucosan, (8) carbohydrates, (9) amino acids, (10) black carbon, including (10a) polyphenyl type, (10b) linear polyaromatic type, (10c) condensed polyaromatic type. 


\section{Results and Discussions}

Figure A3.2.3 shows the van Krevelen Diagrams of DOM compounds containing only C, $\mathrm{H}$ and $\mathrm{O}$. Each dot represents one molecular formula of a particular compound $\left(\mathrm{C}_{\mathrm{x}} \mathrm{H}_{\mathrm{y}} \mathrm{O}_{z}\right)$. The four samples shown include one FB (T10) wet season sample, one FB (T10) dry season sample and two freshwater (T2 and S2) wet season samples. All compounds in each van Krevelen Diagram were classified into three groups: non-aromatic compounds (black color), aromatic compounds (yellow) and condensed aromatic compounds, or BC (red). From the proportion of red color dots, which represent BC compounds, T10 wet season sample contain more DBC compounds than T10 dry season sample and the freshwater samples contain much more DBC compounds than both FB samples.

To better observe what type of extra DBC compounds is present in freshwater samples or in wet season T10 samples, subtractions of van Krevelen diagrams were used to show the unique dots. In Fig. A3.2.4, grey dots are compounds in common and colored dots represent unique molecular formulae. Plot A is the subtraction result between T10 wet and dry season; plot B and $\mathrm{C}$ are the results of $\mathrm{T} 2$ and $\mathrm{S} 2$ wet season sample diagrams subtracted by T10 wet sample diagram. Three circles were used to better identify different subcategories of DBC compounds according to Fig. A3.2.2. From plot A, T10 wet season sample contained a few more condensed polyaromatic type $\mathrm{BC}$ compounds than $\mathrm{T} 10$ dry season sample. From plot B and $\mathrm{C}$, freshwater wet season samples contained much more condensed polyaromatic type $\mathrm{BC}$ and some extra linear polyaromatic type $\mathrm{BC}$ compounds than the $\mathrm{FB}$ wet season samples. This is in agreement with the principal component analysis (PCA) findings in Chapter III that freshwater marshes samples (or wet season samples) have higher percentage of $\mathrm{B} 5 \mathrm{CA}$ and $\mathrm{B} 6 \mathrm{CA}$ derived from more condensed DBC compounds than FB samples (or dry season samples). Such molecular level 
variation of DBC is most possible caused by source difference. When freshwater and wet season samples receive more soil leachate $\mathrm{BC}$ from biomass burning, $\mathrm{FB}$ and dry season samples receive a relative higher proportion of $\mathrm{DBC}$ from atmospheric deposition, which contains smaller DBC molecules from fossil fuel burning or vegetation combustion soot.

\section{Conclusions}

The extreme complexity of DOM and the limitation of analytical techniques result in a poor understanding of its structure and composition. However, the recent application of ultrahigh resolution MS, especially FT-ICR/MS, on DOM characterization has offered us more detailed information on molecular formula and structure. The van Krevelen diagram is the best data interpretation tool so far to integrate thousands of molecular formulae in the same graph. The subcategory of different BC type from Schmitt-Kopplin et al. (2011) offered the chance to compare the DBC compounds with different aromaticity and structure. The results present here is the first time to study the $\mathrm{BC}$ content difference from the molecular level. The findings are in accordance with the PCA results, showing that freshwater and wet season samples containing more condensed DBC compounds than the FB and dry season sample. Such difference of DBC in molecular level is probably due to the loading difference between soil leachate and atmospheric deposition.

\section{References}

Abe T, Watanabe A (2004) X-ray photoelectron spectroscopy of nitrogen functional groups in soil humic acids. Soil Science 169(1): 35-43

Almendros G, Knicker H, Gonzalez-Vila FJ (2003) Rearrangement of carbon and nitrogen forms in peat after progressive thermal oxidation as determined by solid-state C-13 and N-15-NMR spectroscopy. Organic Geochemistry 34(11): 1559-1568 
Aluwihare LI, Repeta DJ, Pantoja S, Johnson CG (2005) Two chemically distinct pools of organic nitrogen accumulate in the ocean. Science 308(5724): 1007-1010

Alvarez-Salgado XA, Miller AEJ (1998) Simultaneous determination of dissolved organic carbon and total dissolved nitrogen in seawater by high temperature catalytic oxidation: conditions for precise shipboard measurements. Marine Chemistry 62(3-4): 325-333

Amon RMW, Fitznar HP, Benner R (2001) Linkages among the bioreactivity, chemical composition, and diagenetic state of marine dissolved organic matter. Limnology and Oceanography 46(2): 287-297

Boyer JN, Fourqurean JW, Jones RD (1997) Spatial characterization of water quality in Florida Bay and Whitewater Bay by multivariate analyses: Zones of similar influence. Estuaries 20(4): $743-758$

Childers DL, Boyer JN, Davis SE, Madden CJ, Rudnick DT, Sklar FH (2006) Relating precipitation and water management to nutrient concentrations in the oligotrophic "upside-down" estuaries of the Florida Everglades. Limnology and Oceanography 51(1): 602-616

Davis SE, Childers DL, Day JW, Rudnick DT, Sklar FH (2001) Nutrient dynamics in vegetated and unvegetated areas of a southern Everglades mangrove creek. Estuarine Coastal and Shelf Science 52(6): 753-768

Ding Y, Yamashita Y, Dodds W, Jaffé R (2013) Dissolved black carbon in grassland streams: Is there an effect of recent fire history? Chemosphere 90(10): 2557-2562

Dittmar T (2008) The molecular level determination of black carbon in marine dissolved organic matter. Organic Geochemistry 39(4): 396-407

Dittmar T, de Rezende CE, Manecki M, Niggemann J, Ovalle ARC, Stubbins A, Bernardes MC (2012a) Continuous flux of dissolved black carbon from a vanished tropical forest biome. Nature Geoscience 5(9): 618-622

Dittmar T, Koch B, Hertkorn N, Kattner G (2008) A simple and efficient method for the solidphase extraction of dissolved organic matter (SPE-DOM) from seawater. Limnology and Oceanography-Methods 6: 230-235

Dittmar T, Koch BP (2006) Thermogenic organic matter dissolved in the abyssal ocean. Marine Chemistry 102(3-4): 208-217

Dittmar T, Paeng J (2009) A heat-induced molecular signature in marine dissolved organic matter. Nature Geoscience 2(3): 175-179

Dittmar T, Paeng J, Gihring TM, Suryaputra IGNA, Huettel M (2012b) Discharge of dissolved black carbon from a fire-affected intertidal system. Limonology and Oceanography 57(4): 11711181 
Forbes MS, Raison RJ, Skjemstad JO (2006) Formation, transformation and transport of black carbon (charcoal) in terrestrial and aquatic ecosystems. Science of the Total Environment 370(1): 190-206

Hedges JI, Keil RG, Benner R (1997) What happens to terrestrial organic matter in the ocean? Organic Geochemistry 27(5-6): 195-212

Hertkorn N, Benner R, Frommberger M, Schmitt-Kopplin P, Witt M, Kaiser K, Kettrup A, Hedges JI (2006) Characterization of a major refractory component of marine dissolved organic matter. Geochimica Et Cosmochimica Acta 70(12): 2990-3010

Jaffé R, Ding Y, Niggemann J, Vähätalo AV, Stubbins A, Spencer RGM, Campbell J, Dittmar T (2013) Global charcoal mobilization from soils via dissolution and riverine transport to the oceans. Science 340(6130): 345-347

Jaffé R, Yamashita Y, Maie N, Cooper WT, Dittmar T, Dodds WK, Jones JB, Myoshi T, OrtizZayas JR, Podgorski DC, Watanabe A (2012) Dissolved organic matter in headwater streams: compositional variability across climatic regions of North America. Geochimica et Cosmochinica Acta (94): 95-108

Jeff S, Hunter K, Vandergucht D, Hudson J (2012) Photochemical mineralization of dissolved organic nitrogen to ammonia in prairie lakes. Hydrobiologia 693(1): 71-80

Kasischke ES, Turetsky MR (2006) Recent changes in the fire regime across the North American boreal region - Spatial and temporal patterns of burning across Canada and Alaska. Geophysical Research Letters 33(9): L09703

Knicker H (2004) Stabilization of N-compounds in soil and organic-matter-rich sediments - what is the difference? Marine Chemistry 92(1-4): 167-195

Knicker H (2007) How does fire affect the nature and stability of soil organic nitrogen and carbon? A review. Biogeochemistry 85(1): 91-118

Knicker H, Almendros G, GonzalezVila FJ, Martin F, Ludemann HD (1996) C-13- and N-15NMR spectroscopic examination of the transformation of organic nitrogen in plant biomass during thermal treatment. Soil Biology \& Biochemistry 28(8): 1053-1060

Knicker H, Gonzalez-Vila FJ, Polvillo O, Gonzalez JA, Almendros G (2005) Fire-induced transformation of $\mathrm{C}$ - and $\mathrm{N}$-forms in different organic soil fractions from a Dystric Cambisol under a Mediterranean pine forest (Pinus pinaster). Soil Biology \& Biochemistry 37(4): 701-718

Knicker H, Ludemann HD (1995) N-15 and C-13 CPMAS and solution NMR-studies of N-15 enriched plant-material during 600 days of microbial-degradation. Organic Geochemistry 23(4): $329-341$

Kramer RW, Kujawinski EB, Hatcher PG (2004) Identification of black carbon derived structures in a volcanic ash soil humic acid by Fourier transform ion cyclotron resonance mass spectrometry. Environmental Science \& Technology 38(12): 3387-3395 
Krupka HM (1989) Transformations of nitrogen forms in epilimnion of the eutrophic Glebockie Lake (Masurian Lake District, Poland). Polskie Archiwum Hydrobiologii (36): 26-96

Maie N, Parish KJ, Watanabe A, Knicker H, Benner R, Abe T, Kaiser K, Jaffé R (2006) Chemical characteristics of dissolved organic nitrogen in an oligotrophic subtropical coastal ecosystem. Geochimica Et Cosmochimica Acta 70(17): 4491-4506

Parker AE (2005) Differential supply of autochthonous organic carbon and nitrogen to the microbial loop in the Delaware Estuary. Estuaries 28(6): 856-867

Paul EA, Clark MJ (1996) Soil Microbiology and Biochemistry. Academic Press, San Diego

Porter LK (1975) Nitrogen transfer in ecosystems. In: Paul EA \& McLaren AD (eds) Soil Biochemistry. Marcel Dekker, New York. p 1-30

Schlesinger WH (1997) Biogeochemistry: An Analysis of Global Change. Academic Press, San Diego

Schmidt MWI, Noack AG (2000) Black carbon in soils and sediments: Analysis, distribution, implications, and current challenges. Global Biogeochemical Cycles 14(3): 777-793

Schmitt-Kopplin P, Hertkon N, Harir M, Kanawati B, Gebefugi I, Lucio M (2011) Environmental metabolomics: an intergrated Bio-Geo analysis. In: International Water Association (IWA) Specialty Conference in Natural Organic Matter: From source to Tap and Beyond., Costa Mesa, CA, USA.

Sleighter RL, Hatcher PG (2007) The application of electrospray ionization coupled to ultrahigh resolution mass spectrometry for the molecular characterization of natural organic matter. Journal of Mass Spectrometry 42(5): 559-574

Sleighter RL, Hatcher PG (2008) Molecular characterization of dissolved organic matter (DOM) along a river to ocean transect of the lower Chesapeake Bay by ultrahigh resolution electrospray ionization Fourier transform ion cyclotron resonance mass spectrometry. Marine Chemistry 110(3-4): 140-152

Stenson AC, Landing WM, Marshall AG, Cooper WT (2002) Ionization and fragmentation of humic substances in electrospray ionization Fourier transform-ion cyclotron resonance mass spectrometry. Analytical Chemistry 74(17): 4397-4409

Stenson AC, Marshall AG, Cooper WT (2003) Exact masses and chemical formulas of individual Suwannee River fulvic acids from ultrahigh resolution electrospray ionization Fourier transform ion cyclotron resonance mass spectra. Analytical Chemistry 75(6): 1275-1284

Tremblay LB, Dittmar T, Marshall AG, Cooper WJ, Cooper WT (2007) Molecular characterization of dissolved organic matter in a North Brazilian mangrove porewater and mangrove-fringed estuaries by ultrahigh resolution Fourier Transform-Ion Cyclotron Resonance mass spectrometry and excitation/emission spectroscopy. Marine Chemistry 105(1-2): 15-29 
Wangersky PJ (1993) Dissolved organic-carbon methods - a critical review. Marine Chemistry 41(1-3): 61-74

Ziolkowski LA, Druffel ERM (2010) Aged black carbon identified in marine dissolved organic carbon. Geophysical Research Letters 37: L16601 

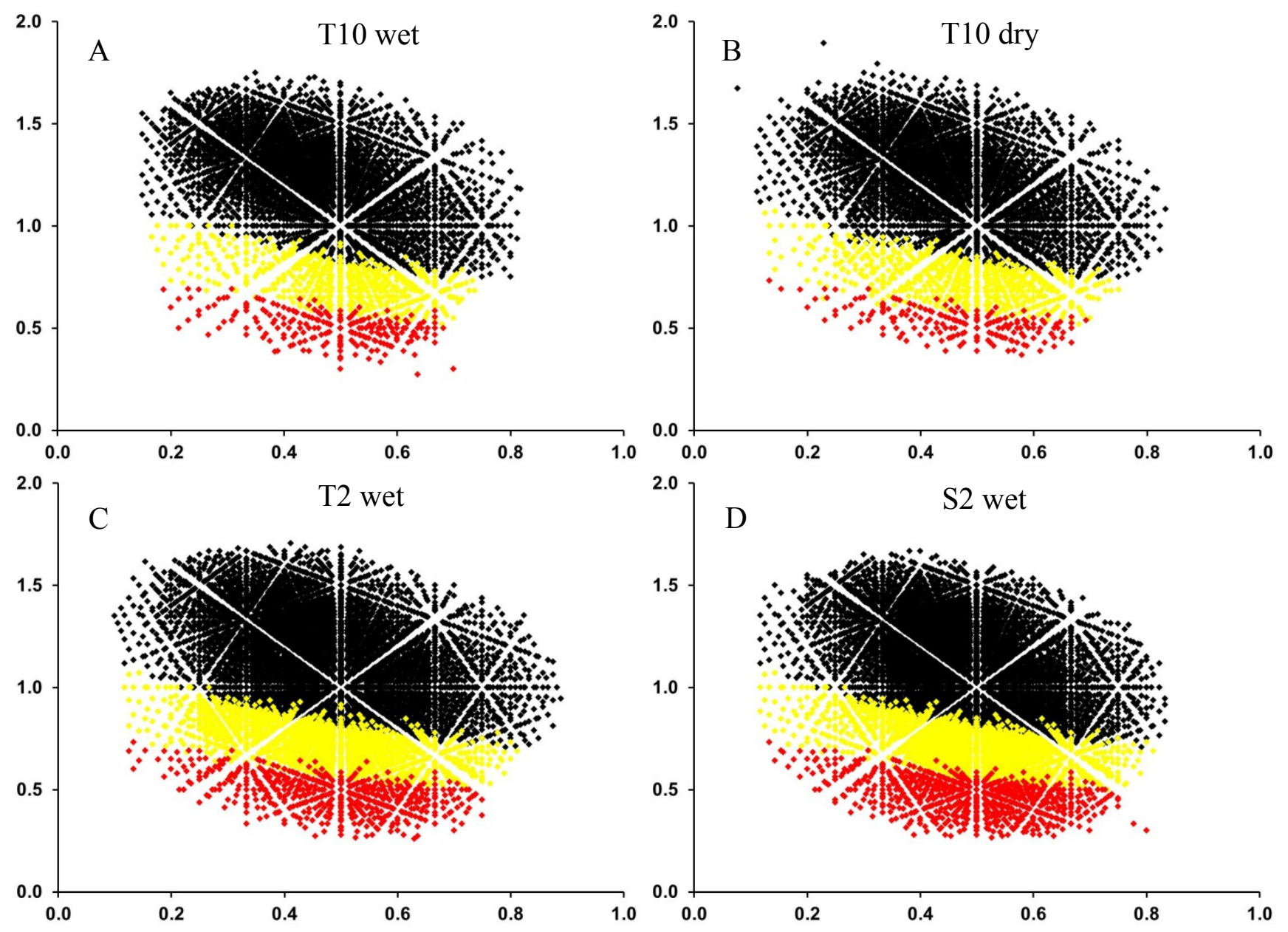

Figure A3.2.3 An example of van Krevelen diagrams of FCE DOM compounds containing only C, H and O. Black: non-aromatic compounds, yellow: aromatic compounds, red: condensed aromatic compounds. A: T10 wet season sample, B: T10 dry season sample, C: T2 wet season sample, D: S2 wet season sample. 


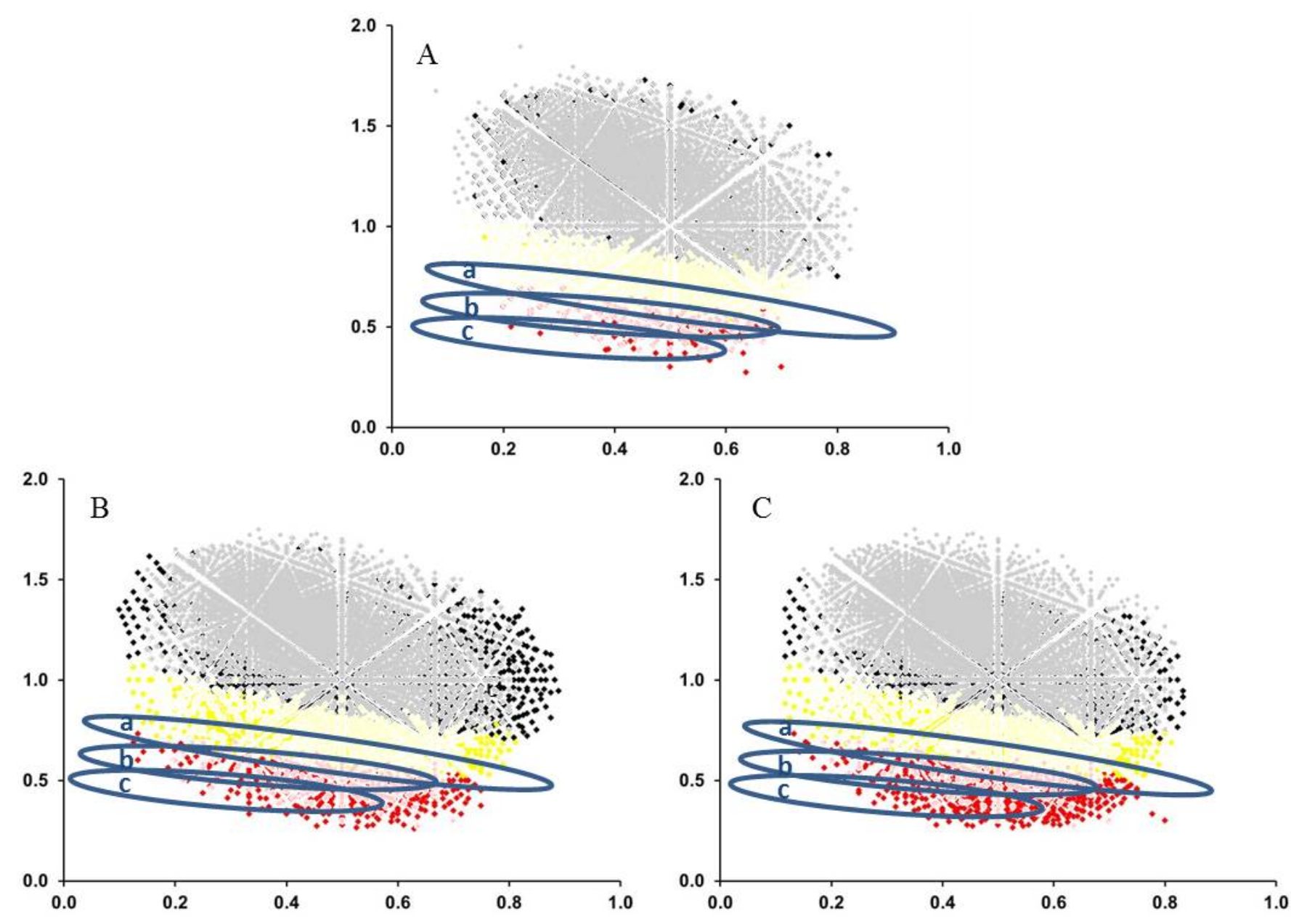

Figure A3.2.4 Subtractions of van Krevelen diagrams from different samples. All gray dots represent common compounds and colored dots represent the unique compounds in a particular sample. A: T10 wet - T10 dry, the colored dots are unique compounds in T10 wet; B: T2 wet - T10 wet, the colored dots are unique compounds in T2 wet; C: S2 wet - T10 wet, the colored dots are unique compounds in S2 wet. (a) polyphenyl type $\mathrm{BC}$, (b) linear polyaromatic type $\mathrm{BC}$, (c) condensed polyaromatic type 
VITA

\section{YAN DING}

Born, Nanjing, China

2004-2008

B.A., Pharmaceutical sciences

China Pharmaceutical University

Nanjing, China

2008-present

Doctoral Candidate

Florida International University

Miami, Florida

Teaching Assistant

Florida International University

Miami, Florida

Lab Manager

Florida International University

Miami, Florida

2011 summer

Doctoral Evidence Acquisition Fellowship

Florida International University

Miami, Florida

\section{PUBLICATIONS AND PRESENTATIONS}

Jaffé R, Ding Y, Niggemann J, Vahatalo AV, Stubbins A, Spencer RGM, Campbell J, Dittmar T (2013) Global mobilization of charcoal from soils via dissolution and subsequent riverine transport to the oceans. Science 340(6130): 345-347

Ding Y, Yamashita Y, Dodds W, Jaffé R (2013) Dissolved black carbon in grassland streams: Is there an effect of recent fire history? Chemosphere 90(10): 2557-2562

Cawley K, Ding Y, Fourqurean J, Jaffé R (2012) Characterizing the sources and fate of dissolved organic matter in Shark Bay, Australia: A preliminary study using optical properties and stable carbon isotopes. Marine and Freshwater Research 63(11): 10981107

Ding Y, Watanabe A, Jaffé R (to be submitted) Dissolved black nitrogen (DBN) in freshwater environments: Source and land to ocean flux assessment. Geophysical Research Letters 
Ding Y, Cawley K, Cunha CN, Jaffé R (to be submitted) Environmental dynamic of dissolved black carbon in wetlands. Biogeochemistry

Ding Y, Yamashita Y, Jones J, Jaffé R (to be submitted) Source and dynamics of dissolved black carbon in boreal forest rivers and glacial streams in central Alaska. Water Research

Khan AL, Ding Y, McKnight D, Jaffé R (2013) Black carbon as a proxy of human impact in the McMurdo Dry Valleys, Antarctica. ASLO 2013 Aquatic Sciences Meeting, New Orleans, Louisiana, Feb. 17-22.

Tzortziou M, Zeri C, Dimitriou E, Pirra W, Neale PJ, Jaffé R, Ding Y (2012) Dissolved Organic Matter cycling in the Evros trans-boundary river corridor and coastal delta of Eastern Mediterranean. Planet Under Pressure Conference, London, UK, Mar. 26-29.

Ding Y, Jaffé R, Niggemann J, Dittmar T (2012) The Ubiquity of Dissolved Black Carbon in Freshwater Environments. TOS/ASLO/AUG 2012 Ocean science meeting, Salt Lake City, Utah, Feb. 20-24.

Ding Y, Yamashita Y, Jones J, Dodds W, Jaffé R (2011) Environmental Dynamics of Dissolved Organic Matter Associated Black Carbon (DOM-BC) in Freshwater Ecosystems. International Water Association (IWA) Specialty Conference on Natural Organic Matter: From Source to Tap and Beyond, Costa Mesa, CA, Jul. 26-29.

Ding Y, Yamashita, Jaffé R (2011) Environmental Dynamics of Dissolved Organic Matter Associated Black Carbon (DOM-BC) in the Florida Everglades. Long Term Ecological Research All Scientists Meeting (ASM), Miami, FL, Jan. 6-7.

Ding Y, Yamashita, Jaffé R (2010) Environmental Dynamics of Dissolved Organic Matter Associated Black Carbon (DOM-BC) in the Florida Everglades: Methods Development and Preliminary Results. Society of Environmental Toxicology and Chemistry (SETAC) Asian/Pacific 2010 annual meeting, Guangzhou, China, Jun. 4-7.

Ding Y, Yamashita, Jaffé R (2010) Environmental Dynamics of Dissolved Organic Matter Associated Black Carbon (DOM-BC) in the Florida Everglades: Methods Development and Preliminary Results. Long Term Ecological Research All Scientists Meeting, Miami, FL, Mar. 15-16. 